\title{
The European Central Bank's Monetary Policy during Its First 20 Years
}

\begin{abstract}
On June 1, 2018, the European Central Bank (ECB) celebrated its 20th anniversary. This paper provides a comprehensive view of the ECB's monetary policy over these two decades. The first section gives a chronological account of the macroeconomic and monetary policy developments in the euro area since the adoption of the euro in 1999, going through four cyclical phases "conditioning" ECB monetary policy. We describe the monetary policy decisions from the ECB's perspective and against the background of its evolving monetary policy strategy and framework. We also highlight a number of the key, critical issues that were the subject of debate. The second section contains various assessments. We analyze the achievement of the price stability mandate and developments in the ECB's credibility, and we also investigate the ECB's interest rate decisions through the lens of a simple empirical interest rate reaction function. Finally, we present the ECB's framework for thinking about nonstandard monetary policy measures and review the evidence on their effectiveness. One of the main themes of the paper is how the ECB utilized its monetary policy to respond to the challenges posed by the European twin financial and sovereign debt crises and the subsequent slow economic recovery, making use of its relatively wide range of instruments, defining new ones where necessary, and developing the strategic underpinnings of its policy framework.
\end{abstract}

Conflict of Interest Disclosure: The authors are senior managers of the European Central Bank, the public authority whose monetary policy is discussed in this paper. They did not receive any financial support from any firm or person with a financial or political interest in the paper. No outside party had the right to review the paper before circulation. 
E uropean Economic and Monetary Union (EMU) is an unprecedented historical project, in which 11 European Union countries initially introduced a common currency - the euro-with a single central bank-the European Central Bank (ECB) — and a single monetary policy. By the time of writing, 19 quite diverse EU countries have joined the euro area, meaning that the ECB runs the monetary policy for about 341 million citizens (compared with about 326 million citizens for the U.S. Federal Reserve System) or an economic area that constitutes 11.6 percent of the world's GDP (compared with 15.3 percent for the U.S. or 18.2 percent for China, all in terms of purchasing power parity) (ECB 2018b). The motivation for this paper is that on June 1, 2018, the ECB celebrated its 20th anniversary. As two economists who have been on the staff of the ECB from the beginning, we take this opportunity to look back at the first two decades of our institution, describing and assessing its experience with monetary policy.

An important starting point is the statutory objectives of the ECB, as laid down in the Treaty on the Functioning of the European Union and the Treaty on European Union (EU 2012a, 2012b). ${ }^{1}$ The ECB's primary objective is to maintain price stability. Without prejudice to the objective of price stability, the ECB also supports the general economic policies of the European Union, with a view to contributing to the achievement of its objectives. These (often called secondary) objectives include, for example, balanced economic growth and a highly competitive social market economy, aiming at full employment and social progress. This hierarchy of objectives is interpreted in lexicographic order (Driffill and Rotondi 2004; Artus and others 2008). Only to the extent that the primary objective is fulfilled can the ECB consider growth and employment. Such "single" central bank mandates, focusing on price stability as the primary objective, are quite common in advanced economies. For example, they apply to all the central banks of the Group of Seven, except the U.S. Federal Reserve.

From the euro's introduction in January 1999-the beginning of stage 3 of EMU - the ECB started with a strong and self-contained mandate to define and implement monetary policy for the euro area. For other tasks that central banks often fulfill, however, it had more indirect or

1. For simplicity, we are abstracting from the legally precise distinctions between the ECB, the Eurosystem (comprising the ECB and the national central banks of countries that have joined EMU), and the European System of Central Banks (comprising the Eurosystem and all other EU central banks). National central banks play an important role in ECB decisions, their preparation, and implementation; but unfortunately, we do not have the space in this paper to provide a proper account of these collective aspects of Eurosystem functioning. 
contributing roles, notably in the prudential and financial stability arena. ${ }^{2}$ (In November 2014, however, the ECB was given the role of banking supervisor for the countries that joined the European Banking Unionwhich is congruent with the euro area (EU 2013). It needs to conduct banking supervision and monetary policy separately.)

This paper focuses on the ECB's experience conducting monetary policy for the euro area. ${ }^{3}$ Our overall goals are to provide a rigorous and comprehensive "inside" view of what the ECB has been concerned with in this area, how its monetary policy has evolved during its first 20 years, and how it has performed in achieving its primary objective of maintaining price stability. Obviously, one main theme of the paper is how the ECB has responded to the enormous challenges posed by the European twin crises (in the European case, the financial crisis of 2007-9 morphed into the sovereign debt crisis of 2010-13) and the subsequent slow economic recovery, making use of its relatively wide range of instruments, defining new ones where necessary, and developing the strategic underpinnings of its policy framework. But given the main motivation for our paper, we should not limit the attention only to the second decade of the ECB's existence.

Before we delve deeper into the details of the ECB's monetary policy, we provide a perspective on the broader issues with which the ECB has been concerned during the last 20 years via the themes that ECB Executive Board members have addressed in their public communications. ${ }^{4}$ Figure 1 shows the number of public speeches Board members gave every year between 1999 and 2017. The figure's different shades and patterns refer to the shares of these speeches that were dedicated to any of nine different themes. We did not predetermine these themes. Instead, we applied a machine-learning approach to uncover them from the texts of the 1,892 board speeches displayed on the ECB's website for the period May 1998-April 2018. (As of 2014, the data set also began to include the speeches by the ECB's chair and vice chair, and the four ECB representatives from the Supervisory Board of the Single Supervisory Mechanism.)

2. For complete lists of ECB tasks and functions, see EU (2012b, 2012c).

3. In a companion paper (forthcoming), we discuss the ECB's experience with financial stability.

4. The Board comprises the ECB president, vice president, and four further members, who are appointed by the European Council, usually for a term of eight years (EU 2012b, 2012c). They are collectively responsible for the current business of the ECB and play an important role in the Governing Council, the main decisionmaking body of the ECB and the Eurosystem. The other Governing Council members are the governors of the euro area national central banks. 
Figure 1. Speeches by the ECB's Executive and Supervisory Board Members and Their Decomposition in General Themes, 1999-2017

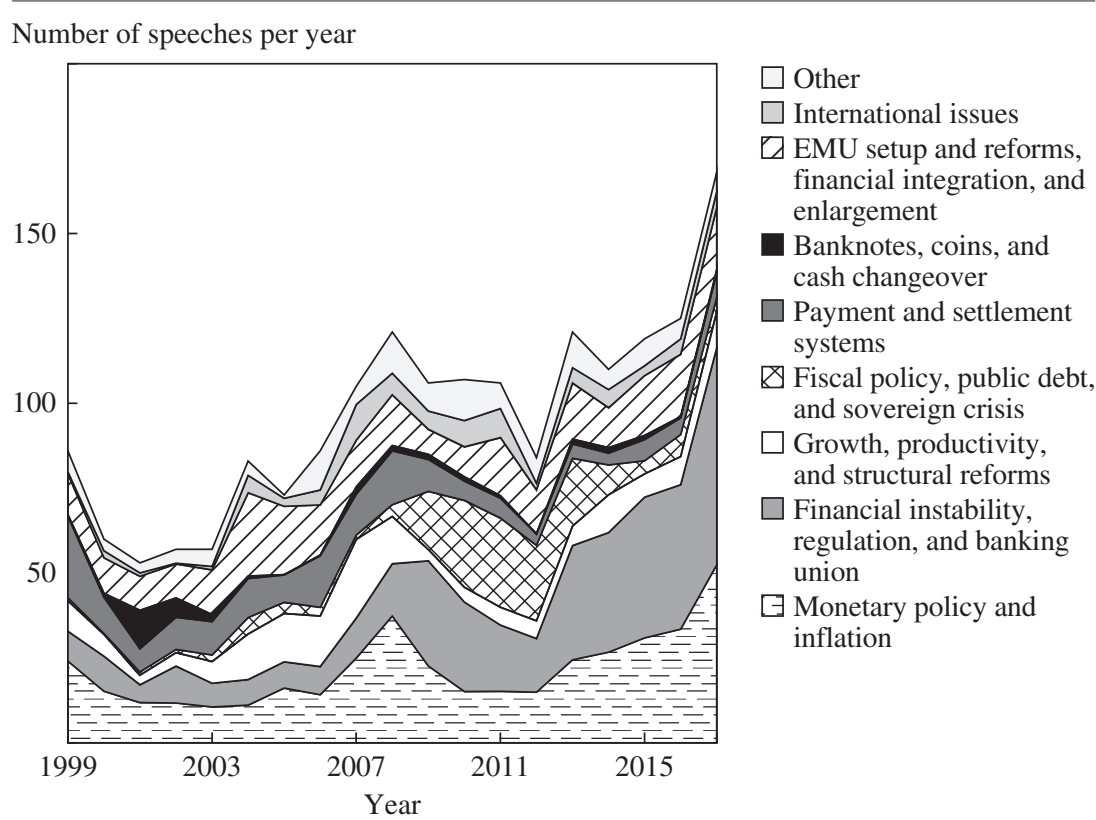

Sources: Authors' research; ECB data.

a. The figure is based on an application of the Latent Dirichlet Allocation methodology (Blei, $\mathrm{Ng}$, and Jordan 2003) to identify the topics addressed in the public speeches given by Executive Board members of the European Central Bank between May 1998 and April 2018. All speeches on the ECB website section (https://www.ecb.europa.eu/press/key/date/2017/html/index.en.html) have been considered as documents. Since 2014, the speeches by the chair, vice chair, and ECB Supervisory Board members of the Single Supervisory Mechanism have also been included (https://www.bankingsupervision.europa. eu/press/speeches/date/2017/html/index.en.html).

Overall, the document set comprises 1,892 speeches. The figure shows results only for full years, that is, 1999-2017 (1,829 speeches). The upper line shows the total number of speeches per year. The shades and patterns of the areas underneath describe for a given year the shares of these speeches addressing nine general themes; see the legend. The themes have been derived by the authors grouping the topics found by the Latent Dirichlet Allocation machine-learning algorithm, which defines a topic as a set of words that occur together within documents and derives the probability that a given document addresses this topic. Applying the metric of Cao and others (2009), the total number of topics has been set at 50. A speech can address more than one topic. The full list of topics and their grouping in themes is available from the authors upon request. 
Using the Latent Dirichlet Allocation method for textual analysis (Blei, Ng, and Jordan 2003) and the metric developed by Juan Cao and others (2009) for the optimal number of topics, we identify 50 specific topics that have been addressed in these speeches over time. For the purpose of the first general overview given in figure 1, we group this rather large number of topics into the 9 general themes displayed.

The results give a good impression of the breadth of issues that the ECB was concerned with (via the external communication of Board members) and how they changed over time. First, the core theme of "monetary policy and inflation" (the dashed area in figure 1) covered a sizable share most of the time, but it was particularly important at the time of the ECB's inception in 1999; when the financial crisis hit, in the years 2007-9; and during the post-sovereign debt crisis, low-inflation recovery period, 2013-17. Clearly, these were three periods with increased needs for monetary policy communication. Second, financial stability and supervisory issues received particular attention when the financial crisis struck and after the 2012 agreement about the European Banking Union that granted supervisory responsibility to the ECB (the medium gray area, second from the bottom, of figure 1). Third, growth and productivity (the white area), fiscal matters (the checkered area) and international developments (the lighter gray area, second from the top), which all have implications for the conduct of monetary policy, received regular attention. But the attention paid to public debt and sovereign risk (part of the checkered area) was most pronounced when the financial crisis morphed into the European sovereign crisis in 2009-10. Structural reforms, productivity and competitiveness issues (part of the white area) were very much discussed before the start of the financial crisis.

Board members also addressed a number of other themes of great importance for the ECB that we do not touch upon at all in this paper. For example, one can see in figure 1 that in 2001-before the introduction of euro notes and coins in 2002-Board members prepared the public for the cash changeover (the black area of figure 1). In 2004 and 2005, at the time of the EU's major eastern enlargement, they communicated more about accession and convergence issues (part of the diagonally striped area). Finally, payment and settlement issues (the dark gray area, fifth from the top) played a greater role in Board members' external communications (in 2006), shortly before the ECB's initial TARGET large-value payment system migrated to the single-platform TARGET2 system, and during 2008, when the TARGET2-Securities project was launched to establish a single, pan-European platform for securities settlement. 
Returning to this paper's main focus, figure 2 shows only the speeches dealing with the core theme of "monetary policy and inflation" (the dashed area of figure 1), breaking it down in the shares of the 10 underlying topics that fall under this theme (out of 50 found by our machine-learning algorithm). In the beginning, the largest focus was on explaining the new institution's monetary policy strategy, including its monetary analysis aspect (the medium gray area, second from the bottom, of figure 2; see subsection I.A below). In the financial crisis period, the ECB's market operations and liquidity management (the white area) became an important focus, in line with the policy approach taken at the time (see subsection I.C below). In the last period, the focus of the ECB's Board members' public speeches moved to how the ECB used nonstandard monetary policy measures, such as large-scale asset purchases (the black area) and negative interest rates (the checkered area areas in figure 2), to strengthen the fragile recovery and ensure that inflation would return to the ECB's objective (the light gray area at the top) in an environment of interest rates close to their effective lower bound (see subsection I.C below).

The rest of the paper is organized in two main sections. Section I provides a chronological account of the macroeconomic, monetary, and financial developments in the euro area since the adoption of the euro, as well as of the ECB's monetary policy decisions. We divide the section into the four cyclical phases that "conditioned" ECB monetary policy between 1999 and 2018: the end of the technology cycle, the economic upturn with a buildup of imbalances, the "double-dip" recessions associated with the financial and sovereign debt crises, and the low-inflation recovery. Each of these four subsections in turn has three divisions: first, on developments in the ECB's monetary policy strategy and operational framework; second, on the conjuncture and actual decisions; and third, a discussion highlighting critical issues that were the subject of public debate.

In section II, we assess selected aspects of the ECB's monetary policy in the last 20 years. We first analyze the achievement of the price stability mandate and developments in the ECB's credibility and discuss possible implications for the ECB's inflation aim (subsection II.A). Next, we examine the ECB's interest rate decisions through the lens of a simple empirical interest rate reaction function (subsection II.B). This is appropriate until the ECB hits the zero lower bound in mid-2012. Finally, we present the ECB's framework for thinking about nonstandard monetary policy measures-many of which draw on its broad and flexible 
Figure 2. Speeches by ECB Executive Board Members on Monetary Policy and Inflation and Their Decomposition in Topics, 1999-2017 ${ }^{\text {a }}$

Number of speeches per year

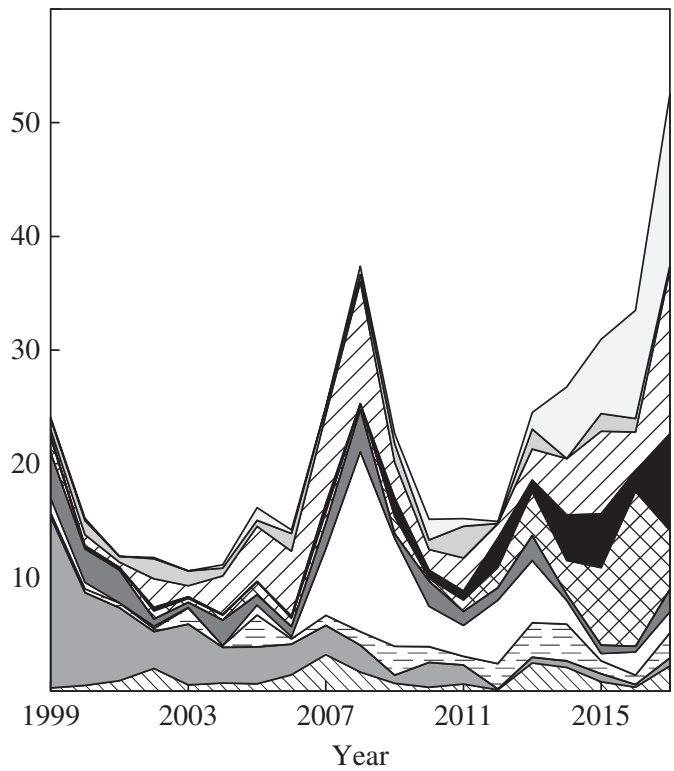

Postcrisis recovery and sustained inflation

$\square$ Monetary policy, cycles, and asset prices

$\square$ Inflation and the Phillips curve

Asset purchases

$\triangle$ Negative rates and lower bound

Governing Council decisions, independence, and accountability

$\square$ Market operations and liquidity

$\boxminus$ Financial structure and small and medium-sized enterprises' financing conditions

$\square$ Monetary policy strategy and monetary analysis

$\nabla$ Central bank communication, uncertainty, and forward guidance

Sources: Authors' research; ECB data.

a. This figure is based on an application of the Latent Dirichlet Allocation methodology (Blei, $\mathrm{Ng}$, and Jordan 2003) to identify the topics addressed in the public speeches given by Executive Board members of the European Central Bank between May 1998 and April 2018. All speeches on the ECB website section (https://www.ecb.europa.eu/press/key/date/2017/html/index.en.html) have been considered as documents. Since 2014, the speeches by the chair, vice chair, and ECB Supervisory Board members of the Single Supervisory Mechanism have also been included (https://www.bankingsupervision.europa.eu/ press/speeches/date/2017/html/index.en.html).

Overall, the document set comprises 1,892 speeches. The figure shows results only for full years, that is, 1999-2017 (1,829 speeches). Applying the metric of Cao and others (2009), the total number of topics has been set to 50 . The figure only refers to the 10 topics - see the legend-that can be grouped to a general theme denoted as "monetary policy and inflation" (see also figure 1). The upper line refers to the number of speeches per year addressing these 10 topics. The shades and patterns of the areas underneath describe the shares of these speeches addressing each topic for a given year. A speech can address more than one topic. The Latent Dirichlet Allocation machine-learning algorithm defines a topic as a set of words that occur together within documents and derives the probability that a given document addresses this topic. The descriptions of the topics shown in the legend have been formulated by the authors, based on the words included in the different topics and their reading of the speeches that addressed the topics with high likelihood. 
Figure 3. Output Gap Estimates and the Unemployment Rate for the Euro Area, 1999-2017

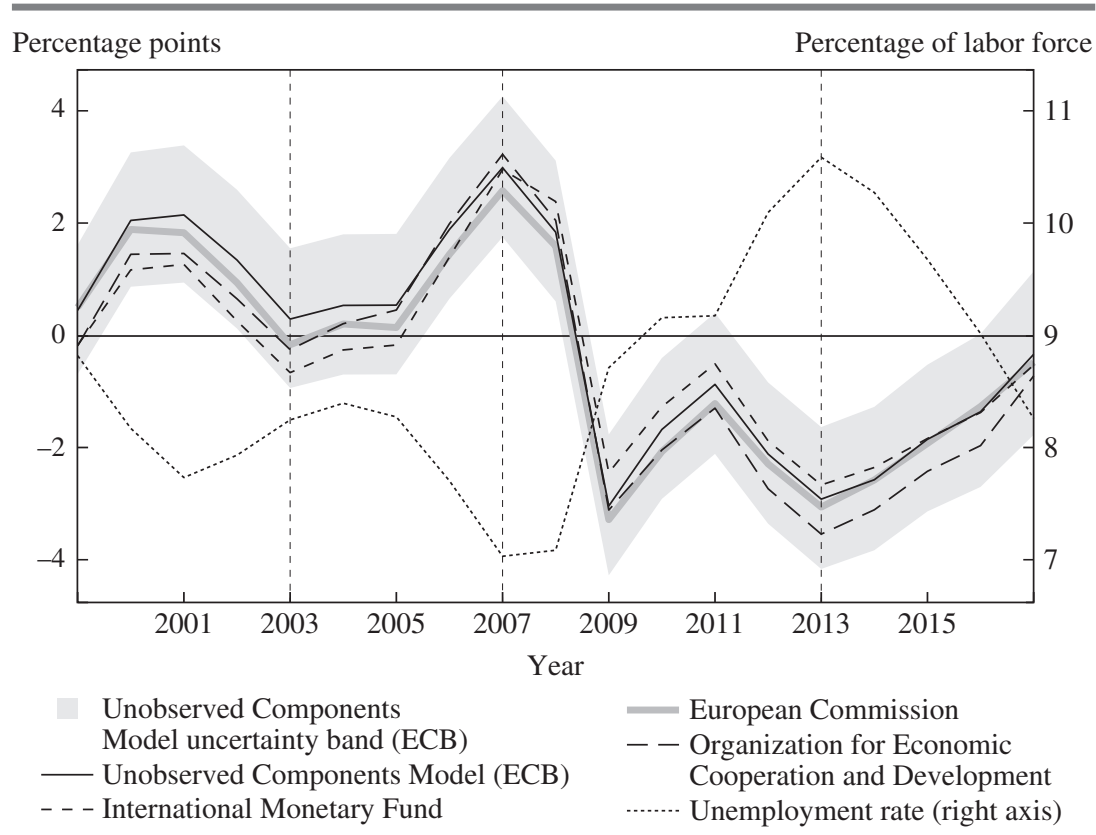

Sources: European Commission (2018); International Monetary Fund (2018); Organization for Economic Cooperation and Development (2018); ECB data.

a. Yearly data and estimations are the latest available, and therefore are not in real time. The Unobserved Components Model (ECB) has been run following Szörfi and Tóth (2018), and the output gap estimates from it should not be regarded as official ECB output gaps. The uncertainty bands refer only to the Unobserved Components Model (ECB) output gap. Vertical dashed lines are indicative of business cycle troughs and peaks (also see figure 4). The most recent observations are for 2017.

framework for market operations - and we review the evidence on the effectiveness of the nonstandard instruments that have been used (subsection II.C). Section III offers conclusions, and considers how completing EMU could support the ECB's monetary policy.

\section{Two Decades of ECB Monetary Policy: From the Two Pillars to Quantitative Easing}

This section discusses the ECB's monetary policy during the past two decades. It gives a chronological overview of the main macroeconomic, monetary, and financial developments in the euro area since the euro's adoption in January 1999 and how the ECB has responded to them in pursuit of its price stability mandate. Taking a business cycle perspective, 
we use-among other indicators - the euro area output gap estimates and unemployment rate shown in figure 3 for identifying troughs and peaks (marked by dashed vertical lines). This leads to four episodes corresponding to cyclical downturns and upturns: the initial period of a growth slowdown following the collapse of the dot-com bubble accompanied by a weak euro exchange rate, 1999-2003; the boom period in money and credit growth accompanied by relatively stable inflation and accelerating growth, 2003-7; the subsequent double-dip recession due to the start of the U.S. financial crisis and the emergence of the euro area sovereign debt crisis, 2007-13; and, finally, the most recent low-inflation recovery period, 2013-18. Figure 4 (on the next two pages) provides an overview of the four periods-here marked with alternating gray and white areas whose transitions (business cycle troughs and peaks) are dated to the month-for main macroeconomic variables (on the next page) and two key monetary policy indicators (on the subsequent page). The figure also marks major ECB monetary policy actions (on the subsequent page) and other important events (on the next page) that were characteristic of the respective period.

\section{I.A. The Beginning of ECB Monetary Policy toward the End of the Technology Cycle, January 1999-June 2003}

The beginning of the ECB's monetary policy was characterized by the first application of a new monetary policy strategy and framework. Challenges during the first cyclical period included a test of the ECB's anti-inflationary resolve related, among other things, to a protracted depreciation of the euro and a reversal of the perspective due to the collapse of the technology euphoria from the late 1990s.

A NEW STABILITY-ORIENTED MONETARY POLICY STRATEGY AND OPERATIONAL FRAMEWORK FOR THE ECB As discussed in the introduction, the treaty creating the European Economic and Monetary Union established price stability as the primary objective of monetary policy in the euro area. Under the leadership of Otmar Issing, its first chief economist, the ECB early on developed a monetary policy strategy that had the aim of providing a solid basis for the conduct and communication of monetary policy in pursuit of price stability. ${ }^{5}$ It also developed an elaborate operational framework for implementing monetary policy decisions. ${ }^{6}$

5. For an extensive presentation and justification of the original two-pillar, stabilityoriented monetary policy strategy, see ECB (1999); and Issing and others (2001).

6. See ECB (2000a). The monetary policy strategy and operational framework were developed building on the extensive preparatory work carried out by the European Monetary Institute- the ECB's predecessor. 


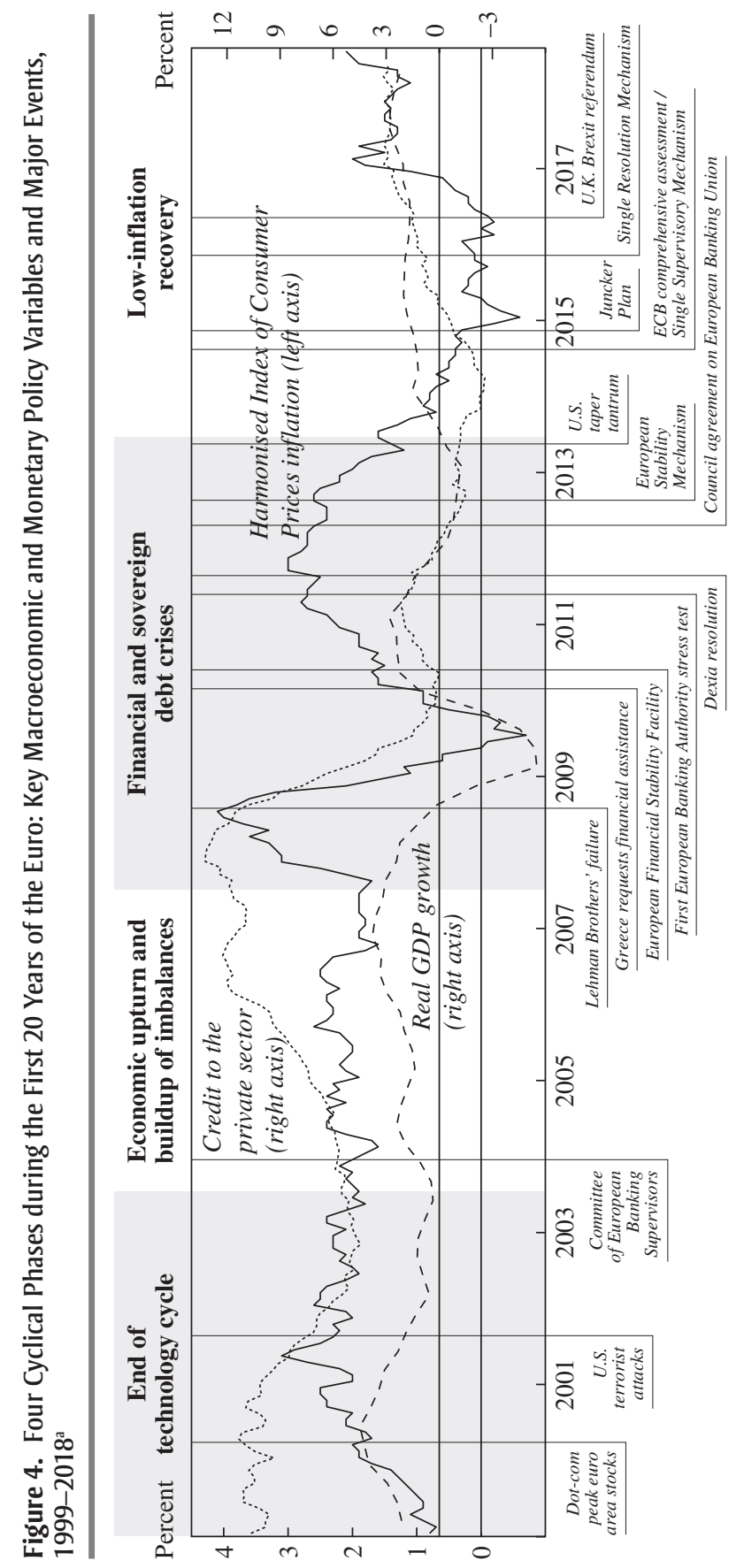




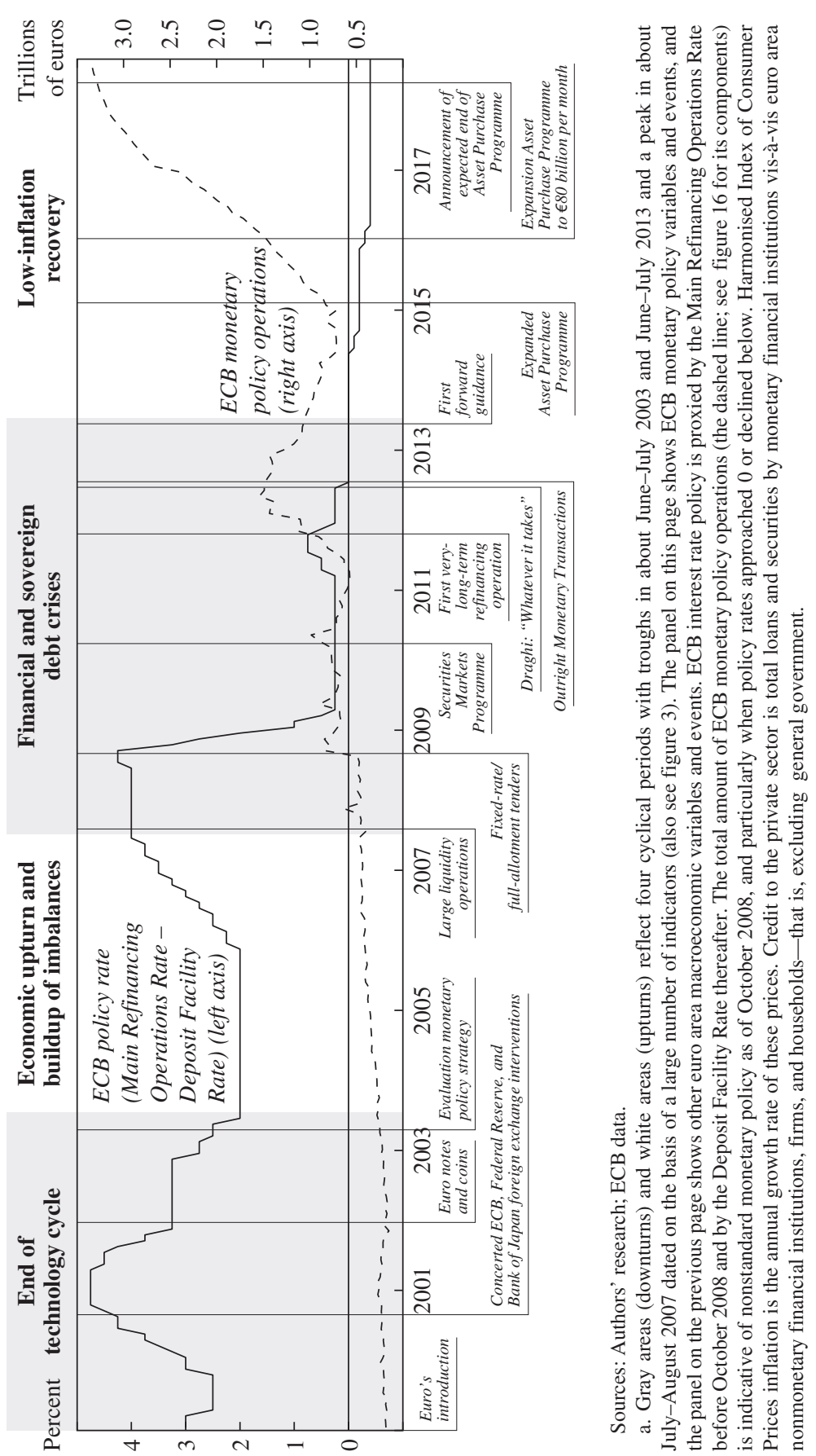


In addition to being operationally ready from day one, there were two main and interrelated challenges. The first challenge was to establish, as quickly as possible, the credibility of the new institution for maintaining price stability. A high level of initial credibility would facilitate the transition to EMU and reduce the potential costs of having to build such credibility. ${ }^{7}$ The second challenge was to ensure a consistent and systematic approach to the conduct of monetary policy in an uncertain economic environment after a fundamental regime change and where the national central banks preceding the ECB/Eurosystem had different frameworks and traditions. Robustness in the face of pervasive uncertainty and country heterogeneity was seen as an important guiding principle for the design of the new strategy (Issing and others 2005; Issing 2008). In response to these two challenges, three main components were developed: first, a quantitative definition of the ECB's primary objective of price stability as a clear yardstick for accountability; second, a two-pillar framework as the organizing principle for the analysis underlying the assessment of the outlook for price developments and for a structured policy discussion; and third, an elaborate communication and accountability framework. Before describing the economic and monetary developments in this initial phase, we briefly describe these three elements. We also briefly characterize the initial operational framework. As we discuss in subsequent sections, elements of these building blocks have evolved in response to challenges over time (Constancio 2018).

The quantitative definition of price stability. In December 1998, the Governing Council of the ECB adopted a quantitative definition of price stability, which reads: "Price stability shall be defined as a year-onyear increase in the Harmonised Index of Consumer Prices (HICP) for the euro area of below 2 percent." Price stability "is to be maintained over the medium term" (ECB 1999, 46). This definition allows economic agents and observers to assess the ECB's performance at any time and over any horizon. It enhances the ECB's accountability by forcing the central bank to explain why inflation has at times deviated from its definition, and it thereby helps anchor medium- to long-term expectations. The definition focuses on the euro area as a whole, reflecting the fact that, within a monetary union, monetary policy cannot address country-specific inflation developments. It makes clear that medium-term inflation above 2 percent is not consistent with price stability. However, it also implies

7. Whether the ECB would have a deflationary bias in order to establish its anti-inflation credibility was hotly debated at the time. See, for example, Begg and others $(1998,1999)$. 
that very low inflation rates, and especially deflation, are not consistent with price stability either. Following criticism of the perceived asymmetry of the quantitative definition, this was clarified - for example, by the ECB's president, Willem Duisenberg, in an early speech explaining the new strategy. ${ }^{8}$

Another important feature is the medium-term orientation of the ECB's strategy. Because monetary policy can affect price developments only with significant and variable time lags, and only to an uncertain extent, it is impossible to maintain a specific, predefined inflation rate at all times or to bring it back to a desired level within a very short period. Consequently, monetary policy needs to act in a forward-looking manner and focus on the medium term. This also helps to avoid excessive activism and the introduction of unnecessary volatility into the real economy, thereby contributing to the stabilization of output and employment. See, for example, the papers by Nicoletta Batini and Edward Nelson (2001) and Frank Smets (2003), who show the equivalence between the length of the policy horizon and the weight on output gap stabilization.

Against the background of the inflation forecast targeting strategies that were popular at the time, two aspects of the ECB's medium-term orientation are worth mentioning. First, the ECB has always emphasized that there is no fixed time horizon over which price stability needs to be reestablished, given that monetary policy should react differently to different sources of economic shocks (for example, demand versus supply shocks). ${ }^{9}$ Second, the medium-term orientation implies a lengthening of the monetary policy horizon beyond the usual two years typically associated with the horizon of inflation forecasts and the lags in monetary policy transmission. For example, then-ECB president Jean-Claude Trichet (2003b) states that "monetary policy needs to focus on the period covering the whole transmission process, bearing in mind that this may sometimes

8. As Duisenberg (1999) stated: "Some observers have criticised this strategy as 'asymmetric.' In other words, they argue that the Eurosystem is more concerned about inflation than it is about deflation. In their view, such asymmetry will impose a drag on the overall performance of the euro area economy as a whole because monetary policy will be overly restrictive on average, and risks triggering a damaging deflationary spiral in some circumstances. . . . I reject this criticism. The use of the word 'increases' in the definition imposes a floor of at least zero for the lower bound. . . . Let me state categorically, as I have often done in the past, that neither prolonged inflation nor prolonged deflation in the euro area would be deemed by the Governing Council to be consistent with the maintenance of price stability."

9. This feature of the ECB's monetary policy strategy was eventually also adopted in inflation-targeting central banks, which have also recognised the need for a more flexible policy horizon. See, for example, Bean (2003). 
span a protracted period of time." As a result, the horizon for evaluating the credibility of the central bank should also extend beyond two years. In subsection II.A, we take an admittedly somewhat arbitrary five-year horizon, which typically should be enough to let the effects of the shocks that the central bank cannot control wash out.

The two-pillar framework. In the original formulation (ECB 1999), the "two pillars" of the ECB's strategy were described as (1) a prominent role for money, as signaled by the announcement of a quantitative reference value for the growth rate of a broad monetary aggregate, known as M3; and (2) a broadly based assessment of the outlook for price developments and risks to price stability in the euro area as a whole, which includes the macroeconomic projections. ${ }^{10}$ The two-pillar framework was a unique feature of the ECB's monetary policy strategy and was seen as a partial answer to the two challenges described above. First, the prominent role for money would help the ECB gain rapid credibility by borrowing some of the elements of the Deutsche Bundesbank's stability-oriented monetary policy strategy. Second, the two-pillar framework would allow the ECB to bring different traditions under one roof and provide a robust framework in an environment of high uncertainty, pervasive structural change, crosscountry heterogeneity, and convergence. It would also bring together perspectives from the two leading economic paradigms-Keynesianism and monetarism - that had very much shaped macroeconomic debates in the preceding decades, rather than focusing mainly on one of them.

The reference value for M3 growth (see the thick gray dashed line in figure 9 below) underlined both the relative importance of the role of money and the medium-term orientation of the ECB's strategy. At a press conference on October 13, 1998, President Duisenberg was asked about the relative weight of the two pillars. He replied: "It is not a coincidence that I have used the words that money will play a prominent role. So if you call it the two pillars, one pillar is thicker than the other is, or stronger than the other, but how much I couldn't tell you" (Duisenberg 1998). The choice of M3 was based on the evidence that this monetary aggregate exhibited a close relationship with the price level. At the same time, it was made clear from the very beginning that monetary policy would not react mechanically to deviations of M3 growth from the reference value; it was not a monetary growth target (ECB 1999). The

10. In fact, the internal briefing process supporting the Governing Council's monetary policy decisions was, and still is at the time of writing, organized along the two pillars, later called economic and monetary analysis (see subsection I.B). 
monetary pillar also involved an analysis of different monetary aggregates and the asset side of the banking system, in particular developments in credit to firms and households.

The reference value for M3 growth of 4.5 percent implicitly also revealed that the ECB was aiming at the upper half of the below-2-percent price stability definition. Because, in this period, the trend growth rate of GDP was assumed to lie in the range of 2 to 2.5 percent and the trend rate of decline in the velocity of circulation of M3 in the range of -0.5 to -1 percent, the arithmetic of the quantity equation for money suggests an operational inflation aim between 1 to 2 percent. Although it was never explicitly acknowledged, this was consistent with the emphasis on positive, but uncertain, measurement biases in HICP inflation (up to 1 percent), which was given as one of the explanations for why the ECB did not formulate a clear lower bound in the quantitative definition of price stability (Issing and others 2001).

Communication and accountability. Legally, the ECB is probably one of the most independent central banks in the world. Its independence is not simply a result of domestic law, but is based on the international Treaty on European Union (EU 2012a). Changing this treaty would require the agreement of every signing country. ${ }^{11}$ Transparency and clear communication are a natural complement to strong independence, because it makes it easier to hold the central bank accountable, which in turn is a key element to maintain political support for the ECB's high degree of independence. ${ }^{12}$ Clear communication is also important for effectively conducting monetary policy, as it helps anchor inflation expectations, reduce policy-induced uncertainty, and make the transmission process of policy decisions more effective.

From the very outset, the ECB put great emphasis on communicating its policy actions and the economic rationale underlying its decisions to financial market participants and the general public in a transparent and timely manner. Since the start, the main communication vehicle has been the monetary policy press conferences held by the president and the vice president

11. The treaty gives the ECB and the members of its decisionmaking bodies (the Governing Council) a very high degree of institutional (vis-à-vis Community institutions or bodies and any government of a member state), personal (relatively long fixed-term contracts), financial (own budget), and functional (exclusive competence for monetary policy in the euro area and prohibition of monetary financing) independence.

12. See Tucker (2018) for a recent in-depth discussion of the political economy of central bank independence. 
immediately after each monetary policy Governing Council. ${ }^{13}$ On this occasion, the introductory statement is presented by the president on behalf of the Governing Council. It provides a summary of the policy-relevant assessment of economic and monetary developments, as well as the monetary policy stance, and it is structured along the lines of the ECB's monetary policy strategy. The press conference includes a question-and-answer session, which is attended by key media representatives from across the euro area and beyond. The press conference was seen as an effective means of presenting and explaining in a very timely manner the discussions in the Governing Council, and thus the monetary policy decisionmaking process. In the context of a global trend toward more detailed and transparent communications by central banks, this feature of the ECB's communication strategy has increasingly been adopted by other central banks (such as the Federal Reserve).$^{14}$ Other important communication channels used by the ECB are the Monthly Bulletin (since January 2015, this has been called the Economic Bulletin, and it is published less frequently than monthly), which gives a detailed and comprehensive analysis of the economic environment and monetary developments, the quarterly appearances of the ECB president before the European Parliament's Committee on Economic and Monetary Affairs (Fraccaroli, Giovannini, and Jamet 2018), and a large number of public speeches (see figures 1 and 2) and interviews with media by members of the Executive Board.

The operational framework. The monetary policy stance decided on by the Governing Council is implemented through ECB market operations. As a matter of fact, the statute of the ECB delegated the conduct of these operations to the Executive Board from the start of the euro (see Article 12.1, second paragraph, in EU 2012c), creating some separation of the operational decisions from the general monetary policy debate. The operational decisions are further executed in a decentralized way between the counterparties and their respective national central banks. Originally, the market operations aimed primarily at keeping very-short-term money market rates close to the policy rate decided by the council. More goals

13. The frequency of the monetary policy Governing Council meetings was monthly (the first Governing Council meeting of the month) until December 2014, and was changed to eight times a year as of 2015 (a frequency very similar to the U.S. Federal Reserve's Federal Open Market Committee meetings). One reason for this was that after one month, often only a limited amount of new information was available but the fact that a new monetary policy decision had to be made could lead to some market volatility.

14. See, for example, Yellen (2012). 
were only added much later, when the policy rate came close to its effective lower bound and other means than short-term interest rates needed to be used for easing monetary policy further (see subsection I.D). In designing its operational tools, the ECB prioritizes what is needed for the smooth implementation of its monetary policy. Next, it considers what is good for market functioning, neutrality, and risk control.

One important feature of the ECB's operational framework is its breadth, despite a focus on banks related to the predominant financial structure in the euro area (Hartmann, Maddaloni, and Manganelli 2003). Given the diversity of euro area countries' financial systems, a very broad framework was needed to meet the above-noted criteria. The very long experience of many euro area national central banks was particularly helpful in this regard. Until the present day, the ECB's operational framework has contained four types of instruments: (1) open market credit operations; (2) standing facilities; (3) minimum reserve requirements; and (4) outright asset purchases. ${ }^{15}$

Initially, only the first three instruments were actively used. Reserve requirements extended the liquidity deficit of the banking sector vis-à-vis the central bank that bank note issuance and government deposits create. Euro area banks need to hold a small share of their short-term liabilities ( 2 percent until January 2012, and 1 percent thereafter) on their Eurosystem accounts, and these required reserves are remunerated at the rate set by the ECB for its Main Refinancing Operations (MROs), the MRO Rate (MROR). This needs to be the case only on average over a reserve maintenance period of a few weeks. Normally, the averaging procedure has a stabilizing effect, because it encourages liquidity planning and helps mitigate the effects of unexpected short-term liquidity shocks-the main purpose of the reserve requirements.

Open market operations allow ECB counterparties to acquire the liquidity needed to close the aggregate deficit, so that short-term money market rates stay close to the policy rate decided by the Governing Council. Before the European crises, the bulk of the liquidity was provided through MROs, so the MROR constituted a key policy rate for the Governing Council. MROs started as weekly tenders of two-week collateralized credit

15. The complete formal description of the framework is published in the Official Journal of the European Union as the "Guideline of the European Central Bank on the Implementation of the Eurosystem Monetary Policy Framework," which originally was often called "General Documentation of Eurosystem Monetary Policy Instruments and Procedures." An updated version can be found on the ECB website: https://www.ecb.europa.eu/ecb/legal/pdf/ celex_02014o0060-20180416_en_txt.pdf. 
operations (repurchase agreements) with Eurosystem counterparties, in which the ECB fixed the MROR, estimated the overall liquidity needed by the banking system, and allocated the amounts pro-rata according to the bids received. After some internal and external discussion about overbidding and underbidding phenomena (Ayuso and Repullo 2001; Bindseil 2005; Ehrhart 2001; Nautz and Oechsler 2006), in June 2000 the ECB switched to variable rate tenders, with the minimum bid rate constituting the policy rate. In those, the ECB determined the total amount to be allotted and counterparty banks could bid for a larger or smaller share via the rates they were willing to pay at or above the minimum bid rate. In March 2004, the maturity of MROs was shortened to one week. A second type of open market operations from the start were Long-Term Refinancing Operations (LTROs), with a maturity of normally three months. In early times, a third type-fine-tuning operations - were used quite sparingly.

The ECB's two standing facilities create a corridor for very-short-term money market rates around the MROR. At the deposit facility, counterparties can "park" unused liquidity overnight, receiving an interest ratethe Deposit Facility Rate (DFR) - that is lower than the MROR. At the marginal lending facility, counterparties can borrow overnight (against eligible collateral) any liquidity that they are missing at the end of a day, paying a penalty rate-the Marginal Lending Facility Rate (MLFR), which is set above the MROR. Before the financial crisis, the corridor defined by the standing facilities was set most of the time symmetrically around the MROR, with a width of 200 basis points. Figure 5 shows the three policy rates-MROR, DFR, and MLFR_-between January 1999 and August 2018.

The breadth of the ECB's operational framework is defined not only by the set of different instruments that can be used but also by the number of counterparties entitled to transact with the ECB and by the range of assets eligible as collateral. Any euro area credit institution that is financially sound, supervised in the EU (or under a comparable third country regime), and fulfills some operational criteria can become an ECB counterparty. The number of effective counterparties is about 2,000, which amounted to a quarter of all euro area banks during the early years of the euro and about a third of them more recently.

Its statutes stipulate that the ECB can lend to counterparties only against "adequate" collateral (EU 2012c, Article 18). Given the wide-ranging differences in EU member countries' banking and financial systems, the ECB decided from the start that a rather broad set of collateral assets need to be eligible for its operations. But they have to fulfill a number of criteria 
Figure 5. The ECB's Policy Interest Rates and the Overnight Money Market Rate, 1999-2018

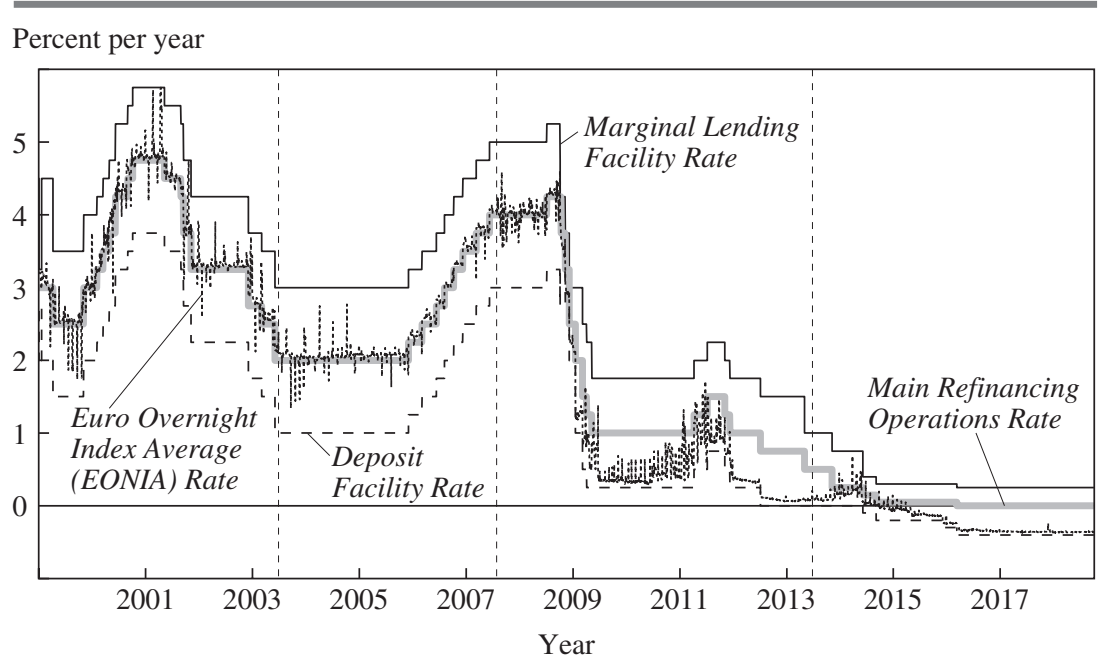

Source: ECB data.

a. The most recent observation is for October 10, 2018.

relating, among other things, to currency denomination; the location of the issuer, issuance, or any guarantor; and, notably, the risks involved. Risk control for collateral and counterparties is, of course, important for protecting the central bank from losses that could impair its credibility, hinder its operations, or even endanger its independence. It also shields euro area treasuries from reduced revenues originating from lower transfers of central bank monetary income (which ultimately means to protect taxpayers). Therefore, the ECB uses a risk management framework that has been adapted and improved over time, depending on new experiences. For example, like many other central banks, it applies haircuts to riskier assets and does not accept collateral below a certain quality in its credit operations (that is, not below a rating of A- before October 2008). ${ }^{16}$ Although the assets used as collateral for Eurosystem monetary policy operations changed over time, public sector debt securities, corporate bonds, asset-backed securities, and covered bonds, as well as various forms of credit claims, have always played significant roles.

16. This also applies to government bonds, because EMU does not include a fiscal union between member states. 
During the global financial crisis starting in 2007, it turned out that the overall operational framework of the ECB was not only quite broad for dealing with the specific difficulties encountered but also quite flexible in adapting to new challenges.

THE ECB'S FIRST INTEREST RATE CYCLE Against this background, we next describe the first cyclical period experienced by the ECB. ${ }^{17}$ When describing economic developments, we take the ECB's perspective, as reflected in the introductory statements of its monthly press conferences and its Monthly Bulletin. The main macroeconomic, monetary, and financial developments to which we refer are depicted in figures 3 to 15 throughout the paper.

When stage 3 of EMU started in January 1999, the ripples of the financial crises in Asia in 1997 and Russia in August 1998, together with the near collapse of the Long-Term Capital Management hedge fund in September 1998, were still visible in the high volatility of financial markets. The high level of uncertainty clouded prospects for economic growth in the euro area. In a coordinated move on December 3, 1998, all the national central banks in the euro area had lowered their key central bank interest rates to 3 percent, which de facto determined the level of short-term interest rates with which the ECB started stage 3 of EMU.

In early 1999 , it became increasingly clear that, on balance, the risks to price stability over the medium term were mainly on the downside. Inflation rates were very low by historical standards (below 1 percent; see figure 6) and were significantly below the ceiling of the ECB's definition of price stability amid emerging signs of a strong economic slowdown, which eventually did not materialize (figure 7). In spite of rising oil prices starting in mid-February 1999 (figure 8), a depreciating effective euro exchange rate, buoyant loan growth of about 10 percent, and headline M3 growth above the reference value (figure 9), the Governing Council reduced the policy rate by 50 basis points on April 8, 1999, from 3.0 to 2.5 percent (figure 5).

However, as sharp increases in oil prices and a general rise in import prices continued to exert upward pressure on prices in the short term in the context of robust economic growth, the risks of indirect and second-round effects on consumer price inflation via wage setting rose significantly in the course of 2000. These concerns were compounded by a trend depreciation of the euro exchange rate, especially in the second half of 2000, when it moved further out of line with the sound fundamentals of the euro area

17. For reviews of the first 10 years of the ECB, see ECB (2008a); Mackowiak and others (2008); Buti and others (2010); and Galí (2003). 
Figure 6. The Euro Area's Headline Inflation, Core Inflation, and Longer-Term Inflation Expectations, 1999-2018

Year-on-year percentage change

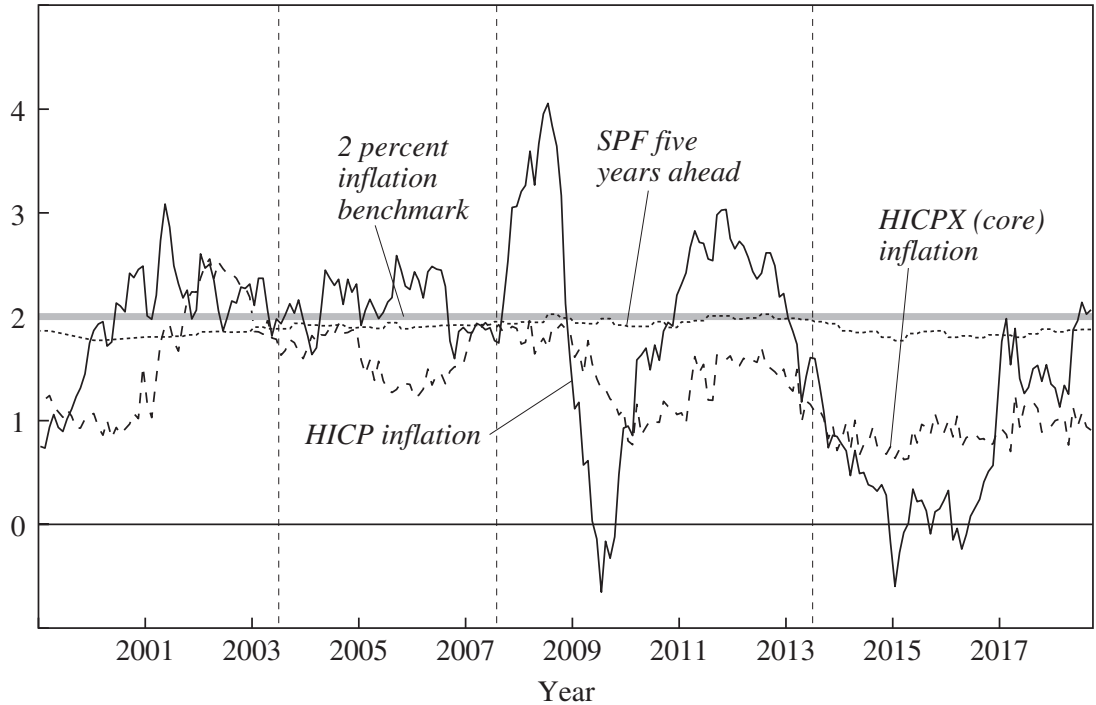

Sources: ECB data; Survey of Professional Forecasters (SPF).

a. HICP $=$ Harmonised Index of Consumer Prices; HICPX refers to HICP excluding energy and food. $\mathrm{SPF}$ five years ahead $=$ the average $\mathrm{HICP}$ inflation rate expected by the respondents to the SPF. The most recent observation is for September 2018.

Figure 7. The Euro Area's Real GDP Growth and Its Components, 1999-2018

Annual percentage changes and percentage-point contributions

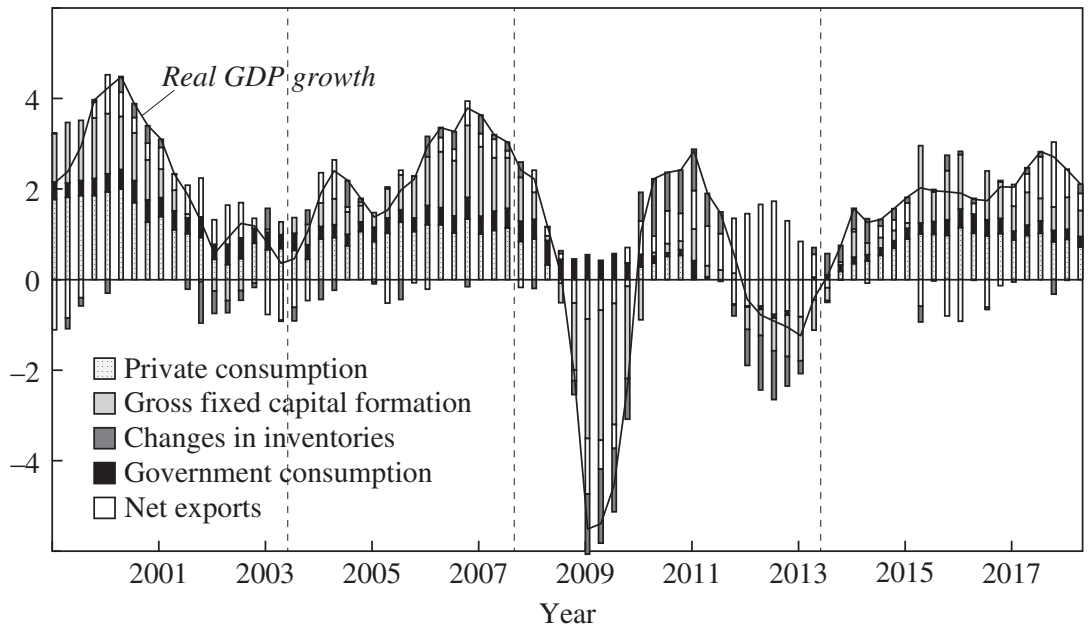

Source: ECB data.

a. This figure shows data for the 19 euro area countries (fixed composition). The most recent observation is for 2018:Q2. 
Figure 8. Global Prices for Oil, Metals, and Food, 2000-2018

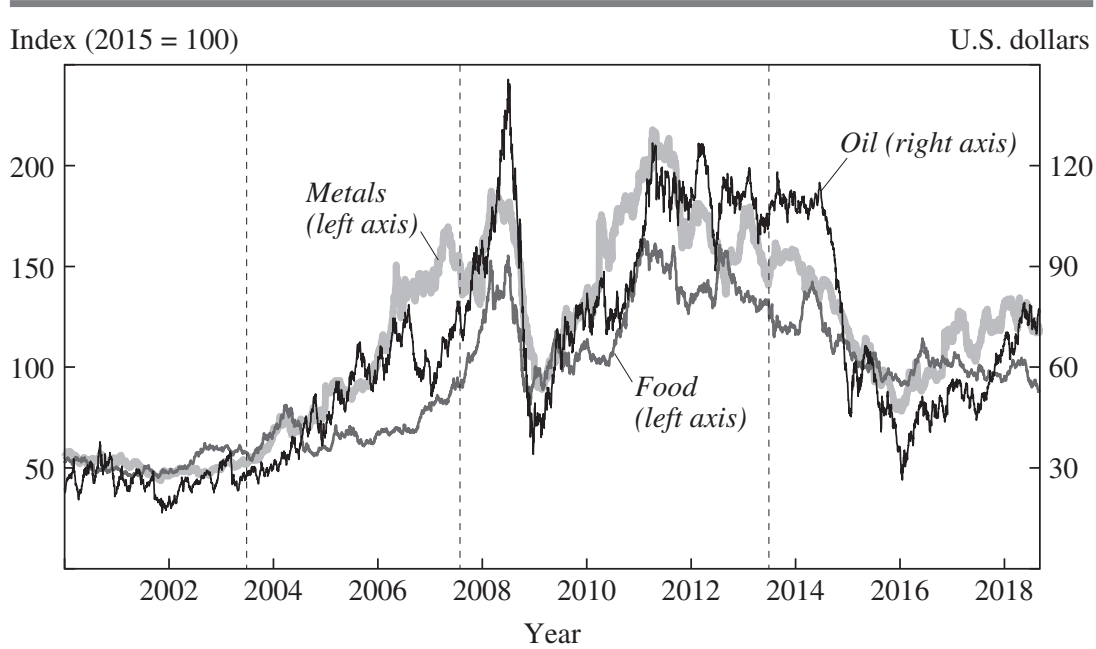

Sources: Bloomberg; Hamburgisches Weltwirtschaftsinstitut; ECB staff calculations.

a. Oil prices refer to the Daily Brent Oil spot prices per barrel in U.S. dollars. Food and metal prices are the respective subindexes of the Hamburgisches Weltwirtschaftsinstitut's total commodity price index, which are normalized to 100 in 2015. The most recent observation is for September 7, 2018.

(figure 10). Economic activity in the euro area expanded very rapidly in early 2000 , heading above a 4 percent growth rate, and was set to continue along this path (figure 7), due to the strong dynamism of the world economy, especially in the sectors of the "new economy." Also, the protracted monetary expansion above the reference value was increasingly pointing to upside risks to price stability at medium- to longer-term horizons over the course of 1999 and in early 2000 (figure 9). Against this background, the Governing Council raised the key ECB interest rates by a total of 225 basis points in a series of interest rate hikes between November 1999 and October 2000, bringing the main policy rate to a level of 4.75 percent in October 2000 (figure 5).

As of 2001, the prospects for economic growth deteriorated in the wake of severe shocks that hit the world economy and global financial markets, such as the collapse of the dot-com bubble and associated corporate scandals, the terrorist attacks in the United States on September 11, 2001, and the escalation of geopolitical tensions related to Iraqall of which increased the degree of economic uncertainty and undermined confidence. Overall, economic growth in the euro area turned 
Figure 9. Growth of M3 and Monetary Financial Institutions' Credit to the Private Sector for the Euro Area, 1999-2018

Annual percentage change

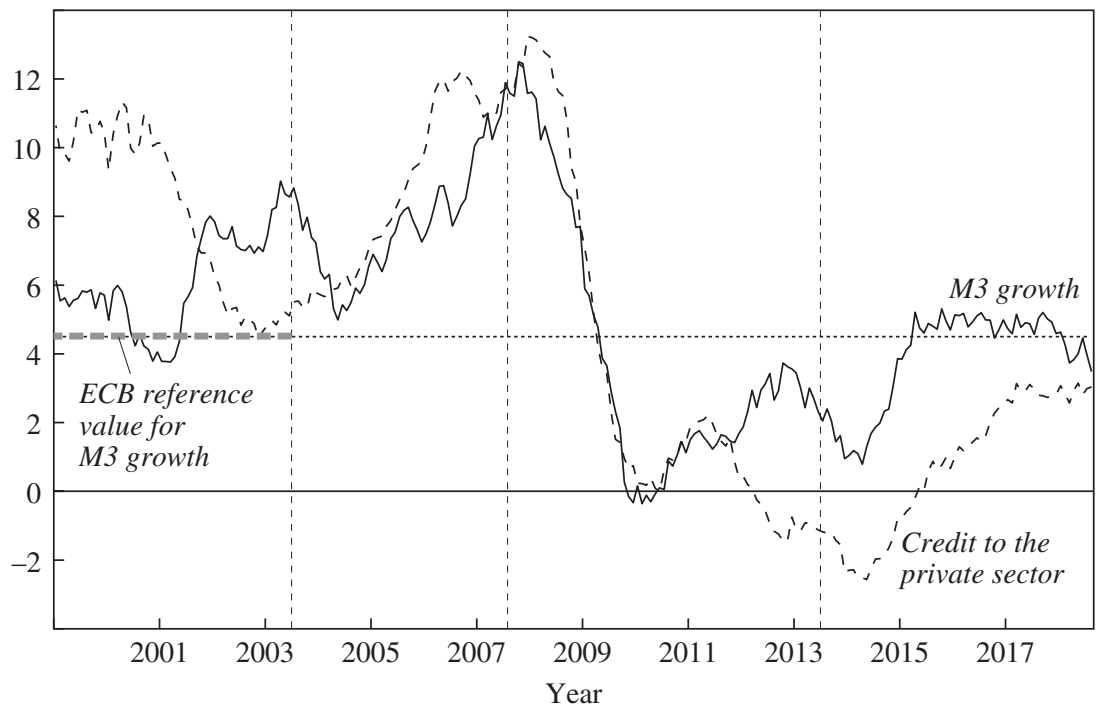

Source: ECB data.

a. Monetary financial institutions' credit to the private sector refers to total loans and securities vis-à-vis euro area nonmonetary financial institutions, firms, and households, excluding general government. The thick gray dashed line refers to the ECB's reference value of 4.5 percent for M3 growth, signaling a particularly prominent role of money until the ECB reviewed its monetary policy strategy in May 2003. The line is thinly dotted after the review, indicating that the annual review of the reference value was discontinued and the role of money diminished. The most recent observation is for August 2018.

rather weak in 2002, and this performance did not change fundamentally in 2003 (figure 7). ${ }^{18}$ Initially, annual HICP inflation rose further in 2000 and the first half of 2001, despite a marked fall in oil prices and a significant appreciation of the euro exchange rate against all major currencies after concerted foreign exchange interventions by the ECB, the Federal Reserve, and the Bank of Japan in September 2000. ${ }^{19}$ The

18. Note that in contrast to the National Bureau of Economic Research's business cycle dating committee for the United States, the Centre for Economic Policy Research's committee never called a recession in the euro area in the early years of the new millennium.

19. The ECB and several Eurosystem national central banks also intervened a number of times during the first half of November. 
Figure 10. The Euro Exchange Rate Against the U.S. Dollar, and in Effective Terms, 1999-2018

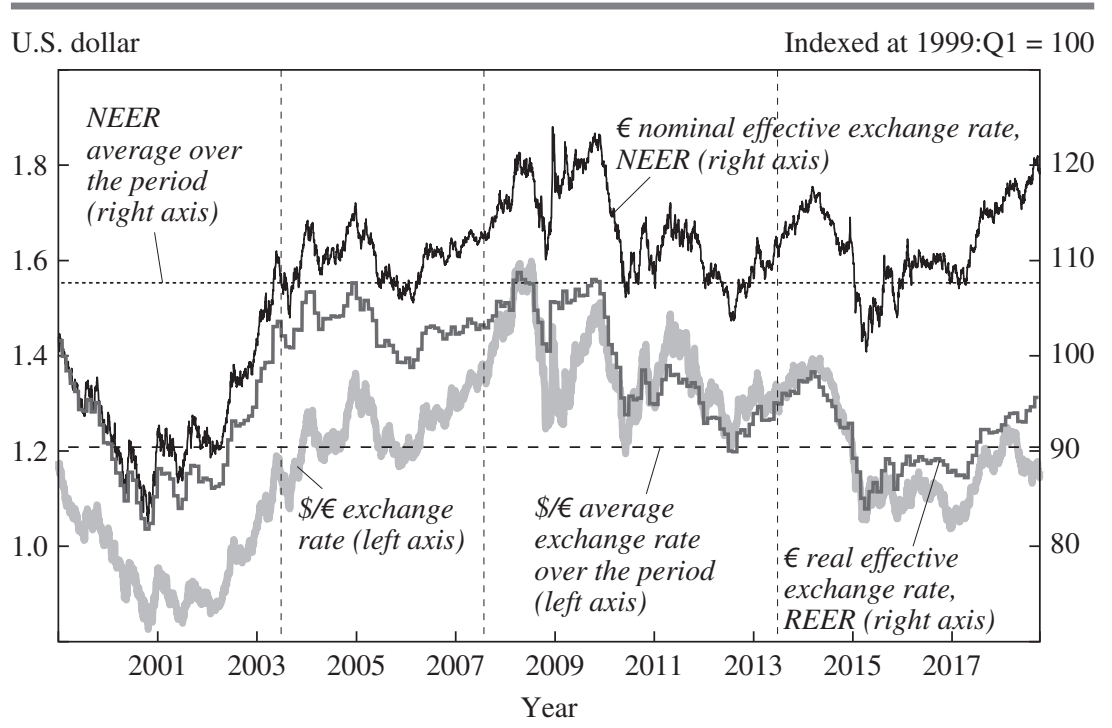

Source: ECB data.

a. NEER = nominal effective exchange rate; REER = real effective exchange rate. The REER of the euro is calculated as the geometric weighted average of bilateral nominal exchange rates, which are deflated using relative price or cost measures; the weights used are the trade weights assigned to the currency of each trading partner. The 38 trading partners included in the NEER and REER are Algeria, Argentina, Australia, Brazil, Chile, Bulgaria, Canada, China, Croatia, the Czech Republic, Denmark, Hong Kong, Hungary, Iceland, India, Indonesia, Israel, Japan, Malaysia, Mexico, Morocco, New Zealand, Norway, the Philippines, Poland, Romania, Singapore, South Korea, Sweden, Switzerland, Russia, South Africa, Taiwan, Thailand, Turkey, the United Kingdom, the United States, and Venezuela. The most recent observation is for April 5, 2018.

concerns about second-round effects gradually dissipated over time as the outlook for the euro area economy continued to deteriorate. Average annual HICP inflation remained slightly above 2 percent from 2000 to the first half of 2003 (figure 6), but the subdued pace of economic activity and the significant appreciation of the euro after the spring of 2002 were expected to dampen inflationary pressures. Looking at the monetary developments, annual M3 growth accelerated strongly from mid-2001 onward (figure 9). However, this increase was not interpreted as implying risks to price stability at medium to longer horizons because it was mostly due to sizable shifts in private investors' portfolios from shares and other longer-term financial assets toward safe and more liquid monetary assets included in M3 in the aftermath of the global stock market correction and the terrorist attacks of September 11, 2001 
(ECB 2008a, 44). This assessment was supported by the fact that annual growth of credit to the private sector continued to decline (figure 9), especially to nonfinancial corporations, in a context of rather subdued economic activity. In this period, the Governing Council lowered the key ECB interest rates by a total of 275 basis points (figure 5). This included a joint 50-basis-point cut coordinated with the Federal Reserve on September 17, 2001, in response to the adverse confidence effects of the terrorist attacks. ${ }^{20}$ The policy rate reached a-at that timehistorically low level of 2 percent in June 2003. At the same time, ECB policymakers saw the sustained growth in M3-correcting for the estimated impact of portfolio shifts - as an important indicator arguing against the emergence of deflationary risks for the euro area in 2002 and 2003 (ECB 2008a, 44).

DISCUSSION Overall, the ECB's first interest rate cycle contained a first test of the ECB's anti-inflation credibility as the euro exchange rate depreciated - and was only stopped by foreign exchange interventionsand annual headline inflation peaked at about 3 percent. The sources of the initial depreciation of the euro against the dollar (from a peak of 1.19 in January 1999 to a historic low of 0.83 in October 2000) were heavily discussed. As the main source, Giancarlo Corsetti and Paola Pesenti (1999) and Alberto Alesina and others (2001) pointed to fundamentals such as revisions in the forecasts of the output growth rate differential in the United States and in the euro area. In May 2000, President Duisenberg nevertheless issued a press release to EU citizens reassuring them of the euro's stability (ECB 2000b). And ultimately, the ECB intervened, together with the Federal Reserve and the Bank of Japan, based on a "shared concern about the potential implications of recent movements in the euro exchange rate for the world economy" (ECB 2000c).The underlying concern was that a disorderly depreciation process would add to the inflationary pressures in an environment of relatively high oil prices (figure 8), and affect its credibility (subsection II.A).

Once the cycle turned, after the bursting of the dot-com bubble in stock markets, the perspective reversed. As interest rates dropped to a historically low level in the euro area, and even more so in the United States, the

20. In the days after September 11, 2001, the ECB also undertook a series of crisis management operations to deal with the substantial effects of the severe damage to the U.S. financial market infrastructure and its effects on the euro area financial system. These included overnight fine-tuning operations and a swap line with the Federal Reserve Bank of New York that allowed Eurosystem national central banks to provide dollar liquidity to their banks. 
policy and academic debate turned to the consequences of the lower-bound constraint on interest rates for the fulfillment of monetary policy objectives (Bernanke 2002).

The other feature of this period was the decoupling of money and credit growth (figure 9), which called into question the prominent role of money in the ECB's monetary policy strategy. From the start, money's prominent role was a controversial feature of the ECB's strategy. For example, Alesina and others (2001) thought the ECB should abandon the two pillars and adopt a flexible inflation-targeting strategy, which they regard as simpler. In their view, the M3 pillar stood in the way of effective communication. The ECB nevertheless used robust money growth to argue against further cuts in interest rates in $2003 .{ }^{21}$ Both issues featured in the review of the strategy in 2003, which we discuss in the next section.

Another discussion was related to the ECB's transparency and predictability. Although opinions differ about the ECB's degree of transparency (also compared with that of other central banks), the ECB generally scores quite high on this front, and over time it has also increased its transparency in response to demands from the European Parliament and other advocacy groups (Geraats 2002). For example, in December 2000 the ECB started to publish its macroeconomic projections (ECB 2013a). Nevertheless, two elements of criticism coming mostly from the inflation-targeting proponents were prominent in the early years. First, the ECB released neither the minutes of its policy deliberations nor the votes and their attribution to members of the Governing Council.. ${ }^{22}$ It argued that the press conference gave a real-time account of the discussion and could therefore be seen as a substitute, and that publishing the minutes could expose the individual members of the Governing Council to pressure from their national constituencies and undermine the consensual nature of the ECB's decisionmaking and "one voice" communication strategy. As communication became more complex after the financial crisis, this was partly addressed in January 2015, when the Governing Council decided to publish an account of its monetary policy deliberations about four weeks after the meeting (Draghi 2014a).

The second criticism was that the ECB did not publish its own interest rate forecasts (Alesina and others 2001; Geraats, Giavazzi, and Wyplosz 2008). Instead, the ECB focused on trying to explain its reaction function. It argued that in view of the effects of various unexpected shocks that can

21. See, for example, the introductory statement of the monetary policy press conference in December 2003 (ECB 2003c).

22. See, for example, the debate between Buiter (1999) and Issing (1999). 
hit the economy and the long and variable time lags with which monetary policy actions are transmitted to prices, the precise timing, and sometimes even the direction, of an interest rate decision is difficult to predict. Also, by publicly announcing its monetary policy strategy and communicating its regular assessment of economic developments in a transparent manner, it could clarify its reaction function, achieve a high degree of predictability, and thereby make monetary policy more effective (Blattner and others 2008). In fact, although the 50-basis-point sizes of the first and second interest rate decisions in April (a cut) and November 1999 (an increase) somewhat surprised market participants, various empirical studies showed that relatively early ECB interest decisions had already usually been predicted quite well by the market, at least as well as the decisions of the Federal Reserve or, for example, the Bank of England (Hartmann, Manna, and Manzanares 2001; Bernoth and von Hagen 2004; Wilhelmsen and Zaghini 2011). Still, the ECB often emphasized the need to maintain a full-information, state- and data-driven policy approach, and that it did not want to communicate or commit to future policy actions given the large uncertainties about the state of the economy in the future. This changed in 2013, when the ECB started giving forward guidance on its future policy actions (see subsection II.C).

\section{I.B. Recovery and Growing Imbalances, July 2003-July 2007}

At the transition between the first and second cyclical periods of the euro area, the ECB reviewed its monetary policy strategy against its experiences, and it clarified and amended some aspects. A little more than halfway through the period, the ECB started making a series of interest rate hikes in order to keep the inflationary pressures in check that emerged, among other things, from increasingly solidifying growth as well as increasingly vigorous money and credit dynamics. That the latter were a harbinger of a severe crisis only became clear during the next period (section II.C).

THE 2003 REVIEW OF THE STRATEGY In 2003, after about four years of experience with the ECB's new strategy, Otmar Issing initiated a review of it, which led to three main measures: (1) a clarification of the definition of price stability: the Governing Council would aim at a year-on-year HICP inflation rate of "below, but close to 2 percent over the medium term"; (2) the termination of the annual review of the reference value for M3 growth; and (3) a restructuring of the introductory statement of the president at the monthly monetary policy press conference, which now started with the economic analysis followed by the monetary analysis (ECB 2003a, 2003b). 
The clarification of the price stability definition in the ECB's strategy was a response to the strengthened need to establish a sufficient inflation buffer as a discussion of deflation risks took place in 2002-3. Such a buffer was deemed to be necessary for two reasons. First, a small positive, steady state inflation rate would reduce the probability of hitting the lower bound on nominal interest rates. Second, a positive inflation rate also greases the wheels of the labor market, particularly in a monetary union with still segmented labor markets, because it reduces the need for wage deflation in the face of asymmetric economic developments. Such wage deflation was thought to be costly in the presence of widespread evidence of downward nominal wage rigidity in the euro area. ${ }^{23} \mathrm{~A}$ number of studies had shown that an inflation buffer of close to 2 percent would significantly reduce the probability of hitting the zero lower bound on nominal interest rates or downward nominal wage rigidity constraints (Issing 2003a; Reifschneider and others 2000).

The specific formulation of the inflation aim of "below, but close to 2 percent over the medium term" was the result of a compromise that maximized the buffer, while remaining consistent with the definition of price stability and not giving a sense of unwarranted precision associated with inflation-targeting regimes. The sense of continuity was made clear by Issing at the press conference in May 2003 explaining the outcome of the review. When asked whether the aim of "below but close to 2 percent" is a change, he replied: "This 'close to 2 percent' is not a change, it is a clarification of what we have done so far, what we have achieved-namely, inflation expectations remaining in a narrow range of between roughly 1.7 and 1.9 percent—and what we intend to do in our forward-looking monetary policy" (ECB 2003b). Although all this should have removed (or very significantly reduced) the room for interpretation about how low the lower bound of the price stability definition was, the reformulation did not extinguish perceptions by some observers of an asymmetric inflation objective. Symmetry was seen as important by the proponents of inflation targeting (Bernanke and others 1999), but even German monetarists like Manfred Neumann $(2010,235)$ thought that "the lack of a lower bound as part of the definition was an unnecessary drawback."

The second and third measures mentioned above de facto meant a downgrade of the prominent role of money in the ECB's strategy relative to the weight put on it, for example, by President Duisenberg (1999). This

23. See, for example, the findings of the Wage Dynamics Network, as given by ECB (2009b). 
reflected the reality that, on a monthly basis, monetary policy decisions were mostly driven by the broadly based assessment of the outlook for price developments and the risks to price stability (the "economic analysis"), of which the ECB's macroeconomic projections were an important part. ${ }^{24}$ It also reflected emerging evidence on instability in money demand and the need to explain "distortions" or "portfolio adjustments" in M3 growth that were not linked to the medium-term risks to price stability as discussed above..$^{25}$ A revamped monetary analysis was now presented as a cross-check of the economic analysis from a medium- to long-term perspective, given the long-run monetary nature of inflation. It clarified that the main challenge facing monetary analysis is to see past inevitable short-term disturbances of the underlying relationship between money and prices so as to discern longer-term inflationary risks. This was also reflected in the changed structure of the introductory statement at the monetary policy press conferences, which now started with the economic analysis and ended with a cross-check from the monetary analysis.

The rearrangement of the pillars was applauded by academics favoring inflation targeting (Svensson 2003), while at the same time it was acknowledged that the money pillar had been useful during the first years of the ECB because it made it easier for it to gain credibility as a sign of "the new institution's fidelity to principles stressed earlier by the Deutsche Bundesbank, which had in turn played a critical role as the anchor of the previous European Monetary System" (Woodford 2006, 87). But the debate on the role of monetary analysis and the need to have two separate pillars continued (Issing 2005). On November 9 and 10, 2006, the ECB held a symposium to discuss this from both academics' and practitioners' points of view (Beyer and Reichlin 2006). At the conference, Björn Fischer and others (2008) reviewed the actual ECB experience with its monetary analysis from 1999 through 2006 and emphasized the real-time and comprehensive nature of the monetary analysis that had been performed in the quarterly monetary assessments since December 1999. These authors described the tools that were used, making a distinction between money demand equations, judgmental analysis, and money-based inflation forecasts. They also assessed the forecasting performance of moneybased tools and found that there was information value in addition to the

24. Also see the evidence on the ECB's projections presented in subsection II.B.

25. For alternative views on money demand stability, see Alves, Robalo Marques, and Sousa (2007); and Bruggeman, Donati, and Warne (2003). 
Broad Macroeconomic Projection Exercise forecasts. Finally, based on an in-depth analysis of the monetary analysis input, they concluded that the economic pillar prevailed in influencing the decision when the monetary pillar gave a blurred signal. This finding is confirmed below in the analysis of an interest rate rule in subsection II.B.

The broader discussion at the symposium pointed to two ongoing developments in the nature and role of monetary analysis. First, monetary analysis was evolving from a narrower perspective based on the quantity theory of money to a broader set of analyses that also include the role of financial frictions and financial intermediation in macroeconomic developments. This led to a revamping of the debate on why the two pieces of the analysis should be kept separate, given the intimate linkages between financial and real factors. At the symposium, ECB vice president Lucas Papademos conjectured that if "in the future, we will be in a position to develop and reliably estimate a single empirical approximation of a general theoretical framework in which money is of central importance. . . It may be possible to merge the two pillars of our analysis into a single one. But this will be a larger pillar in which money will continue to play a prominent role in guiding our monetary policy decisionmaking" (Papademos 2006, 202). In 2007, the Governing Council endorsed a research program to further enhance monetary analysis, including by developing methodologies for cross-checking and building structural models that embody an active role for money and credit in the determination of inflation dynamics (Papademos and Stark 2010).

The second theme that received increasing attention during this period was the link between money and credit, asset price developments, and financial stability (for example, ECB 2005). Although this financial stability angle was not taken up as an explicit justification for the twopillar approach in the 2003 review, the ECB paid increasing attention both in research and policy communication to this link and the associated view promoted by the Bank for International Settlements (Borio and Lowe 2002) that it may be necessary for monetary policy to lean against the wind of growing financial imbalances (Detken and Smets 2004; Issing 2003b). This also became part of the research program mentioned above (Detken, Gerdesmeier, and Roffia 2010). In a speech on asset price bubbles and monetary policy, then-ECB president Trichet (2005) conjectured that while "a leaning against the wind" approach is "compelling in many theoretical aspects, in practice. ... It is likely that the circumstances will be rare that a policy maker will embark with confidence on an explicit leaning against the wind policy." But he also argued that monetary 
analysis helps in incorporating emerging financial stability risks with implications for price stability from a medium-term perspective: "The fact that our monetary analysis uses a comprehensive assessment of the liquidity situation that may, under certain circumstances provide early information on developing financial instability is an important element" (Trichet 2005). With particular reference to asset price bubbles and housing booms, this became part of the rationale for the monetary analysis (Issing 2005).

STABLE RATES, MONETARY TIGHTENING, AND NO ADDITIONAL "LEANING AGAINST THE WIND" Starting in June 2003, the ECB kept interest rates steady for almost two and a half years. So the previous decision to lower the MROR to a historically low level of 2.0 percent nurtured the economic recovery for quite a while. The overall picture of economic activity brightened during the second half of 2003, when the euro area's exports increased significantly as a result of the renewed dynamism of the world economy. Also, domestic demand and investment picked up, not least in view of the low level of interest rates and the generally favorable financing conditions (figure 5; also see figures 14 and 15 below). The recovery in economic activity moderated somewhat in the second half of 2004 and the first half of 2005, partly on account of rising oil prices (figure 8), lower consumer confidence, a temporary deceleration of global economic growth, and the lagged effects of the past appreciation of the euro (figure 10). However, in the second half of 2005, the expansion of economic activity in the euro area regained momentum. On the price side, HICP inflation did not fall as swiftly and strongly as previously expected, largely due to adverse food price developments and oil prices that were higher than expected-although the latter were attenuated by the euro's appreciation. Annual HICP inflation remained above 2 percent in 2005, but underlying domestic inflationary pressures were contained throughout 2004 and most of 2005 (figure 6), justifying the prolonged accommodative monetary policy stance.

As 2005 progressed, the ECB's economic analysis suggested that upside risks were increasing, especially due to potential second-round effects in wage setting and price setting that stemmed from higher oil prices. But this time it was the monetary analysis that carried the day. As of mid-2004, robust credit and monetary expansion (see figure 9 below) reflected the stimulating effect of the then-prevailing very low level of interest rates in the euro area and, later on, renewed dynamism of the euro area's economy, rather than portfolio shifts (as between 2001 and 2003), indicating increasing upside risks to price stability at medium- to longer-term horizons toward the end of 2005. In response, the ECB started raising its policy 
rate as of December 2005, and eventually, by a total of 200 basis points, to a level of 4 percent by the end of June 2007 (figure 5).

The gradual withdrawal of monetary accommodation took place against the background of solid economic growth and a continued strong money and credit expansion in the euro area. The economic expansion gained momentum in the first half of 2006 and became gradually more broadbased and self-sustaining, with domestic demand as the main driver. Notwithstanding the impact of high and volatile oil prices, real GDP rose by about 3.3 percent in 2006, compared with about 1.7 percent in 2005 and about 2.1 percent in 2004, and continued to expand at a solid rate of about 3.1 percent in 2007 (see figure 7, which, however, shows annualized quarterly data). With regard to prices, average annual HICP inflation was slightly above 2 percent in 2006 and 2007, mainly driven by domestic demand, as underlying inflation developments were largely in line with the ECB's inflation aim (figure 6). Money and credit expansion became increasingly vigorous throughout this phase, supported by a persistently strong growth of bank loans to the private sector (figure 9).

DISCUSSION Overall, this second phase was characterized by an increasingly solid expansion of economic activity and increasingly vigorous money and credit growth (double the reference value toward the end), following a long period of low interest rates. Against the background of the discussion above on the approach of "leaning against the wind," with the benefit of hindsight, the question emerges to what extent monetary analysis was used in guiding monetary policy in the face of growing financial imbalances. At the time, the ECB Board members warned of the potential for emerging misalignments in asset prices, notably in housing, due to strong money and credit growth. ${ }^{26}$ Also, Trichet (2008) pointed to the December 2005 episode as one where the monetary pillar was crucial in driving the monetary policy decision. Indeed, based on a reading of the introductory statements at the end of 2005, Neumann (2010) argues that monetary analysis was one of the driving forces behind the decision to start raising interest rates in 2005. However, as we argue in subsection II.B below, it is difficult to detect significant deviations from the ECB's usual reaction to the outlook on growth and inflation in this period. This suggests that the tightening of policy rates in 2005 did not go beyond what would be indicated by the usual economic analysis and monetary cross-check, contrary

26. For example, Issing (2005): "Moreover, strong money and credit growth in a context of already ample liquidity in the euro area implies that asset price developments, particularly in housing markets, need to be monitored more closely, given the potential for misalignments to emerge." 
to what would have been the case under an active leaning-against-the wind approach trying to enhance financial stability through restrictive monetary policy action.

Although this does not prove conclusively that low monetary policy rates did not play any role in strong credit growth and bank risk-taking-in fact, to some extent they are a natural and desired effect of an expansionary monetary policy stance - the institutional setup for financial supervision in the euro area at the time located the primary responsibility for containing the buildup of financial risks with national prudential authorities. The ECB could only "contribute to the smooth conduct of policies pursued by the competent authorities relating to the prudential supervision of credit institutions and the stability of the financial system" as long as price stability was ensured (EU 2012b, Article 127.5). But not being a regulatory or supervisory authority itself, the ECB did not possess any prudential policy instruments that could address emerging financial imbalances. The available prudential instruments were all with national prudential authorities, subject to some cooperation through EU committees. ${ }^{27}$ Moreover, before the climax of the financial crisis in 2008 the macroprudential approach to maintaining financial stability was not very well developed in the competent prudential authorities. ${ }^{28}$

A related important feature of this period is that, underlying the aggregate euro area output and credit boom, there were diverging intra-euro area current account balances. These imbalances played an important part in the propagation of the subsequent twin financial and sovereign debt crises in the euro area, which we discuss in the next section. As shown in figure 11, the countries that, leading up to 2007, had accumulated large current account deficits along with high unit labor cost and credit and house price growth differentials relative to their euro area peers, were also among the ones that suffered the highest fallout from the financial crisis - for example, as measured by the subsequent level of the unemployment rate in 2013 (Constancio 2013; Smets 2014; Martin and

27. See our companion paper (forthcoming) for a description of the evolving prudential framework since the introduction of the euro and the ECB's role in it. Some of the national central banks were banking supervisors but not as part of their Eurosystem roles. The European System of Central Banks' Banking Supervision Committee brought all EU banking supervisors at one table. Though the ECB hosted its secretariat, it could not oblige the members to take any action.

28. The De Larosière Report (High-Level Group on Financial Supervision 2009) led to the establishment of the European Systemic Risk Board in 2010, a macroprudential body whose secretariat is provided by the ECB but that can only make risk warnings or policy recommendations without having its own policy instruments. 
Figure 11. The Euro Area Countries' Economic and Financial Imbalances Before the European Twin Crises and Unemployment Thereafter ${ }^{\mathrm{a}}$

\section{Current account balance and unemployment rate}

Current account as percentage of GDP, 2007

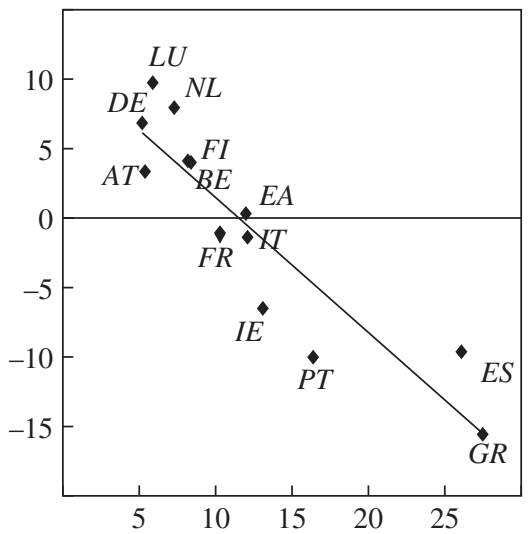

Unemployment rate as percentage of labor force, 2013

\section{Credit growth and unemployment rate}

Average percentage credit growth per year, 2007

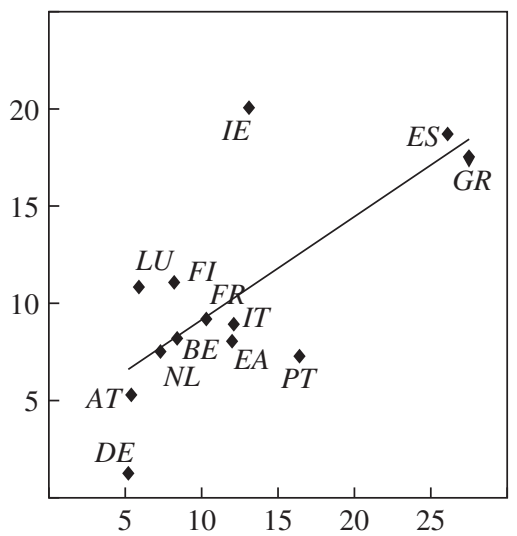

Unemployment rate as percentage of labor force, 2013

\section{Unit labor cost and unemployment rate}

Cumulated percentage growth of unit labor cost, 2002-7

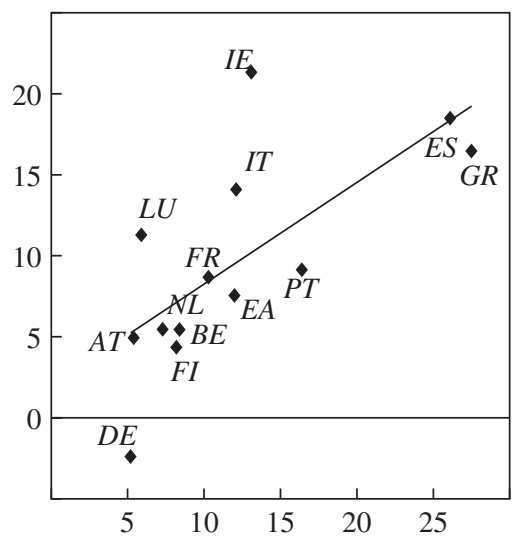

Unemployment rate as percentage of labor force, 2013

\section{House prices and} unemployment rate

Cumulated percentage growth of house prices, 2002-7

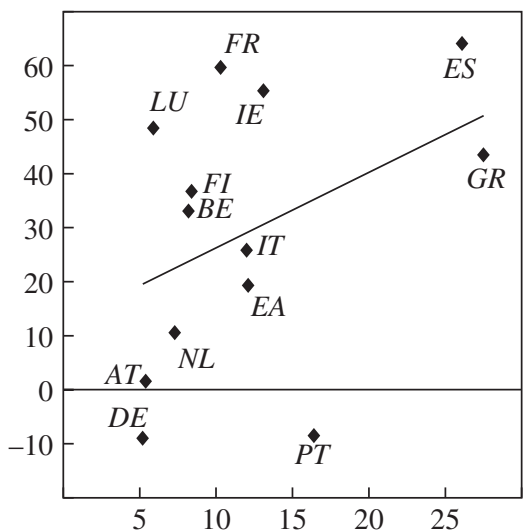

Unemployment rate as percentage of labor force, 2013

Sources: Eurostat; authors' calculations.

a. These countries and regions are shown in this figure: $\mathrm{DE}=$ Germany, $\mathrm{AT}=\mathrm{Austria}, \mathrm{LU}=\mathrm{Luxem}-$ bourg, $\mathrm{NL}=$ the Netherlands, $\mathrm{BE}=$ Belgium, $\mathrm{FI}=$ Finland, $\mathrm{FR}=$ France, $\mathrm{EA}=$ euro area, $\mathrm{IT}=$ Italy, $\mathrm{IE}=$ Ireland, $\mathrm{PT}=$ Portugal, $\mathrm{GR}=$ Greece, and $\mathrm{ES}=$ Spain. 
Philippon 2017). Or, put differently, all the countries that ultimately ended up in macroeconomic adjustment programs-Greece, Ireland, Portugal, and Spain-ran substantial current account deficits in 2007. The ECB's communication focused particularly on the need to address divergences in productivity and competitiveness across the various euro area countries (Trichet 2006; or the white area of figure 1).

Preparing the ground for subsection I.C, one narrative behind these boom-and-bust developments (put forward after the fact) runs as follows (Baldwin and Giavazzi 2015). Easy global financial conditions (partly driven by the global savings glut), as well as greater integration of wholesale financial markets within the monetary union (with disappearing risk premiums), encouraged cross-country capital flows from the EU's "core" to its "periphery" (Blanchard and Giavazzi 2002; Lane 2015). Although the aggregate euro area current account was in balance throughout most of this period, large intra-euro area current account imbalances were building up, feeding nontradable sectors like government consumption and housing in the "periphery" countries, driving up wages and costs, and resulting in competitiveness losses that undermined the traded goods sectors and validated the current account deficits. With the exception of Greece, explicit public debt was not the first problem, according to this narrative, although from an ex post perspective, building up higher buffers may have been advisable, as shown by Philippe Martin and Thomas Philippon (2017). Instead, the private debt buildup was very significant, mimicking some of the developments in the U.S. and other countries that belong to the Organization for Economic Cooperation and Development. ${ }^{29}$ Moreover, there was a mismatch between the longer-term loans to households and firms made by domestic banks and the short-term, cross-country interbank funding that financed this debt.

Other observers (Feld and others 2016) put more weight on the fiscal vulnerabilities of some euro area countries, even before the start of the financial crisis. The Stability and Growth Pact had been regularly broken by a variety of countries since the introduction of the euro. Between 1999 and 2008, the aggregate debt-to-GDP ratio of the euro area hovered close

29. Euro area countries with particularly high and increasing household debt levels in the years before the crisis included Cyprus, Ireland, the Netherlands, Portugal, and Spain. (Germany's household debt was high in the early years of the euro but then consistently declined.) Countries with particularly high and increasing debt levels for nonfinancial corporations included Ireland, Luxembourg, the Netherlands (not increasing), Portugal, and Spain. Interestingly, neither Greece nor Italy had particularly high private debt levels, even though they increased in both cases. In many cases, the increases in private debt levels were part of a long-term trend, at least after the start of the euro. 
to 70 percent, 10 percentage points above the Stability and Growth Pact's limit of 60 percent for individual countries. The countries that had entered the euro area with very high public debt levels (that is, significantly above 100 percent of GDP) were Belgium, Greece, and Italy. They all gradually reduced these levels in the early years, helped by strong nominal GDP growth and low interest rates; but because of rapidly eroding primary surpluses, this process stopped at levels of about 100 percent of GDP or slightly above, except for Belgium. In other words, the euro area entered the financial crisis with one large and one smaller fiscally vulnerable country. ${ }^{30}$

In sum, among the countries that turned out to be stressed during the European twin crises (see the next section) beforehand, Cyprus, Ireland, Portugal, and Spain were more vulnerable in terms of private debt and Greece and Italy more in terms of public debt. Both groups together account for about a third of euro area GDP (roughly 39 percent of its total population), but the latter is a bit larger than the former. However, as we shall see further below, many more than these two important fundamental factors came together in determining the severity of the European twin crises and the obstacles that they implied for successful monetary policy.

The significant worsening of the financial crisis in key advanced countries in the course of 2008, which revealed the exposure of some European banks to toxic subprime mortgages in the U.S. and to other increasingly impaired credit instruments, and the revelation of the Greek deficit deceit in late 2009 were the triggers that led to a sudden stop of cross-country capital flows and exposed private and public debt overhangs in the respective euro area countries. Several negative propagation mechanisms then came into action. First, the need to backstop the weakened banks in the absence of a European resolution framework undermined the credit rating of a number of national governments. Second, weakened sovereigns and a faltering economy further increased the fragility and the undercapitalization of national banking sectors, leading to further deleveraging and "closing" the doom loop between national sovereign and banking instabilities. Third, the results of the Deauville Summit of France, Germany, and Russia in October 2010 — which included a Franco-German agreement to promote "private sector involvement" in handling public debt overhangs-and associated discussions on a Greek debt restructuring that was only implemented

30. Other euro area countries whose public debt levels increased before the crisis and cut through the 60 percent limit included France, Germany, and Portugal. Austria fluctuated around 70 percent without a clear trend. Portugal had some vulnerabilities because of weak state-owned enterprises whose debt was not included in the Stability and Growth Pact's debt figures but migrated to them during the crisis. 
Figure 12. Aggregate of the Euro Area Member Countries' Fiscal Policies, 1999-2018

Percentage of GDP

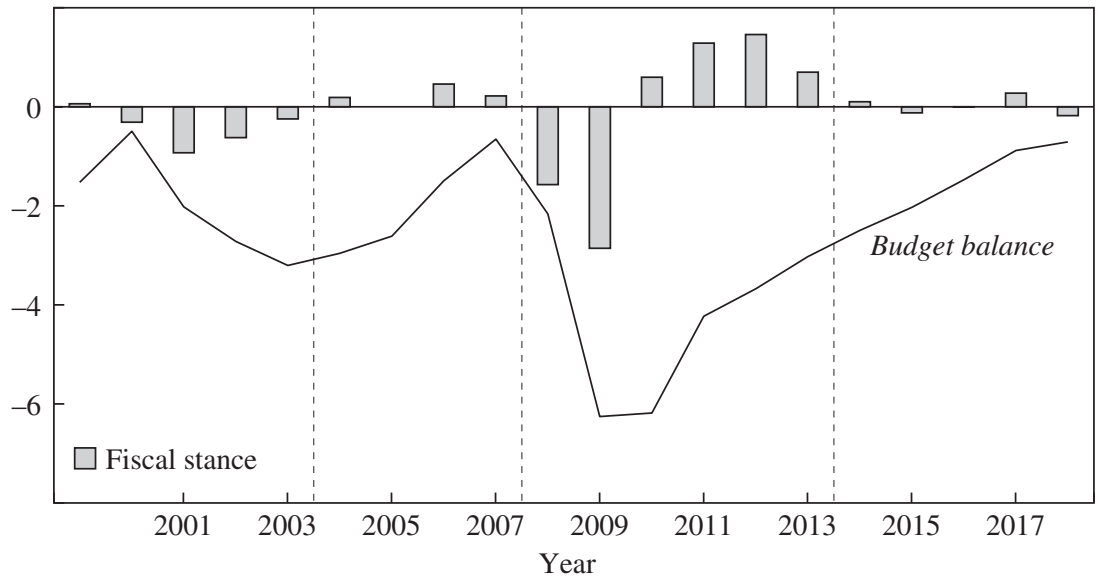

Source: ECB data.

a. The euro area's fiscal stance is computed as the aggregate change in the cyclically adjusted primary balances of all member countries' governments. The cyclically adjusted primary balance corresponds to the budget balance, minus interest payments and adjusted for cyclical factors. The budget balance refers to the difference between total government revenues and expenditures. The most recent observation is for 2018, and was taken from the ECB's June 2018 Broad Macroeconomic Projection Exercise.

in 2012 - though good for ex ante incentives of controlling public deficits-facilitated contagion toward other sovereigns ex post, because a euro area backstop for governments was lacking. Finally, weakened sovereigns also led to procyclical fiscal policy, which deepened the recession in the absence of fiscal policy coordination and a common budget. As shown in figure 12, the coordinated fiscal expansion of 2008-9 turned into a significant and protracted tightening of the fiscal policy stance from 2010 to 2013. As a result of the concurrence of all these factors, the sudden stop turned into a crisis and a prolonged double-dip recession (Corsetti 2015; Corsetti and Dedola 2016), to which we turn in the next section.

\section{I.C. The Financial Crisis, the Sovereign Debt Crisis, and the Double-Dip Recession, August 2007-June 2013}

The European sequence of crises starting in the summer of 2007 can be decomposed in the early turmoil in funding markets, the systemic banking crisis, and the sovereign debt crisis. The ECB managed the first phase with liquidity operations; it managed the second phase with decisive interest rate cuts, further enhanced with liquidity operations and a first asset 
Figure 13. The Euro Area's Money and Government Bond Market Spreads, 1999-2018

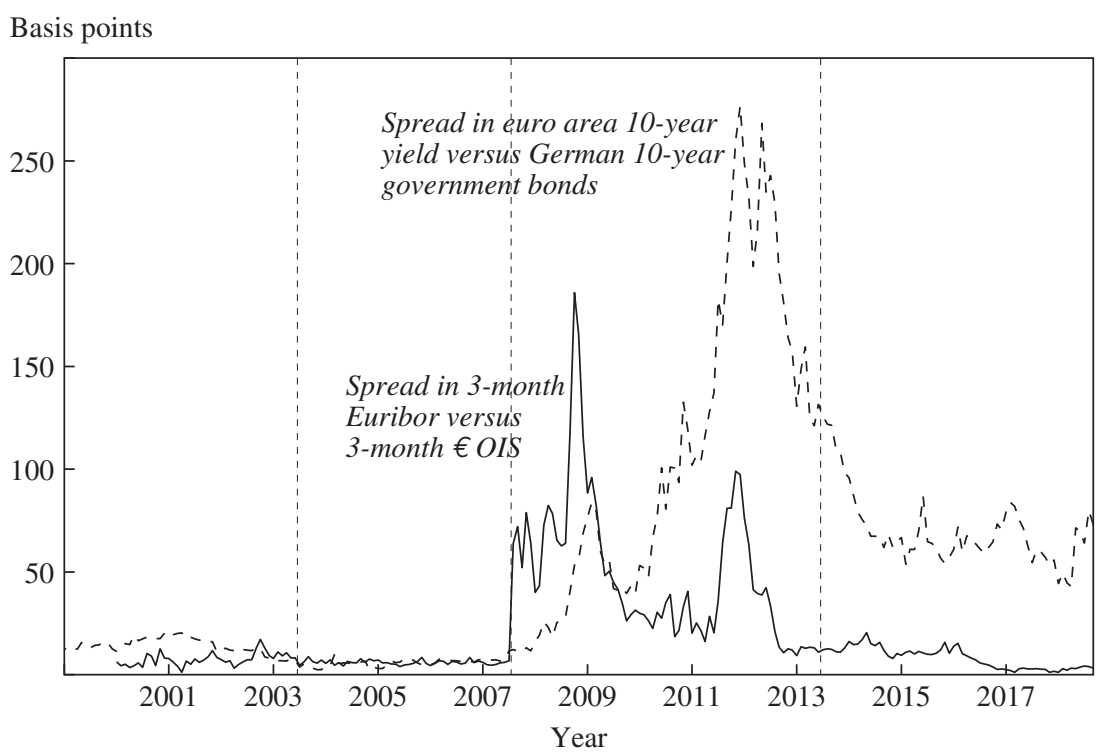

Source: ECB data.

a. Euribor = Euro Interbank Offered Rate; $€$ OIS = Euro Overnight Index Swap Rate. The euro area's 10 -year yield is a GDP-weighted average of euro area member countries' government bond yields. The most recent observation is for September 2018.

purchase program for covered bonds; and it managed the third phase with a first asset purchase program for government bonds, very-long-term liquidity operations, and interest rate cuts to basically zero. The turning point toward recovery occurred when the EU's political leaders agreed on a series of EMU reforms in the summer of 2012 and President Draghi announced that the ECB would do "whatever it takes" to preserve the euro, backed up shortly afterward by the ECB's powerful Outright Monetary Transaction Programme.

THE ECB'S MONETARY POLICY MOVES TO CRISIS MANAGEMENT MODE In the early phase of the financial crisis, the ECB's operational framework took center stage. ${ }^{31}$ The reason was that wider problems first emerged in interbank and other short-term funding markets (figure 13), which could largely

31. For a recent description and chronology of the ECB's monetary policy responses since the onset of the crisis, see Camba-Méndez and Mongelli (2017). 
be addressed with liquidity management tools. Moreover, it allowed the ECB to continue to follow the so-called separation principle, meaning that the conduct of monetary policy focused on setting policy rates for achieving price stability over the medium term and that market operations focused on ensuring that market turbulences would not disturb the transmission of the policy rates to the economy. Another way of saying this is that those operations acted as complements to conventional interest rate policy (and were not intended to act as substitutes). The separation principle was in line with the traditional analysis done by William Poole (1970), according to whom stabilizing the short-term interest rate in the face of purely financial shocks is the best way to insulate the real economy from the effects of those shocks (Fahr and others 2013; ECB 2008a). In the early phase, the operations were mainly focused on money and other bank funding markets; but when the sovereign debt crisis emerged in 2010, they also started to address malfunctioning government bond markets and extended liquidity beyond one year. These included asset purchases of both covered and government bonds (for an overview of the main ECB monetary policy measures during the two crises and the subsequent recovery, see figure 26 below).

As monetary policy moved into crisis management mode, the twopillar approach took a backseat in communication. Although the introductory statements at the regular monetary policy press conferences remained structured along the two pillars, including a cross-checking section-also in line with how staff analyses still supported the Governing Council's decisionmaking process - few speeches by Executive Board members dealt with the two-pillar structure of the ECB's strategy (the medium gray area of figure 2 above becoming quite thin).

The crisis nevertheless had a big impact on the ECB's monetary analysis. The focus turned to how to identify and address the impairments in the transmission mechanism of monetary policy. The financial crisis necessitated a further comprehensive broadening of the monetary analysis toward detailed macroeconomic and microeconomic analyses of the financial system and of the bank lending channel in particular (given the euro area's financial structure). For example, the ECB's Bank Lending Surveyalready launched in 2003-became a prominent tool for understanding supply-side restrictions in bank credit markets (ECB 2018a). More generally, a deep analysis of the capital, leverage, and liquidity positions of banks became important, as well as a comprehensive and disaggregated look at both bank and nonbank financing conditions in the economy. This led to a thorough revamping of the ECB's quarterly monetary assessments. 
At the same time, given the intimate interaction between financial and real factors, it also blurred the distinction between the economic and the monetary analysis.

FROM LIQUIDITY OPERATIONS TO DECISIVE RATE CUTS AND EARLY ASSET PURCHASE PROGRAMS The third cyclical phase of the ECB's history can be divided into three subperiods. The first period, August 2007-September 2008, is often denoted as financial market turmoil (Evanoff, Hartmann, and Kaufman 2009). The collapse of the U.S. subprime mortgage market led to a general repricing of risk in the asset-backed securities (ABSs) and other structured credit markets of developed countries, which seriously impaired interbank and other short-term funding markets. The second period, October 2008-May 2010, covers the intense systemic financial crisis affecting many developed countries, after the failure of Lehman Brothers, the Great Recession, and the associated collapse of international trade. The third period, June 2010-June 2013, starts with the emergence of the sovereign debt crisis specific to the euro area, when the Greek fiscal situation deteriorated significantly and several other euro area countries subsequently became distressed.

Financial turmoil impairing money market functioning, August 2007September 2008. Financial turmoil first erupted in Europe with the emergence of money market tensions on August 9, 2007, after the announcement that a number of investment funds had to close because they could no longer value their portfolios owing to the illiquidity of ABS markets. The uncertainty about the values of ABS and other structured credit products and the asymmetric information about their location among banks led to adverse selection, liquidity hoarding, and the freezing of interbank and other short-term funding markets (such as asset-backed commercial paper and repurchase agreements) (Cassola and others 2008; Gorton and Metrick 2012; Heider and others 2015). Despite these difficulties, large bank failures did not occur in the euro area during this period. Only a few mid-sized German banks, which had been particularly engaged in structured credit practices and wholesale funding, received public support. One indicator of the difficulties in bank funding markets (mixing credit and liquidity risks) is the spread between the unsecured interbank rate and the overnight swap rate, which is only subject to a minimum amount of counterparty risk (figure 13). After remaining very close to zero for years, this spread rose to about 60 basis points.

Reacting immediately on August 9 with a fixed-rate, overnight finetuning operation allotting the full demand of $€ 95$ billion to counterparties, the ECB was the first major central bank to respond to the turmoil. In the 
following days, weeks, and months the series of operational measures addressing the euro money market disturbances included further finetuning operations, intra-maintenance period "front-loading" (meaning that the ECB provided very ample liquidity early in each reserve maintenance period, which then ran down until the end of each maintenance period), and a relative extension of the maturity profile of aggregate market operations (by running supplementary three-month LTROs) (ECB 2007a). In line with the separation principle, however, the measures were designed to keep the overall monetary policy stance unchanged. In the second half of December 2007, the ECB also joined forces with the Federal Reserve by providing U.S. dollar liquidity to Eurosystem counterparties through a swap arrangement. The Bank of Canada, the Bank of England, and the Swiss National Bank made parallel similar arrangements "to address elevated pressures in short-term funding markets" (ECB 2007b). Interestingly, none of these measures were mentioned in any of the introductory statements of the Governing Council's press conference at the time, which only contained references to financial market volatility and reappraisals of risk and to the ECB paying great attention to them. They were announced in separate press releases, and were later summarized in the ECB's Monthly Bulletin.

With the advent of financial turmoil, the outlook for future economic activity became clouded, and the balance of risks to the growth outlook tilted to the downside. Nevertheless, euro area growth remained above 2 percent for a while (figure 7), with corporate profitability sustained, employment growth strong, and the unemployment rate declining to 7.4 percent, a level not seen for 25 years (figure 3). At the same time, annual inflation rose sharply toward the end of 2007 , reaching levels significantly above 2 percent (above 3 percent still in the same year, and above 4 percent in the summer of 2008; figure 6), driven largely by the very significantly increasing prices of commodities, including oil (figure 8). Although moderate wage developments and anchored medium- to longerterm inflation expectations helped to dampen inflationary pressures, the risks to price stability over the medium term were still judged to be on the upside. A cross-check with the ECB's monetary analysis appeared to confirm this (figure 9). The ECB paid particular attention to monetary developments, also with a view to better understanding the shorter-term response of financial institutions, households, and firms to the financial market's turmoil in the second half 2007. At the time, there was little evidence that the turmoil had strongly influenced the overall dynamics of money and credit expansion, also thanks to the effectiveness of ECB liquidity management, 
which contained volatility in money market rates. Accordingly, the ECB decided to raise the MROR by 25 basis points in July 2008 to avert the risk of second-round effects on wages.

The financial crisis, the collapse of bank intermediation, and the Great Recession, October 2008-April 2010. This increase in the policy rate was quickly reversed when the financial turmoil escalated to a systemic financial crisis after the collapse of the U.S. investment bank Lehman Brothers on September 15, 2008..$^{32}$ At that time, it became clear that even prominent and systemically important institutions could fail, and many more of them would have failed if they had not been taken over by other financial institutions or supported by the government. ${ }^{33}$ So interbank and other financial markets seized up both internationally and within the euro area-for example, giving rise to large spreads between secured and unsecured money market rates (as shown in figure 13). Economic activity was disrupted, and many of the major economies were on the verge of collapse. Tensions spilled over from the financial sector into the real economy, leading to the Great Recession. The U.S. economy, which had slowed considerably when the financial turmoil first began, entered a severe recession in December 2007 and exited it in June 2009.

Owing to strong economic and financial ties, the crisis spread to the United States' main trade and financial partners, including the euro area countries. For example, a number of large euro area banks (compared with their home country) failed and/or were supported by their sovereignssome more for their exposure to the collapse of the global credit trading system (triggered by the U.S. subprime mortgage crisis and the revelation of many toxic ABSs), and others more for their exposure to their tanking local economies and real estate markets. ${ }^{34}$ On the back of confidence

32. The ECB's response to the financial crisis is described in detail by Pill and Reichlin (2014); and the crisis responses by the ECB and the euro area's fiscal and prudential authorities are described by Hartmann (2010).

33. In other words, the devastating systemic nature of the crisis was caused by a mixture of contagion among financial intermediaries and, notably, the unwinding of the widespread imbalances that had built up in the years before on financial institutions' balance sheets, particularly from the combination of originate-to-distribute behavior and the global trading of the resulting credit products (ABS, collateralized debt obligations, collateralized loan obligations, and the like). For the different forms of systemic risk, see ECB (2009a) and De Bandt, Hartmann, and Peydró-Alcade (2015).

34. See Hartmann (2015) for a discussion of different euro area countries' experiences with boom/bust cycles in residential real estate markets and problems with the associated prudential policies and frameworks. 
effects and impaired trade finance, global trade plummeted by about 20 percent in both the fourth quarter of 2008 and the first quarter of 2009 , respectively, which also transmitted economic instability to the countries whose financial intermediaries had not been engaged in unsound international credit trading practices or toxic investments..$^{35}$ The euro area experienced a "sudden stop" of capital flows across its member countries. Within a few months, it had entered its own severe recession, which lasted from the second quarter of 2008 until the second quarter of 2009. During this period, year-on-year GDP growth fell by more than 5 percent (figure 7), and headline HICP inflation was briefly negative in the summer of 2009 (figure 6), also on the back of falling oil prices (figure 8). Money and credit growth dropped to 0 percent at the beginning of 2010 (figure 9). The collapse of bank intermediation, which had gathered pace in the summer of 2008, amounted to about a 13-percentage-point reduction of credit to the private sector between December 2007 and January 2010.

In this period, standard and nonstandard monetary policy measures taken by the ECB worked in tandem, although the separation principle was maintained. After the internationally coordinated interest rate cut of October 8, 2008, by 50 basis points in response to the collapse in output and inflation, the ECB further decreased its key policy rates in six steps by 275 basis points, reaching a level of 1 percent for its main refinancing operation rate in May 2009, a new historical low (figure 5).

At the same time, the ECB took a number of nonstandard measures to satisfy the high demand for liquidity, foster an even transmission of monetary policy impulses across countries and banks, and help fend off risks of an even more dramatic financial meltdown. These measures drew on its broad and flexible operational framework (see subsection I.A), which turned out to be more readily employable for meeting the challenges of the crisis than was the case for some other major central banks. But they were still regarded as complements to interest rate decisions and not substitutes. Starting on October 15, 2008, the ECB's MROs (and all its longer-term refinancing operations) were carried out through a fixed-rate tender procedure with full allotment at the interest rate on the main refinancing operation (MROR; ECB 2008b). The "excess liquidity" that this allowed in the banking sector moved overnight rates from close to the MROR down to close to the Deposit Facility Rate, which therefore became the effective

35. Calculated from the World Trade Organization's international trade statistics and the International Monetary Fund's Direction of Trade Statistics. 
policy rate (figure 5) ${ }^{36}$ In other words, the effective interest rate reduction after October 2008 added up to 400 basis points, from an MROR of 4.25 percent to a DFR of 0.25 percent. In addition, the ECB (2008b) expanded the list of marketable assets eligible as collateral in Eurosystem credit operations. Both measures stepped up significantly the ease with which counterparties could satisfy their liquidity demands. The ECB also reduced the minimum rating threshold for eligible collateral, from A- to BBB-, adjusting to the fact that the crisis had lowered the average credit quality of assets in the market. Furthermore, the ECB enhanced liquidity provision through longer-term refinancing (after having introduced six-month operations already in the preceding March), further lengthening the average maturity of its outstanding operations, and provided U.S. dollar liquidity through foreign exchange swaps (as was already the case in December 2007, January 2008, and March 2008). The former gave greater planning certainty to counterparties, and the latter helped manage dollar shortages in the euro area spilling over from instabilities in the U.S. (ECB 2014). Finally, the corridor of standing facilities was temporarily reduced from 200 to 100 basis points from October 2008 to January 2009 (figure 5), to further contain short-term money market rate volatility. As the ECB became the "market maker" in the money market, its balance sheet expanded significantly.

Additional nonstandard measures were adopted in May 2009—when the MRO rate reached the 1 percent level and the DFR reached the 0.25 percent level— to support the flow of credit to households and corporations. ${ }^{37}$ These included announcements of the lengthening of the maximum maturity of refinancing operations to one year (one-year LTROs, starting in June) and the Covered Bonds Purchase Programme (CBPP, starting in July), the first outright purchase program carried out by the ECB with the aim of reviving the funding channel for banks and support for their credit intermediation. Together with those measures adopted in October 2008, these measures configured the ECB's policy of "Enhanced Credit Support" in response to the financial crisis (Trichet 2009). Interestingly, the press conference after the Governing Council's meeting on May 7, 2009, was the first time that

36. In figure 16 below, the difference between the ECB's total net monetary policy operations, excluding recourse to standing facilities (the upper end of the figure, minus liquidityabsorbing operations) and the banking sector's liquidity needs (thick black line) or the negative values for net recourse to the Deposit Facility and daily reserve surpluses illustrates this excess liquidity in the context of the Eurosystem's balance sheet. Before the fall of 2008, there usually was no material excess liquidity. For the relationship between excess liquidity and money market rates, see figure 21 .

37. A comprehensive description of ECB market operations between the first quarter of 2009 and the second quarter of 2012 is provided by Eser and others (2012). 
Figure 14. Changes in the Euro Area's Bank Credit Standards, 2002-17

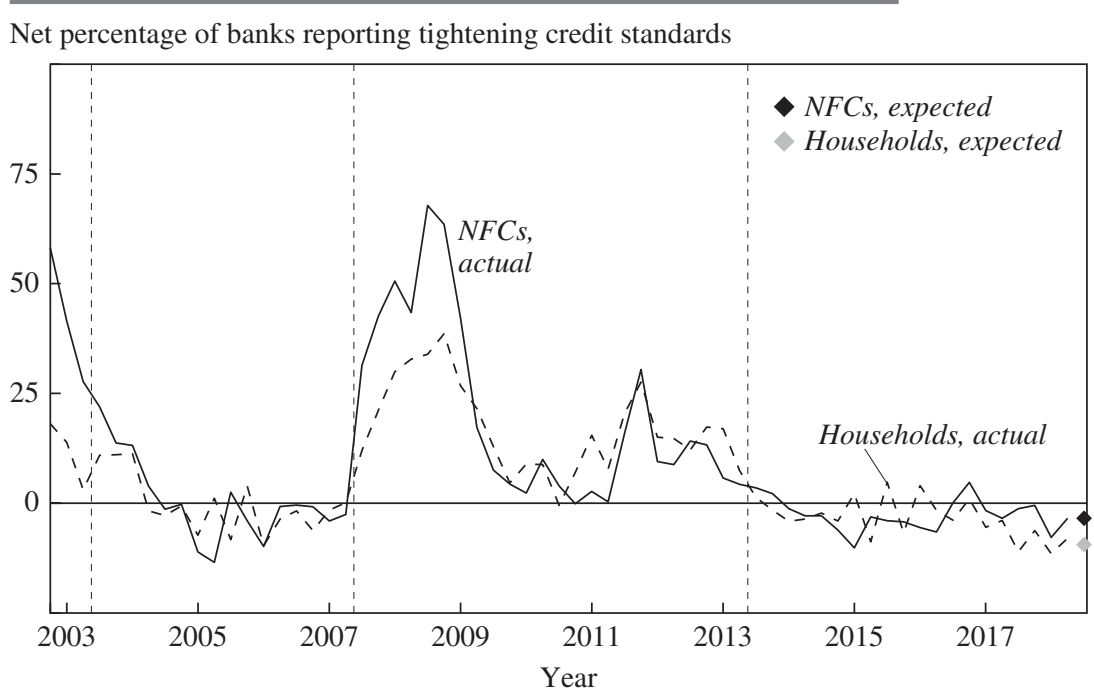

Source: ECB Bank Lending Survey in July 2018.

a. NFCs = nonfinancial corporations. The solid line refers to changes in standards applied to the approval of loans or credit lines to NFCs. The dashed line refers to the standards applied to loans to households for house purchases. Net percentages are defined as the difference between the sum of the percentages of banks responding "tightened considerably" and "tightened somewhat" and the sum of the percentages of banks responding "eased somewhat" and "eased considerably." "Actual" values are changes that the bank respondents to the survey report to have occurred, while "expected" values are changes anticipated by banks. The most recent observations are for 2018:Q2 for actual changes and for 2018:Q3 for expected changes.

some of these nonstandard measures were briefly included in the formal introductory statement by the president (and were only later detailed in separate press releases; ECB 2009c).

The combination of these standard and nonstandard monetary policy responses had a beneficial impact on interbank market spreads (figure 13) and on financing conditions more generally (figures 14 and 15). They contributed, together with expansionary fiscal policies (figure 12) and financial sector support measures, to the initial economic and financial recovery from the Great Recession. ${ }^{38}$ For example, the cumulative government

38. In line with an agreement for strengthening growth reached at the first Group of Twenty's summit in Washington in November 2008, the European Commission combined national initiatives and a smaller share of EU funding to a $\$ 200$ billion concerted European Economic Recovery Plan to boost demand and stimulate confidence in the European Union (European Commission 2008). The total plan amounted to spending of about 1.5 percent of GDP, which was endorsed by the European Council in December 2008. For an analysis of the effects of this fiscal stimulus, see Coenen, Straub, and Trabandt (2012). 
Figure 15. The Euro Area's Bank Lending Rates, 2003-18

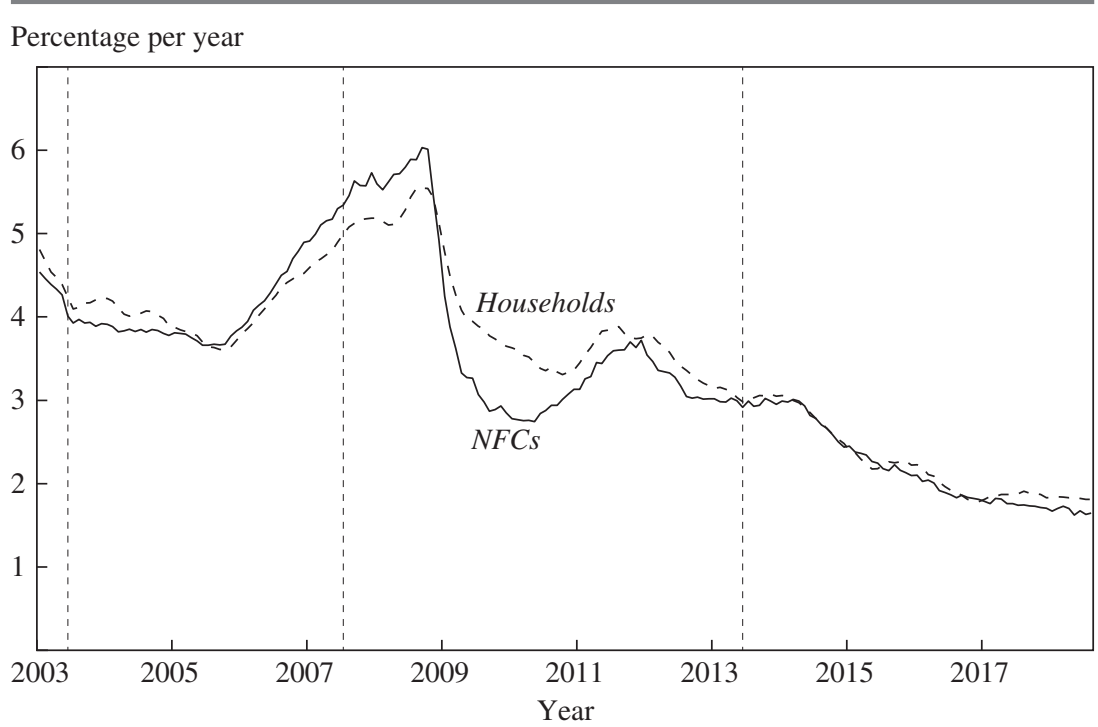

Source: ECB data.

a. NFCs = nonfinancial corporations. The two indicators show the total cost of bank borrowing for NFCs (solid line) and for households financing house purchases (dashed line). They are calculated by aggregating short- and long-term rates using a 24-month moving average of new business volumes. The most recent observation is for August 2018.

support for euro area financial institutions in the form of commitments for capital injections, liability guarantees, or asset support between October 2008 and May 2010 has been estimated by Stéphanie Stolz and Michael Wedow (2010) at about 28 percent of GDP (although the effective amounts were only about half of this). Already at that time, however, bank stress tests did not have all the desirable effects. For example, not long after the first European coordinated tests of 22 major cross-border groups under the Committee of European Banking Supervisors (CEBS 2009)—which, however, was run without a minimum capital threshold - there were further bank failures in the euro area. ${ }^{39}$

By the end of 2009, nevertheless, year-on-year real GDP growth turned positive again and continued to pick up in 2010 (figure 7). The fall in underlying inflation stopped at about 1 percent in late 2009 and early 2010;

39. For a comprehensive overview of national financial sector policies during the crisis, including national stress tests, see European Commission (2017). 
and at about the same time, headline inflation rose quickly again, reaching about 1.7 percent in the second quarter of 2010 and, ultimately, levels above 2 percent (figure 6), as energy prices again increased (figure 8). In addition, a modest recovery in money and credit growth began in mid-2010 (figure 9). This led to an initial discussion about phasing out some of the exceptional monetary policies, which ex post proved to be premature.

The European sovereign debt crisis and the sovereign-bank nexus, redenomination risk, and the second recession, May 2010-June 2013. The financial crisis and the Great Recession had left their mark on public finances. Government bond yield spreads increased significantly in the euro area (figure 13), particularly in those countries whose deficits rose substantially owing to the impact of automatic stabilizers in the face of a deep recession, discretionary expansionary fiscal policy (figure 12), and, importantly, interventions to shore up the banking sector (Stolz and Wedow 2010; Domingues Semeano and Ferdinandusse 2018). For example, public debt in the euro area as a whole rose from about 65 percent of GDP in early 2008 to about 78 percent in early 2010, and to above 90 percent in 2013. Particularly large increases occurred-notably, in Cyprus, Greece, Ireland, Portugal, and Spain. At least to some extent, risk was transferred from the financial sector onto public sector balance sheets, leading to a deterioration of fiscal positions.

Moreover, after the Greek public debt deceit started to be revealed in October 2009-leading, among other things, to a large revision of the reported government deficit for 2009-in April 2010, the Greek sovereign debt market seized up and markets lost confidence in the authorities' ability and willingness to address the large rise in Greek government debt. Despite European governments putting together a rescue package and associated adjustment program for Greece and establishing the European Financial Stability Facility in June 2010 - a (temporary) backstop vehicle for future crisis incidents - other "peripheral" countries faced their own crises in the following two years. Against the background of the discussion on countries with (private and public) debt overhang problems in subsection I.B and the further public debt increases referred to above, it is instructive to note that the affected countries, which needed some form of adjustment program with financial assistance, were precisely Ireland (2010), Portugal and Cyprus (both 2011), and Spain (2012). Over time, Italy also became seriously distressed, but never to the point that it had to start a rescue program.

The ECB's policy response continued to abide by the separation principle. On one hand, in order to ensure depth and liquidity in the sovereign 
bond markets of distressed countries and to restore the appropriate functioning of the monetary policy transmission mechanism, in May 2010 the ECB introduced its first sovereign bond purchase program, the Securities Markets Programme (SMP). To signal that the SMP was not designed to alter the stance of monetary policy, the SMP's purchases of debt securities were sterilized.

On the other hand, as both GDP growth and headline inflation picked up, the ECB raised its key policy rates by 25 basis points in April 2011 and again in July 2011, after almost two years of no change (figure 5). The euro area economy had grown at a quarterly rate of 0.8 percent in the first quarter of 2011, and the economic analysis revealed some upside risks to price stability. In fact, inflation had risen to 2.6 percent in March 2011 (and actually reached 3 percent toward the end of 2011, way above the medium-term objective below but close to 2 percent). There were concerns about second-round effects in the setting of prices and wages, and a risk of inflation expectations becoming unanchored from the ECB's definition of price stability.

Although the econometric evidence reviewed in subsection II.C finds that the SMP's interventions did put downward pressures on and lowered the volatility of sovereign yields for most countries, they did not stop the rise in sovereign spreads. By mid-July 2011, financial tensions intensified again due to the worsening of public finances in several euro area countries and contagion from the agreement to restructure Greek sovereign debt (which was, however, not implemented before 2012). ${ }^{40}$ After bank bailouts had weakened sovereigns, the sovereign-bank nexus closed because the weakened sovereigns implied mark-to-market losses on banks' government debt holdings and an erosion of public guarantees (Acharya and others 2014). The sovereign debt crisis increasingly turned into a twin sovereign debt and banking crisis. Further negative feedback loops between vulnerable banks, indebted sovereigns, and weak economies took hold in several

40. The restructuring of Greek debt reflected one aspect of the Deauville agreement between Chancellor Merkel and President Sarkozy in October 2010, to promote "private sector involvement" in handling a public debt overhang. The lingering question about its application to the Greek case after October 2010, the decision in July 2011 to restructure Greek debt and the delay in its implementation until the spring of 2012 implied an ongoing source of uncertainty and volatility over an extended period of time. It should not be forgotten, however, that the Franco-German Deauville agreement constituted a much more wide-ranging public debt crisis resolution framework for Europe, which included-among other things - the establishment of a permanent rescue facility when the European Financial Stability Facility would expire in 2013. See Zettelmeyer, Trebesch, and Gulati (2013) for a detailed history of the Greek debt restructuring and events around it. 
countries and led to acute financial fragmentation along country borders (Shambaugh 2012; ECB 2012a, 2013b). The most affected countries lost market access and entered adjustment programs (see above), contributing to a period of procyclical fiscal consolidation (figure 12) and stabilization slowdowns.

In addition to the fiscal woes and associated high and diverse sovereign yields across the euro area, monetary transmission remained severely hampered by lingering bank instabilities, which constrained the flow of credit to the economy and imposed significant obstacles to the ECB's Enhanced Credit Support. The reason was that in many countries, particularly the fiscally weak countries, bank recapitalization or resolution processes progressed only very slowly. Cases in point are the two EU-wide coordinated stress-testing exercises in 2010 and 2011. Although 7 euro area banks out of 91 EU banks (a much larger set than in the first, 2009 CEBS exercise) failed the July 2010 tests and had to raise new capital (CEBS 2010), their potentially beneficial effects on confidence in European banks were soon undermined by the fact that the two largest Irish banks, which had passed the test like many others, needed to be bailed out only a few months later. Similarly, 8 euro area banks out of 90 EU banks tested failed to meet the minimum threshold in the 2011 exercise, which was coordinated for the first time by the new European Banking Authority (2011), and were asked to replenish their capital. In October 2011, however, the large Franco-Belgian group Dexia, which had passed the test by a wide margin, went into resolution. ${ }^{41}$ At this point, the credibility of prudential and fiscal authorities' ability to solve Europe's banking problems was in a sorry state. Bank fragility and fragmentation remained a serious impediment to an effective monetary policy for this whole period.

As the financial tensions intensified and fiscal consolidation took hold, economic confidence fell, the economy slowed down rapidly and the euro area entered a double-dip recession in the last quarter of 2011 (figure 7). An important contributing factor was banks' deleveraging needs and the associated tightening of bank lending standards and further reductions in money and credit growth (figures 14, 15, and 9).

In response, the ECB entered a new monetary policy easing phase, during which—in November 2011-Mario Draghi also succeeded Jean-Claude Trichet as ECB president. On August 7, 2011, Trichet made a statement on Italy and Spain and announced that the ECB would reactivate its SMP (ECB 2011b). Toward the end of 2011, the 
ECB introduced several new, nonstandard measures. Two LTROs of 12 and 13 months were announced on October 6, 2011, as well as a second covered bond purchase program (CBPP2) for an intended amount of $€ 40$ billion. Then the ECB reversed the interest rate hikes of April and July 2011 by cutting key policy rates in November and December 2011 by a total of 50 basis points. Moreover, in December 2011 and February 2012, two three-year Very-Long-Term Refinancing Operations (VLTROs), with the option of early repayment after one year, were conducted, with a combined gross amount of more than $€ 1$ trillion. The vertically dashed area in figure 16 shows what a large share these VLTROs assumed in total ECB monetary policy operationsfor example, compared with the 1-year LTROs a few years earlier (the medium gray area of the figure). They gave banks funding certainty, eased redemption of maturing bonds, and helped them sustain credit lines with private customers. Finally, on December 8, 2011, the ECB also decided to again enlarge the collateral list via a reduction of the rating threshold for certain asset-backed securities and reduced the minimum reserve ratio from 2 to 1 percent (see subsection I.A).

These measures brought much needed relief for banks' funding, but-by definition of central bank liquidity operations - could not ensure the much needed balance sheet repair of many euro area banks. Also the need for fiscal consolidation lingered on. In early 2012, weak growth and news of fiscal slippages in several countries once more strained financial markets, and financial tensions rose again. Over the course of the sovereign debt crisis, a new phenomenon had slowly emerged, redenomination risk-the risk that euro assets could be redenominated in legacy currencies (De Santis, forthcoming). In other words, some premiums priced into the government bond yields of a few countries reflected increasing market-derived probabilities that those countries could leave the euro. In 2011 and, particularly, in 2012 some of them reached new heights (De Santis, forthcoming), increasing the cost of funding for several stressed euro area countries and seriously hampering the transmission of the ECB's policy stance to the real economy in those countries. Preserving the unity of the euro area became the defining challenge of the crisis.

This was the context in which, finally, decisive steps were also taken at the political level. For example, the "Fiscal Compact" was signed in March 2012, involving — among other things-a balanced-budget rule. More important, at a key European summit on June 28-29, 2012, the president of the European Council proposed significant reforms to EMU's financial, budget, and economic policy frameworks, notably the establishment 
Figure 16. Quantities of the ECB's Market Operations from a Balance Sheet Perspective, 2007-18

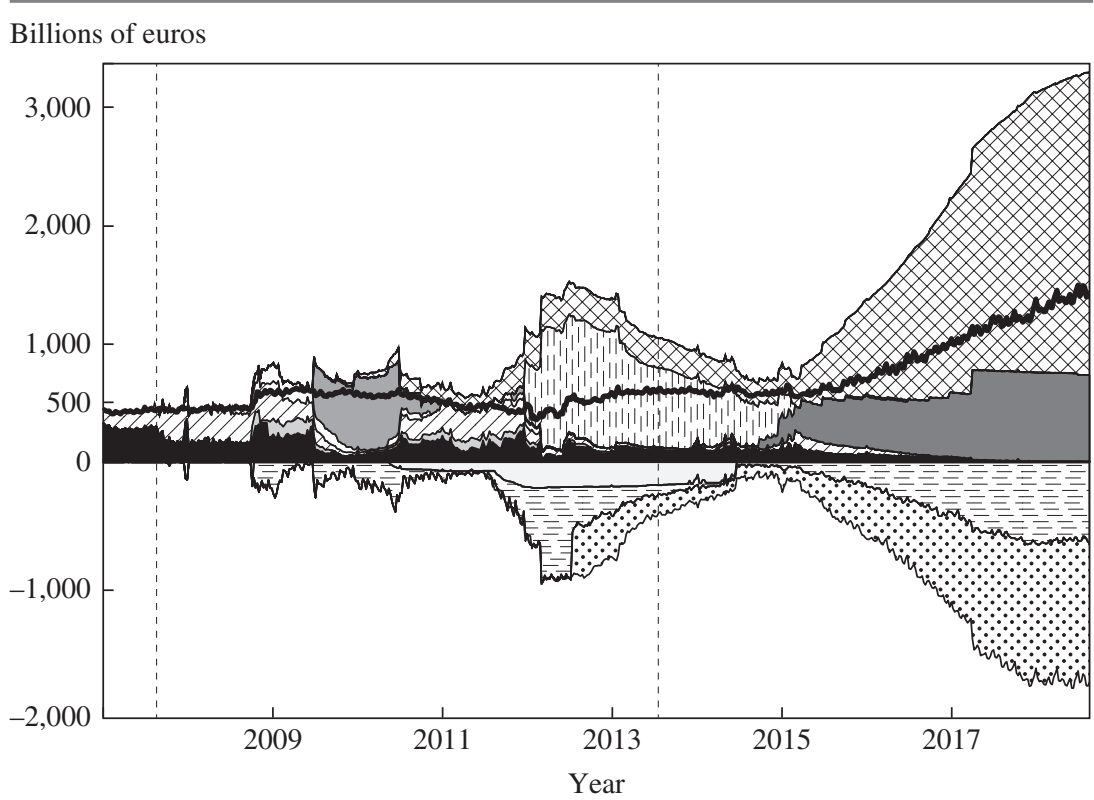

Main refinancing operations

$\triangle 3$-month, longer-term refinancing operations

12-month, longer-term refinancing operations

3-year, longer-term refinancing operations

$\triangle$ Liquidity-providing fine-tuning operations

E Net recourse to deposit facility

- Liquidity needs (autonomous factors + minimum reserve requirements) $\square$ 1-maintenance-period refinancing operations 6-month, longer-term refinancing operations

Targeted, longer-term refinancing operations

囚 Outright purchases (CBPPs, SMP, ABSPP, PSPP, CSPP)

$\square$ Liquidity-absorbing fine-tuning operations

$\because$ Daily reserve surplus

Source: ECB data.

a. CBPPs = Covered Bond Purchases Programmes; SMP = Securities Markets Programme; ABSPP = Asset-Backed Securities Purchase Programme; PSPP = Public Sector Securities Programme; CSPP = Corporate Sector Purchase Programme. This figure shows monetary policy items on the Eurosystem's balance sheet. Total ECB monetary policy operations (see also figure 4) are equal to the sum of Main Refinancing Operations, Longer-term Refinancing Operations (3-month, 6-month, 12-month, and 3-year), and outright purchase programs (CBPPs, SMP, ABSPP, PSPP, and CSSP), but excluding the net recourse to standing facilities (Marginal Lending and Deposit Facility). Liquidity needs are the sum of autonomous factors and minimum reserve requirements. Autonomous factors are factors, like banknotes in circulation and government deposits, that affect the liquidity needs of the banking system but are outside of the control of the central bank. Daily reserve surplus refers to the difference between banks' current account balances held with the central bank and banks' minimum reserve requirements. Excess liquidity can be approximated by adding daily reserve surplus and net recourse to deposit facility. Net recourse to deposit facility is the difference between recourse to the marginal lending facility and recourse to the deposit facility. The most recent observation is for July 17, 2018. 
of the main elements of the European Banking Union-single supervision, resolution, and deposit insurance (European Council 2012a, 2012c). ${ }^{42}$ Making explicit reference to the need for breaking the sovereign-bank nexus, the euro area countries agreed to start with a Single Supervisory Mechanism at the ECB (European Council 2012a). Earlier, it had been agreed that the temporary European Financial Stability Facility (EFSF) would be replaced in October 2012 by the European Stability Mechanism (ESM), an intergovernmental organization to safeguard the financial stability of the euro area through financial assistance against strict conditionality to member states with severe financing problems. The ESM has a lending capacity of $€ 500$ billion, and it later also assumed the possibility of direct bank recapitalizations (European Council 2012a). Details of the reforms were worked out in the Four Presidents' Road Map toward a genuine EMU, published in December 2012 (European Council 2012b), and in subsequent legislation..$^{43}$

In this new context of a much clearer path for fixing some of EMU's most important financial and fiscal weaknesses, on July 11, 2012, the ECB lowered rates by 25 basis points, bringing the Deposit Facility Rate to 0 percent (which was then left unchanged for almost two years; figure 5). More important, on July 26, 2012, ECB president Draghi (2012) delivered a speech in London in which he gave the assurance that "within our mandate, the ECB is ready to do whatever it takes to preserve the euro. And believe me, it will be enough." Several days later, on August 2, 2012, the ECB's Governing Council announced it would introduce the Outright Monetary Transactions (OMT) Programme-which consists of purchasing sovereign bonds in secondary markets under strict conditions, with the aim of "safeguarding an appropriate monetary policy transmission and the singleness of monetary policy" (ECB 2012b) in the face of potentially self-fulfilling redenomination risks. The technical framework of the OMT was announced on September 6, 2012, and on the same day, the SMP was terminated. A necessary requirement for the OMT was strict and effective conditionality attached to an appropriate EFSF/ESM program (including a precautionary program). The OMT backstop was seen as credible, supported by the political agreements at the June Summit and the imminent start of the permanent ESM, and led to an immediate contraction of

42. In June 2012, the European Commission had also presented a first draft of the European Bank Recovery and Resolution Directive.

43. Also, Greek debt restructuring had finally taken place in March and April 2012, although the agreed-on bond exchange already had to be complemented with an EFSF buyback of newly issued debt in December (Zettelmeyer, Trebesch, and Gulati 2013). 
sovereign bond spreads, which rapidly declined to more sustainable levels (figure 13). ${ }^{44}$

On May 8, 2013, the ECB lowered the MRO rate by 25 basis points and the Marginal Lending Facility Rate by 50 basis points, further narrowing the interest rate corridor (figure 5). With the DFR already at 0 percent, room for further cuts in interest rates was increasingly limited. In response to the partial normalization of financial tensions, growth slowly picked up in the course of 2013.

DISCUSSION Overall, in the period between August 2007 and June 2013, the ECB entered the uncharted territory of nonstandard monetary policy measures. ${ }^{45}$ At first, the ECB's operational framework was well suited to address impairments in the interbank market by providing ample liquidity for its wide set of counterparties and against a wide variety of collateral (Cassola, Durré, and Holthausen 2011; Eser and others 2012). The ECB particularly "lent to the market" like a traditional lender of last resort for the banking system. ${ }^{46}$ In so doing, it relied on the separation principle to distinguish very generous liquidity provision from setting the monetary policy stance.

One question in this regard is whether (with the benefit of hindsight) the ECB was too optimistic about its (or other policy branches') ability to contain those impairments-notably, the later and more severe ones (see the next paragraph) - and their macroeconomic effects. This question has become subject to debate, in particular with respect to the shortlived tightening of standard monetary policy in 2008 and 2011 in parallel with continued easy liquidity provision. The reaction function analysis given in subsection II.B, which adopts the adequate real-time perspective, suggests that the July 2008 interest rate increase, although quite short-lived, was not fully in line with the ECB's own falling growth and inflation forecasts. The interest rate increases in 2011 were more in line with the strong growth and inflation forecasts in early 2011, though somewhat delayed. As nonstandard monetary policy measures became

44. For example, the Commission tabled a proposal for the Single Supervisory Mechanism in September 2012.

45. For various studies discussing how monetary and other central bank policies have changed over the last decade and how this is affecting central banks' roles more broadly, see Hartmann, Huang, and Schoenmaker (2018).

46. See, for example, Garcia-de-Andoain and others (2016) for an in-depth analysis of this "lending to the market" between 2008 and 2014. Emergency liquidity assistance to individual banks was undertaken, where needed, by euro area national central banks outside their Eurosystem responsibilities. But banks with sufficient Eurosystem-eligible collateral could also tap the ECB's marginal lending facility. 
more forceful, the distinction between monetary policy stance and market operations started to soften. For example, as mentioned above, with the introduction of the fixed-rate/full-allotment credit operations in October 2008, the excess liquidity that started to build up in the banking system (see figure 16) pushed the overnight rate in the money market from the middle of the ECB's interest corridor to the bottom, making the DFR the effective policy rate. Also, nonstandard measures based on the ECB's market operations sometimes started to be mentioned in the introductory statement at the Governing Council's press conference.

However, as first the financial crisis and then the sovereign debt crisis took hold and the underlying solvency problems of both banks and sovereigns lingered on and reinforced each other, the incompleteness of EMU in the banking and fiscal areas became increasingly obvious (see also European Commission 2015; and Baldwin and Giavazzi 2015, 2016) and undermined the effectiveness of the ECB's monetary policy. The imperfect ways in which major financial and fiscal instabilities were addressed by the competent authorities, and the absence of sufficient institutions and tools for solving the related collective action problems in a highly integrated monetary union of sovereign states with primarily national fiscal and supervisory policies, posed formidable challenges for the ECB's monetary policy. An early indication of this was that in spite of very early generous liquidity provision, the ECB did not succeed in pushing interbank market rates all the way back down close to precrisis levels, as shown in figure 13. One plausible explanation is that these spreads contained a significant credit risk component and that credit risks and liquidity risks were strongly intertwined (Eisenschmidt and Tapking 2009; Angelini, Nobili, and Piscillo 2011). Relatedly, the pass-through of the lower policy rates to bank lending rates became very uneven across countries over time as financial fragmentation took hold, again undermining the effectiveness of monetary policy (ECB 2015b).

ECB monetary policy itself could not address the underlying solvency issues of either banks or governments. In fact, the prohibition of monetary financing laid down in the EU treaty forbids the ECB from directly financing governments or government tasks, such as the recapitalization of banks. ${ }^{47}$ It provides an important protection of the ECB from fiscal

47. Article 123 of the Treaty on the Functioning of the European Union prohibits overdraft facilities or any other type of credit facility for governments or government institutions with the European Central Bank or the Eurosystem, as well as the direct purchase from them of debt instruments. 
dominance over its monetary policy, thereby supporting the achievement of price stability in the medium to long term. Instead, such solvency issues can only be effectively addressed by prudential and fiscal authorities. Unfortunately, major progress in addressing the institutional limitations in the field of supervision and resolution was only achieved toward the end of this period, as political agreements were reached to build a banking union-with the setting up of the Single Supervisory Mechanism at the ECB and the Single Resolution Mechanism-and to strengthen the backstop for governments through the permanent ESM.

Against this background, the ECB's actions had to balance the need to address impairments in the transmission of monetary policy due to malfunctioning financial markets and self-fulfilling market dynamics with the prohibition of monetary financing. This partly explains what some observers regard as the initial timid interventions in the government bond market through the SMP based on implicit conditionality. ${ }^{48}$ Leading up to the June 2012 European Summit, however, the necessary institutions and reforms to improve on the main weaknesses of EMU in the prudential and fiscal fields were put on a credible path. In this context, the ECB stepped up its nonstandard tool kit to the next level, starting with President Draghi's "whatever it takes" speech and the powerful OMT program, based on the explicit conditionality of an adequate EFSF/ESM program.

\section{I.D. Deflation Risks and Low-Inflation Recovery, June 2013-June 2018}

The last cyclical period of the euro area that we cover in this paper concerns the slow recovery after the crises. The protracted low-inflation fallout of the sovereign debt crisis and risks of deanchoring inflation expectations led the ECB to further extend its nonstandard monetary policy and communications tool kit. Although this reinforced discussions about the benefits and risks of such policies, in various dimensions it made the ECB more similar to its main peers.

ADDRESSING THE LOWER BOUND ON INTEREST RATES The fourth and most recent episode was characterized by the ECB's actions to overcome the zero lower bound on interest rates in its attempt to address deflation risks and bring inflation back to levels close to 2 percent. In doing so, the ECB turned to policies such as quantitative easing, funding for lending, and explicit forward guidance that had been used before by other central banks,

48. As discussed in subsection II.C, the ECB characterized the SMP's interventions as limited and temporary, leading markets to doubt that it was prepared to offer a full backstop. 
such as the U.S. Federal Reserve and the Bank of England. The ECB was, however, the first major central bank to also go into negative interest rate territory. We review existing evidence on the effectiveness of these programs in subsection II.C.

As monetary policy became much more complex, there was an increased need for communication. As part of the efforts to provide enhanced communication in a more complex environment, in January 2015 the Governing Council decided to release the accounts of its meetings on monetary policy, about four weeks after each meeting (Draghi 2014a). At the same time, the frequency of these meetings was changed from monthly to eight times a year, in order to better align them with the arrival of sufficient new information and to reduce the number of instances when expectations could cause market volatility. Unlike previous communications, in which the ECB had stated that it would not precommit on monetary policy decisions, it also turned to forward guidance in this period (see figure 26 below). Following the taper tantrum in the U.S., which led to significant undesired interest rate spillovers to the euro area, the ECB introduced explicit forward guidance about the future path of key interest rates in July 2013. As in other central banks, the precise formulation of the forward guidance evolved over time, as we describe later in this subsection.

NEGATIVE RATES, TARGETED LENDING, AND QUANTITATIVE EASING The sovereign debt crisis abated, and the recovery started to take hold, as some of its underlying causes were addressed by the various country adjustment programs, the creation of a banking union with common supervision and resolution, and the establishment of a backstop for governments via the ESM and the ECB's OMT program. However, the damage of high unemployment and negative output gaps in 2012 and 2013 was done (figure 3). Toward the second half of 2013, both headline and core inflation dropped below 1 percent, and headline inflation became negative in the course of 2015 (to a minimum of -0.7 percent in January 2015; see figure 6), largely on account of falling energy prices (figure 8). Inflation expectations, which up until then had remained well anchored, started to decline and to exhibit a significant downward skewing (subsection II.A). ${ }^{49}$ Concerns grew about deflation risks and a prolonged period of low inflation. Moreover, it became increasingly clear that the transmission of the easing of ECB key policy rates had remained impaired and uneven. In particular,

49. For example, in his speech at the Federal Reserve Bank of Kansas City's Jackson Hole Symposium in August 2014, President Draghi (2014b) digressed from his main topic of euro area unemployment to point out that inflation expectations were declining significantly at all horizons (see figures 18 and 20 below). 
the cumulative reduction of 125 basis points in the MROR ( 75 basis points in the DFR) from November 2011 to November 2013 had not yet been transmitted to households and firms in the stressed euro area countries. Over time, as the medium-term outlook for inflation continued to worsen, the ECB's balance sheet shrank; credit growth remained negative, reflecting ongoing deleveraging; and until March 2014, the exchange rate of the euro strengthened (figures 16, 9, and 10).

To stave off emerging deflation risks and address the impairment of the bank lending channel, the ECB embarked on a three-pronged, comprehensive monetary policy easing strategy starting in June 2014. This strategy was foreshadowed in a speech by President Draghi (2014a), in which he laid out the conditions for the three elements of the easing strategy. A first measure was to go into negative interest rate territory. In June 2014, and again in September 2014, the ECB lowered the DFR by 10 basis points, to -0.2 percent. Second, to revive the provision of credit and address the fragmented policy transmission, it announced a renewed round of credit easing measures with a series of Targeted Longer-Term Refinancing Operations (TLTROs) fixed at the MRO rate plus 10 basis points. The surcharge was abolished in January 2015. The maximum maturity for the TLTROs was set to September 2018, and the initial allowance for the maximum amount of borrowing under the TLTRO program amounted to 7 percent of outstanding loans to the euro area's nonfinancial private sector. The maturity of the loans was conditional on banks exceeding certain lending thresholds for the corporate sector. These credit-easing measures were complemented by an asset-backed securities purchase program, and a third covered bond purchase program in September 2014. Third, to provide additional stimulus in an environment where further cuts in short-term rates were constrained, in January 2015 the ECB announced an expanded Asset Purchase Programme (APP), with average monthly purchases of public and private sector securities of $€ 60$ billion. Through the portfolio rebalancing and signaling channels, this put further downward pressure on long-term interest rates and flattened the slope of the yield curve (Coeuré 2015). At the same time, it led to a big expansion of the ECB's balance sheet (figure 16).

The combined impact of these measures was to lower market- and bankbased financing costs and ease financial conditions more broadly (subsection II.C). Figure 15 shows that the composite indicator of the cost of borrowing for nonfinancial corporations (NFCs) and households fell from 3 percent to close to 2 percent at the end of 2015, and bank lending rates started to converge in the wake of the earlier fragmentation. At the same time, banks started easing their lending standards, and credit growth to the 
private sector gradually started recovering (figures 9 and 14). By the summer of 2015, GDP growth had picked up to close to 2 percent (figure 7), and both headline and underlying inflation had stabilized, but at relatively low levels of 0 and 1 percent, respectively (figure 6).

Against this background of still uneven and fragile growth and low inflation, the growth in global demand faltered in the summer of 2015, as a stock market collapse in China and an unexpected depreciation of the renminbi caused financial turbulence in emerging market economies. In order to avoid a renewed increase in deflation risk and to continue to support the gradual recovery of the euro area's economy, the three-pronged package of measures was recalibrated again in December 2015 and March 2016 with a view to adding further monetary policy stimulus. On December 3, 2015, the ECB lowered interest rates further by 10 basis points and announced a recalibration of the APP, prolonging the program until March 2017, or beyond if necessary, to ensure a sustained adjustment of inflation toward the aim of being below, but close to, 2 percent (ECB 2015d). At the same time, the ECB announced that it would reinvest the principal repayments, keeping the stock of the APP portfolio constant after the end of the net purchases for as long as necessary, and extended the list of APP-eligible assets to include securities issued by regional and local governments. On March 10, 2016, the ECB decided again to lower rates, with effect from March 16, bringing the interest rate corridor down to 65 basis points and lowering the DFR by 10 basis points, to -0.4 percent (ECB 2016b, 2016c). At the same time, a considerable expansion of the APP was announced, with average monthly purchases being increased to $€ 80$ billion. The ECB also launched the Corporate Sector Purchase Programme as an integral part of the APP. Finally, four new TLTROs, known as TLTRO-II, each with a maturity of four years, were announced, starting in June 2016 and running until March 2017. The rates on these operations could be as low as the negative DFR, if banks exceeded certain lending benchmarks. The combined effect of these additional easing measures was to further improve financing conditions. This stimulated domestic demand and turned a fragile and uneven recovery into a solid and broad-based expansion, in spite of the temporary weakness of the international economy. Accordingly, but also partly due to rising commodity prices, inflation picked up as of 2016:Q3, reaching almost 1.8 percent in January 2017 (figures 6 and 8).

As the euro area's economy strengthened, but underlying inflation remained subdued, further monetary stimulus was deemed appropriate, but the intensity of the stimulus was gradually adjusted. On December 8, 2016, the Governing Council decided to extend the net APP until the 
end of 2017, while at the same time reducing its monthly pace as of April 2017 to $€ 60$ billion. As of 2017:Q2, growth further increased, peaking at 2.8 percent in September (figure 7). On October 26, 2017, it was decided to further recalibrate the APP, and the program was extended until September 2018, with a reduced monthly pace of purchases of $€ 30$ billion starting in January 2018. Finally, on June 14, 2018, the Governing Council announced an anticipated extension of the net APP until the end of 2018 at a reduced pace of $€ 15$ billion, after which the net APP was expected to end. At the same time, it enhanced its forward guidance on policy rates by stating that it expects policy rates to remain at their present levels at least through the summer of 2019 and, in any case, for as long as necessary to ensure the sustained convergence of inflation to levels that are below, but close to, 2 percent. In fact, headline inflation stabilized at close to 2 percent during the summer of 2018, whereas core inflation continued to "creep up" only very slowly.

DISCUSSION Overall, the fourth episode was characterized by the ECB's actions to overcome the zero lower bound on interest rates in its attempt to address deflation risks and bring inflation back to levels close to 2 percent. In doing so, the ECB turned to policies such as negative interest rates, quantitative easing, funding for lending, and explicit forward guidance; and in this respect, it started to more closely resemble many of its peers.

Most of the debates in this period related to the rationale, the sequencing, and the costs and benefits of the new nonstandard measures. We review the rationale for these various measures and the evidence of their effectiveness in subsection II.C. Here, it is important to realize that, as the ECB ventured into uncharted territory, it learned from its own and other central banks' experience. A prominent example is the introduction of a negative DFR, which was introduced in small steps of 10 basis points and followed the positive experience with negative rates in a number of smaller countries, such as Denmark and Switzerland (Jackson 2015; Martínez Pagés and Millaruelo 2016).

Also, the ECB's forward guidance evolved in this period (see figure 26 below). After the taper tantrum in the United States, the ECB announced that the policy rates were expected "to remain at present or lower levels for an extended period of time" and that this expectation was "based on the overall subdued outlook for inflation extending into the medium term, given the broad-based weakness in the real economy and subdued monetary dynamics" (ECB 2013c). The aim was to anchor policy expectations and maintain an accommodative level of long-term interest rates in the face of rising bond yields in the global market and a still very 
subdued and fragile euro area recovery. As explained by Peter Praet (2013), the forward guidance on interest rates was meant to clarify the ECB's reaction function. As in other central banks, the ECB's forward guidance framework subsequently evolved. It took on a more complex and time- and state-dependent form when the expanded APP was announced in January 2015. On this occasion, the ECB also gave forward guidance on the net asset purchases and announced that they "are intended to be carried out until end-September 2016 and . . in any case . . until [it sees] a sustained adjustment in the path of inflation which is consistent with its aim of achieving inflation rates below, but close to, 2 percent over the medium term" (ECB 2015c). This forward guidance therefore had both time- and state-dependent conditioning elements. The former underscored the commitment made by the Governing Council, whereas the latter made the state-dependent nature of the forward guidance clear. A direct link with the ultimate objective was seen as more appropriate than alternative intermediate targets, also in light of the mixed experience with conditioning variables, such as unemployment in the United States and the United Kingdom. The APP was subsequently extended in December 2015, in December 2016, and in October 2017, maintaining a similar formulation.

In March 2016, when the APP's monthly purchases were increased from $€ 60$ billion to $€ 80$ billion, the ECB also for the first time linked forward guidance on interest rates to that on the APP, by stating that the "key interest rates would remain at present or lower levels for an extended period of time and well past the end of the net asset purchases" (ECB 2016c). This helped to secure the credibility of the interest rate forward guidance (Coenen and others 2017), thereby reinforcing both parts of the easing program, and it also provided clarity on the sequencing in the normalization of the various elements of the easing measures (Praet 2018). In June 2017, the reference to lower interest rates (the "easing bias") was dropped (ECB 2017d). And in June 2018, when the anticipation of the end of the net asset purchases by the end of 2018 was announced, forward guidance on interest rates was delinked from the APP, and it was stated that "the Governing Council expects key interest rates to remain at the present level at least through the summer of 2019 and, in any case, as long as necessary to ensure ... the continued sustained convergence of inflation to levels that are below, but close to, 2 percent over the medium term" (ECB 2018c). A time- and state-based element is now attached to the liftoff of policy rates.

Controversy about the ECB's policy decisions in this period focused mostly on the Public Sector Purchase Programme (PSPP), which constituted the largest part of the APP. Despite an observable slide in inflation, 
there was some opposition to a large-scale bond purchase program because of concerns about potential monetary financing (Article 123 of the Treaty on the Functioning of the European Monetary Union, EU 2012b), additional central bank balance sheet risks, independence in making interest rate decisions with a large government bond portfolio, and possible effects on governments' willingness to pursue debt consolidation and enact reforms (Weidmann 2015). The fact that deploying asset purchases was fully in line with the ECB's mandate was confirmed by the European Court of Justice. In its judgment on the OMT program, it ruled that purchases of government bonds are legal under the ECB's statute and are a legitimate tool of monetary policy (Court of Justice 2015). To ensure that secondary market purchases of government bonds cannot be assimilated to primary market purchases that are forbidden under the monetary financing prohibition, it is, however, also important to ensure that the program is consistent with the ultimate objectives of Article 123, namely, safeguarding (1) the primary objective of price stability, (2) the central bank's independence, and (3) the fiscal discipline of a member state. To this effect, the ECB built sufficient safeguards into the PSPP. First, PSPP purchases adhere to a blackout period; that is, the Eurosystem does not buy near the date of a new issuance, which facilitates the formation of market prices for PSPP-eligible securities (ECB 2015a). Furthermore, the relevant securities are subject to an issue share limit and an issuer limit, which preserve market functioning. Finally, to avoid free-riding by national governments, risk-sharing of the PSPP was limited to 20 percent of the portfolio and the portfolio weights were guided by the capital key-that is, the share of each national central bank in the ECB's capital (ECB 2015e). All these safeguards were designed to ensure that PSPP purchases stay well clear of monetary financing.

\section{Assessing the ECB's Monetary Policy}

After the chronological part in the previous section, we now move to assessing key aspects of the ECB's monetary policy during its first 20 years. In turn, we cover the achievement of price stability, the ECB's primary objective, the standard interest rate decisions, and the more recent nonstandard monetary policy measures.

\section{II.A. The Objective of Price Stability: Performance, Credibility, and Challenges}

Let us start by analyzing the performance and credibility regarding the ECB's primary mandate of medium-term price stability for the euro area. 
Figure 17. The Euro Area's Headline Inflation and a Five-Year Moving Average, 1999-2018

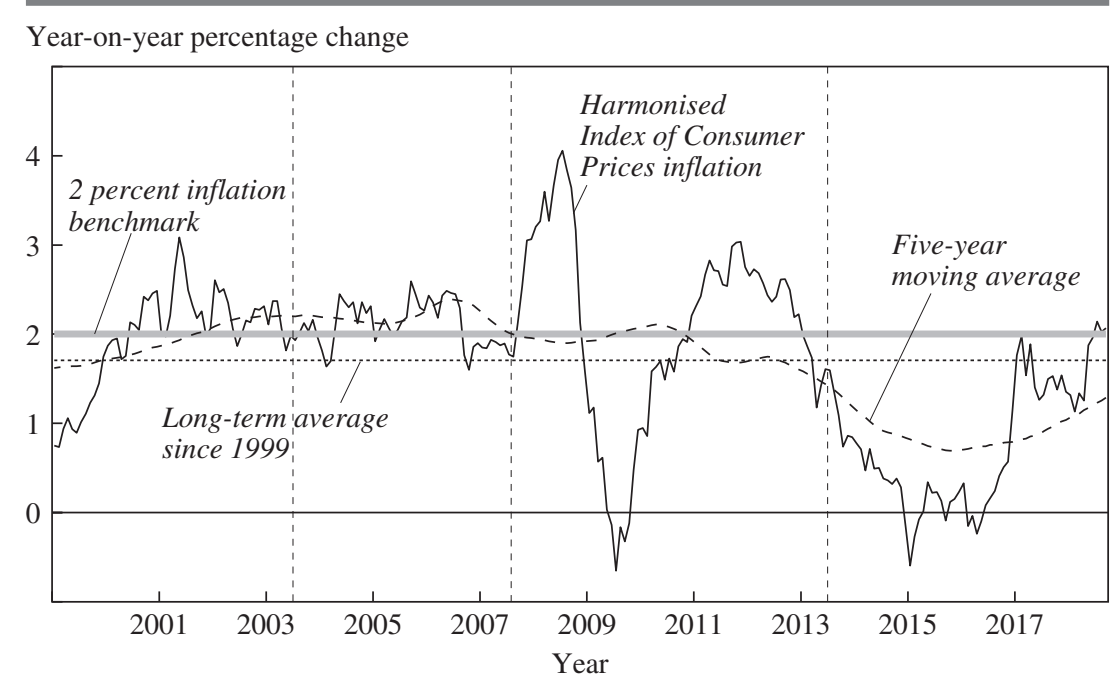

Source: ECB data.

a. The long-term average of inflation according to the Harmonised Index of Consumer Prices since 1999 is 1.7 percent. The moving average is centered, and its values toward the end of the period are calculated using the ECB/Eurosystem inflation projections. The most recent observation is for September 2018.

The key question is to what extent the ECB managed to anchor mediumterm inflation expectations in a way that is consistent with its mandate, particularly in the aftermath of the twin crises. Later in this subsection, we discuss implications for the definition of the ECB's inflation aim.

HOW WELL ANCHORED ARE INFLATION EXPECTATIONS IN THE EURO AREA? Figure 17 shows that over the past two decades, average euro area inflation has been about 1.7 percent. This average outcome is consistent with, but on the low side of, Issing's indication of an inflation aim between 1.7 and 1.9 percent. Over this period, annual HICP inflation has roughly fluctuated between 0 and 4 percent, mostly reflecting the impact of volatile energy and food price inflation. The range for core inflation (that is, HICP inflation, excluding energy and food) is smaller, and lies between 0.6 and 2.6 percent, reflecting its more sluggish nature (figure 6). Figure 17 also depicts a five-year centered moving average of HICP inflation, which may capture a more appropriate medium-term horizon for assessing the ECB's performance. This moving average fluctuated closely around 2 percent until the sovereign debt crisis, but started to decline below its previous range in the second half of 2012 and fell to a historic low of about 
0.7 percent at the beginning of 2016 , and since then has been expected to slowly recover. ${ }^{50}$

Given the imperfect short-term control of inflation by the central bank, it is also useful to examine the stability of medium- to longer-term inflation expectations. The anchoring of longer-term inflation expectations to the ECB's inflation aim is a good measure of the ECB's credibility for maintaining price stability over the medium term. The empirical literature has shown that the degree to which inflation expectations are anchored has been dispersed across countries and time, and appears to co-move with the degree of credibility of monetary policy. The tendency toward betteranchored expectations was typically stronger in countries with official inflation targets, suggesting that agents use inflation targets as focal points when forming longer-term inflation expectations (Demertzis, Marcelino, and Viegi 2009; Gürkaynak, Levin, and Swanson 2010).

A study focusing on the earlier part of the EMU period (Beechey, Johannsen, and Levin 2011) showed that, on average, the euro area's long-run inflation expectations were more firmly anchored than those in the United States. ${ }^{51}$ In this subsection, we follow Jonas Dovern and Geoff Kenny (2017), and use data from the ECB's Survey of Professional Forecasters (SPF) to examine how the various moments of longer-term inflation expectations in the euro area have evolved over the past two decades. Figure 18 shows the evolution of two measures of average 5-year-ahead inflation expectations taken from the SPF (together with two measures of market-based inflation expectations derived from swap rates between inflation-adjusted and nominal government bonds). The average point forecast (the dotted line, as also included in figure 6) stayed close to 2.0 percent over the full EMU period, roughly fluctuating between 1.8 and 2.0 percent. The average mean of the individual forecasters' distributions (dashed line) has fluctuated a bit more, and reached a minimum of 1.65 percent at the beginning of 2016. As shown by Tomasz Lyziak and Maritta Paloviita (2017), there is some dependence of these average forecasts on a moving average of actual inflation, but overall these movements have been very contained. Using more formal tests for breaks in mean longer-term inflation expectations, Dovern and Kenny (2017) find two significant breaks in 2005:Q2 and then again in 2013:Q2. In 2005:Q2, the mean expectation shifted upward, from an estimated 1.85 percent to 1.92 percent. Arguably, this may be due

50. The ECB/Eurosystem's inflation projections are used to calculate the 5-year moving average toward the end of the period.

51. See also Ehrmann and others (2011). 
Figure 18. Survey and Market-Based Inflation Expectations in the Euro Area, 2005-18

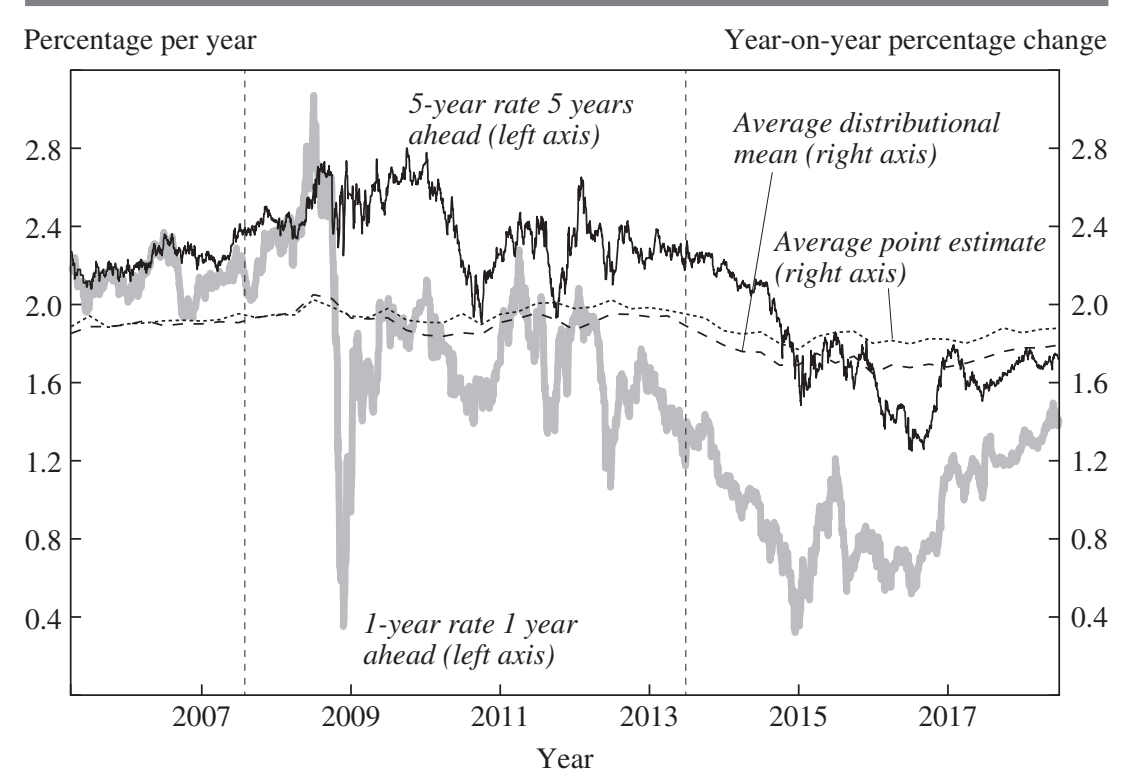

Sources: ECB data; Survey of Professional Forecasters.

a. This figure shows different measures of the first moment of inflation expectations. The average point estimate refers to the average of 5-year-ahead point forecasts for inflation per the Harmonised Index of Consumer Prices (HICP) across contributors to the ECB Survey of Professional Forecasters. The average distributional mean refers to the mean of the aggregate 5-year-ahead forecast distribution for HICP inflation across contributors to the SPF. For further explanations, see ECB (2017a). The most recent observation is for July 2, 2018.

to the clarification of the definition of price stability as below, but close to, 2 percent in 2003. This upward movement in expectations was, however, more than reversed in 2013:Q2, when the mean inflation expectation dropped back to about 1.8 percent, partly in response to the persistently low level of inflation after the sovereign debt crisis in the euro area.

It is also instructive to look at the second moment of the longer-term forecast distribution. Figure 19 shows three measures of longer-term inflation uncertainty based on the SPF. First, it shows a measure of disagreement among professional forecasters, that is, the standard deviation of individual forecasters' point forecasts (the solid line). Disagreement fell significantly in the first decade of EMU, from 0.4 to 0.1 percentage point, suggesting that the ECB's extensive communication about its stability-oriented monetary policy strategy (see figure 2, the medium gray area) and the quantitative definition as well as the consistent and transparent conduct of monetary policy 
Figure 19. Survey-Based Longer-Term Inflation Uncertainty in the Euro Area, 1999-2018

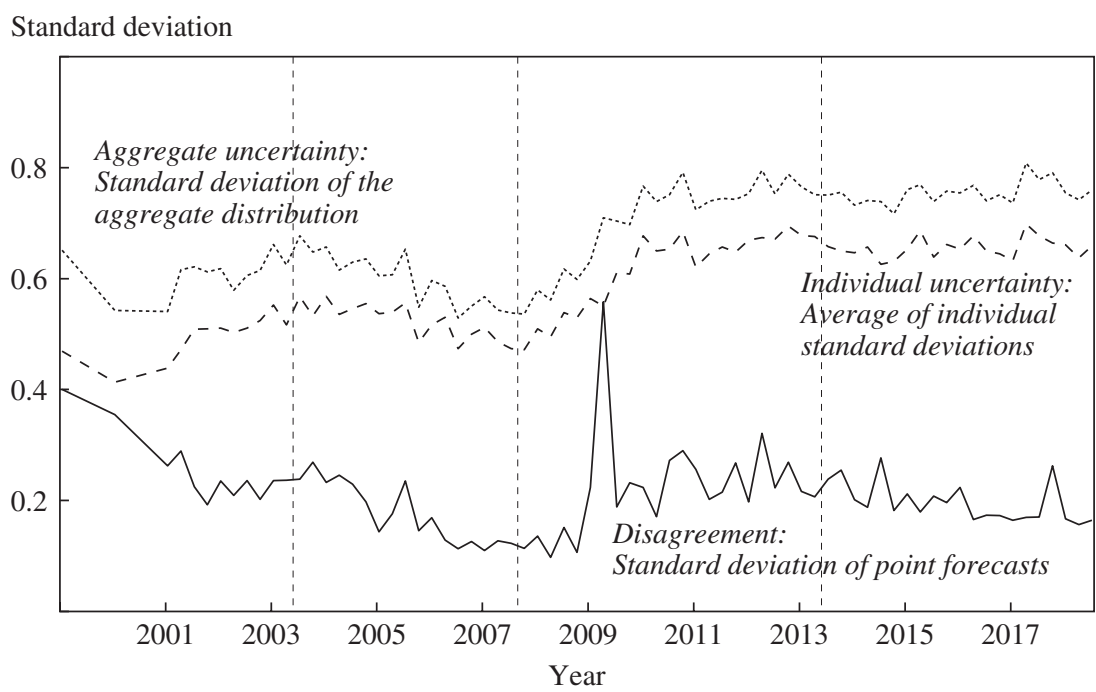

Sources: ECB data; ECB (2017a).

a. This figure shows different measures of the second moment of 5-year-ahead inflation expectations. Disagreement refers to the standard deviation of point inflation forecasts per the Harmonised Index of Consumer Prices (HICP) made by contributors to the ECB Survey of Professional Forecasters. Individual uncertainty refers to the average of individual forecasters' standard deviations for HICP inflation. Aggregate uncertainty refers to the standard deviation of the aggregate distribution of HICP inflation forecasts contributed by participants in the survey. For further explanations, see ECB (2017a). The most recent observation is for July 1, 2018.

were effective in aligning longer-term expectations across forecasters. Although disagreement rose significantly after the start of the Great Recession, it has fallen back, reaching levels close to 0.15 percentage point since then. The other two measures shown in figure 19 take into account the individual forecast uncertainty. After the financial crisis, longer-term inflation forecast uncertainty has clearly increased, also reflecting the higher variance of actual HICP inflation after 2007 (Dovern and Kenny 2017). There is no evidence that this measure of uncertainty has so far significantly reverted to its precrisis level.

Finally, one can also analyze the balance of longer-term inflation risks as captured by the SPF expected distributions. Figure 20 gives the range of a number of such measures, as well as their average. It shows that before the financial crisis, the risks around the longer-term inflation forecast were roughly balanced. Interestingly, a slight negative skewing emerged in about 2003-4, when, as discussed above, there was a debate about the impact of 
Figure 20. The Survey-Based Balance of Longer-Term Inflation Risks and the Inflation Risk Premium in the Euro Area, 1999-2018

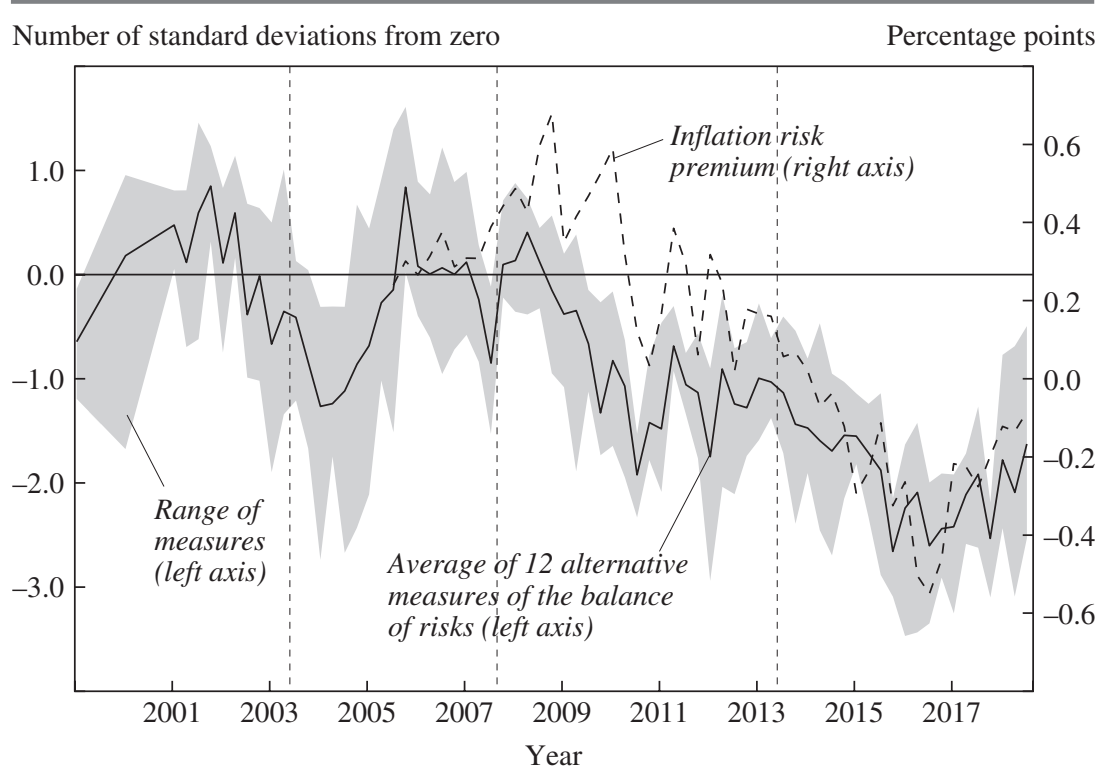

Sources: ECB data; Joslin, Singleton, and Zhu (2011); Camba-Méndez and Werner (2017); ECB (2017a).

a. This figure shows the average and the range of 12 different measures of the third moment (skew) of 5-year-ahead inflation expectations from the ECB Survey of Professional Forecasters. The Inflation Risk Premium decomposition is based on an affine term structure model and fitted to the euro area zerocoupon, inflation-linked swap curve. The estimation method follows Joslin, Singleton, and Zhu (2011); for details, see Camba-Méndez and Werner (2017). For further information, see ECB (2017a). The most recent observation is for August 1, 2018.

the zero lower bound on optimal inflation targets and the ECB's inflation aim was clarified. However, the skewing became persistently negative after the beginning of the financial crisis, and in particular after the sovereign debt crisis. Most recently, there has been a return toward more balanced risks. This is consistent with recent evidence given in a paper by Olesya Grishchenko, Sarah Mouabbi, and Jean-Paul Renne (2017).

Figure 20 also shows that the negative skewing is highly correlated with model-based estimates of the inflation risk premium in inflation-indexed bonds and can explain why market-based, 5-year-ahead, 5-year-forward inflation rates have been more responsive to actual headline inflation than the average survey expectations (figure 18). As the probability of getting trapped in a low inflation or deflation regime increases, the demand for deflation protection rises, affecting inflation risk premiums. 
A second approach for analyzing the anchoring of inflation expectations is to investigate the sensitivity of longer-term inflation expectations to short-term macroeconomic news and inflation developments, as reviewed by Matteo Ciccarelli and Chiara Osbat (2017). Although the reviewed studies differ in the details of their respective methodologies, there are some common findings that are consistent with the evidence noted above. Before the financial crisis, no significant pass-through effects were recorded. But the overall picture is less clear after the start of the crisis. ${ }^{52}$ However, after the negative oil price shock of mid-2014, three out of four pass-through measures identified increasing risks of a deanchoring of longer-term inflation expectations. In 2015, the announcement and subsequent implementation of the APP seem to have softened these risks, and some studies suggest that the pass-through signal has become insignificant.

Overall, this review of the evidence suggests that in contrast to some early fears, the ECB was effective in anchoring medium- to longer-term inflation expectations to its inflation aim early on (Smets 2010). Moreover, modal expectations remained anchored below, but close to, 2 percent throughout the financial and sovereign debt crises. However, the higher uncertainty about the expected longer-term inflation forecast and the emergence of a significant negative skewing in the balance of risks after the beginning of the sovereign debt crisis in particular suggests that the ECB was not able to fully dispel the probability of ending up in a low inflation / deflation regime (as had happened in Japan). This may not necessarily be related to the credibility of the ECB's commitment to maintain price stability, but it may be due to doubts that the ECB had the necessary tools to fight deflation in an environment of low interest rates. Not the willingness of the central bank, but its ability, may have been put in doubt, as the ECB was relatively slow in applying large-scale purchases of government bonds as a monetary policy tool-particularly as compared with other major central banks, such as the U.S. Federal Reserve System, the Bank of England, and the Bank of Japan. This explanation is also borne out by some evidence of asymmetry between the response of longer-term market inflation compensation measures to inflationary and deflationary shocks (Natoli and Sigalotti 2018). Though this may have been more important for the ECB, where a discussion on the

52. For the United States, a number of studies have shown that longer-term mean inflation expectations started to react more strongly to macroeconomic news after the financial turmoil of 2008; see Galati, Poelhekke, and Zhou (2011); and Autrup and Grothe (2014). 
use of quantitative easing was more intense and may explain its delayed implementation, the fact that this feature has to some extent also been observed in other jurisdictions with a single fiscal authority suggests that it may be a more general phenomenon related to the risk that one can get trapped in a deflation regime once inflation expectations adjust (Benhabib, Schmitt-Grohé, and Uribe 2001). As discussed above, the emergence of medium-term deflation risks eventually led the ECB to embark on a comprehensive, unconventional easing program, which helped to remove deflation risks (Andrade and others 2016).

POSSIBLE IMPLICATIONS FOR THE DEFINITION OF PRICE STABILITY A review of the ECB's credibility highlights the reality that over the past two decades, the ECB's initial concerns that it may not have had the same anti-inflation credibility as some of its predecessors, such as the Deutsche Bundesbank, later were turned around into the opposite concern that it may not be sufficiently equipped to avoid a low inflation or deflation equilibrium. In this light, it is worthwhile to review some of the elements of the ECB's definition of price stability.

One issue is whether the excess sensitivity of longer-term inflation expectations to low inflation is partly due to a persistent perception of a lack of symmetry in the ECB's inflation objective. Due to the formulation of the inflation aim ("below, but close to"), many observers continue to think that the ECB's tolerance for lower inflation is higher than its tolerance for higher inflation, although ECB policymakers have continuously stressed the importance of symmetry. ${ }^{53}$ The question of symmetry can be addressed within the literature on the policy reaction function. Maritta Paloviita and others (2017) find no evidence of asymmetry if the inflation target is assumed to be 1.7 percent, but some evidence of asymmetry if the target is assumed to be 2 percent..$^{54}$ In subsection II.B, we test for asymmetry in a simple policy reaction function setup, and find little evidence of a stronger response to positive deviations of inflation than to negative deviations from the ECB's inflation aim.

A related question is whether the precision of the medium-term inflation objective matters. As mentioned above, empirical evidence suggests that a point target helps agents to focus when forming inflation expectations

53. For example, in a recent speech, President Draghi (2016) emphasized the importance of pursuing the price stability objective symmetrically, particularly in a zero-lower-bound and high-debt environment. This criticism was around from day one, as discussed above.

54. Examples of other earlier studies of possible asymmetries in the ECB's monetary policy include those by Aguiar and Martins $(2008,1651)$, who find a "precautionary demand for price stability"; and Surico (2007). 
and contributes to the anchoring of those expectations. This is why many academics were originally in favor of a point target (Bernanke and others 1999). It also explains why most inflation targeting by central banks has a clear focal point, even if this is often embedded within a target range to underline that a central bank cannot precisely pin down inflation at all times. ${ }^{55}$

But what is the optimal focal point for inflation? In the advanced economies, there has been a convergence of inflation targets to 2 percent since the start of inflation-targeting regimes in New Zealand in 1989. Recent examples are the U.S. Federal Reserve in 2012, the Bank of Japan in 2013, and the Norges Bank in 2018. One argument against being very precise is that there is uncertainty surrounding the optimal medium-run inflation objective and that it may change over time. In the academic literature, estimates of the optimal inflation target vary from mild deflation to 4 percent and higher. The recent experience of higher macroeconomic volatility and a lower equilibrium real interest rate have led some macroeconomists to argue for higher inflation targets of 4 percent (Blanchard, Dell'Ariccia, and Mauro 2010; Ball 2014; Krugman 2014). ${ }^{56}$ The higher probability of hitting the zero lower bound in an environment of low interest rates is also brought out in quantitative simulation studies like those by Michael Kiley and John Roberts (2017). At the same time, central banks, including the ECB, have gained much positive experience with the use of unconventional policy measures to circumvent the effective lower bound on short-term interest rates. Recent empirical research suggests that these tools may have been just as effective as the more standard short-term interest rate tools in steering the economy (as discussed in subsection II.C), although they may come with additional side effects. ${ }^{57}$ And changing inflation objectives always runs the risk of undermining the central bank's credibility and increasing uncertainty and the inflation risk premium..$^{58}$

55. A precise numerical target also helps in communication. In the words of Stephen Nickell (2006, 252), former member of the Bank of England's Monetary Policy Committee: "In my own experience, I find being provided with a precise numerical inflation target enormously helpful, since I can then explain my own policy decisions very simply in terms of avoiding an undershoot or overshoot of this target."

56. Early on, Wyplosz (2001) argued for a higher inflation target of 4 to 10 percent for the euro area on the basis of the presence of more significant downward nominal wage rigidities.

57. See, for example, Swanson (2018) — but for an opposite view, see Hamilton (2018).

58. For example, raising an inflation objective could increase the risk that inflation expectations could become unanchored (Ascari, Florio, and Gobbi 2017; Deutsche Bundesbank 2018) or be "too blunt an instrument" compared with alternative options (Coibion, Gorodnichenko, and Wieland 2012, 1371). 
A suggested compromise has therefore been to keep the 2 percent focal point, but to strengthen the role of inflation expectations as an automatic stabilization mechanism to further alleviate the zero lower bound on interest rates. This can, for example, be done by average inflation targeting (Svensson 1999b; Nessen and Vestin 2005). Vitor Gaspar, Smets, and David Vestin (2010) show that the benefits of such an approach continue to exist even in the absence of rational expectations, as long as the agents learn and adapt their expectation formation to changes in the regime. ${ }^{59}$

\section{II.B. The Conduct of Monetary Policy: The ECB's Interest Rate Decisions}

This subsection analyzes the ECB's interest rate decisions through the lens of an empirical interest rate reaction function. This is particularly appropriate until the ECB hits the zero lower bound in July 2012.

We explained in subsection I.A above how the ECB used its operational framework to steer short-term money market rates close to the MROR, during the first decade the main monetary policy rate agreed by the Governing Council. Figure 5 shows the developments of the main policy-controlled interest rates since the start of EMU and how during the first decade of EMU, the euro overnight interest rate-measured by the Euro Overnight Index Average (EONIA) - fluctuated within the corridor given by the MLFR and the DFR. The EONIA stayed relatively close to the MROR - that is, at the midpoint of the corridor-with exceptions at the end of the maintenance period, when unexpected liquidity shortages or surpluses can lead to sharp deviations within the corridor.

Although a number of refinements were made to the ECB's operational framework during its first decade, as we described in subsection I.C the big changes came with the severe worsening of the financial crisis in October 2008 (ECB 2011a). A key one was the switch to fixed-rate/full allotment tenders, as it led the DFR to become the effective monetary policy rate (and not any longer the MRO minimum bid rate). It triggered increasing excess liquidity, which made the EONIA drop below the MROR and toward the bottom of the corridor given by the DFR. The distance of the EONIA rate from the DFR is a (nonlinear) function of the amount of excess liquidity in the banking system, as illustrated in figure 21 (covering data between

59. An argument against average inflation targeting is that it may require short periods of deflation after periods of inflation. This is addressed in the proposal by Bernanke (2017) to install a price-level target only after periods in which the lower bound has been binding. 
Figure 21. The Euro Area Banks' Excess Liquidity and the EONIA-DFR Spread ${ }^{\mathrm{a}}$

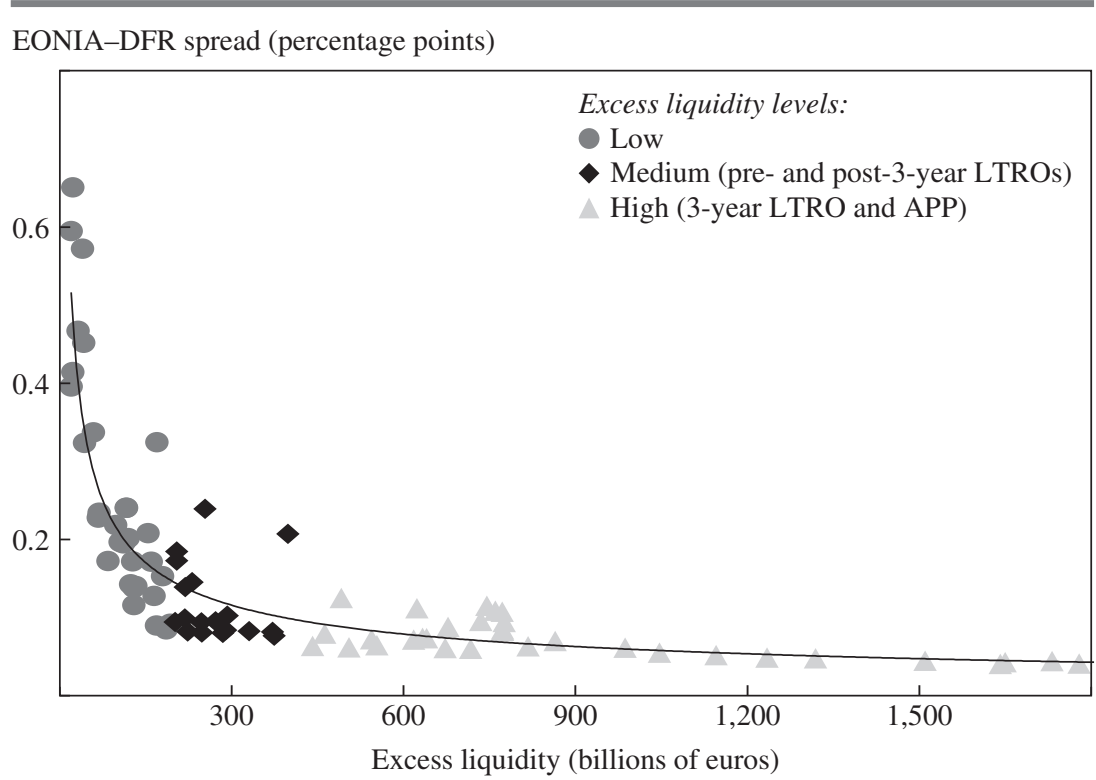

Source: ECB data.

a. EONIA $=$ Euro Overnight Index Average; DFR $=$ Deposit Facility Rate; LTRO = Longer-Term Refinancing Operation; APP $=$ Asset Purchase Programme. Each sign (dot, rhombus, or triangle) corresponds to the average spread between the EONIA and the DFR for a specific reserve maintenance period. Low excess liquidity levels refer to excess liquidity below $€ 200$ billion and correspond to the period before December 2011 and between the end of the 3-year LTROs and the start of the APP (about the end of 2013 and 2014). Medium levels refer to excess liquidity between $€ 200$ billion and $€ 400$ billion, and high levels refer to excess liquidity above $€ 400$ billion. The sample period is from January 20, 2010, to May 2, 2018.

2010 and 2018). For example, two periods were characterized by a rising EONIA relative to the deposit rate (the gray dots in the figure). The first one was 2011, when the macroeconomic picture improved, the ECB raised rates twice, and excess liquidity dropped to very low levels. The second period was toward the end of 2013 and 2014, when excess liquidity again fell to low levels as banks started repaying VLTROs. In figure 21, medium and high levels of excess liquidity are marked, respectively, with black rhombuses and light gray triangles.

In the rest of this section, we analyze the setting of the main policy rate through the lens of a simple, but robust, first-difference policy rule originally proposed by Athanasios Orphanides (2003). This rule links the change in the main policy rate of the ECB (the minimum bid rate in MROs before October 2008, and the DFR after October 2008) to deviations of 
the one-year-ahead inflation forecast from the ECB's inflation aim and deviations of the one-year-ahead real GDP growth forecast from potential output growth:

$$
\Delta i=0.5\left(E \pi_{t+1}-\bar{\pi}\right)+0.5\left(E \Delta y_{t+1}-\Delta \bar{y}\right) .
$$

Orphanides (2003) showed that this rule describes quite well the behavior of U.S. policy rates during the Volcker-Greenspan period. As discussed by Orphanides (2006), one of the advantages of this simple rule is that it avoids having to rely on unobservable concepts such as the output gap and the natural real interest rate, which are subject to considerable uncertainty. Moreover, the first-difference rule has been shown to be robust in a variety of models, reflecting a wide range of data, parameter, and model uncertainties (Orphanides and Williams 2005, 2008). Finally, because the rule can be implemented on the basis of short-term forecasts for growth and inflation that were available at the time of the policy decision, it is an easy way of constructing a real-time policy benchmark that is not contaminated by ex-post information. This rule has been applied to the euro area by, among others, Smets (2010); Orphanides and Volker Wieland (2013); and Tilman Bletzinger and Wieland (2016).

Figure 22 replicates and extends the rule given by Orphanides and Wieland (2013). The dotted line depicts the changes in the relevant policycontrolled interest rate. ${ }^{60}$ The shaded area shows the predictions of the Orphanides rule, where we use the one-year-ahead forecasts for inflation and growth from the SPF and the European Commission's real-time estimate of potential GDP growth as input variables. The upper and lower limits of the shaded area correspond to a range for the inflation aim between 1.5 and 2.0 percent. As also shown by Smets (2010) and Orphanides and Wieland (2013), this simple rule captures the changes in the ECB's policy rate very well (until it becomes zero in July 2012). If we impose the condition that the average error between the actual and predicted interest rate changes is zero (as in a regression analysis), then we can use this rule to calculate the ECB's implied inflation aim, which is 1.76 percent, very close to the midpoint between 1.5 and 2.0 percent and consistent with the range highlighted by Issing at the May 2003 press conference on the

60. Note that the changes in the policy rate are quarterly changes to align it with the quarterly frequency of the SPF forecasts, whereas the policy decisions are monthly through most of the period. We take the policy rate set in the middle of the quarter to align it with the time when the SPF forecasts are first available to the Governing Council. 
Figure 22. The Orphanides Rule for the Euro Area, 1999-2018

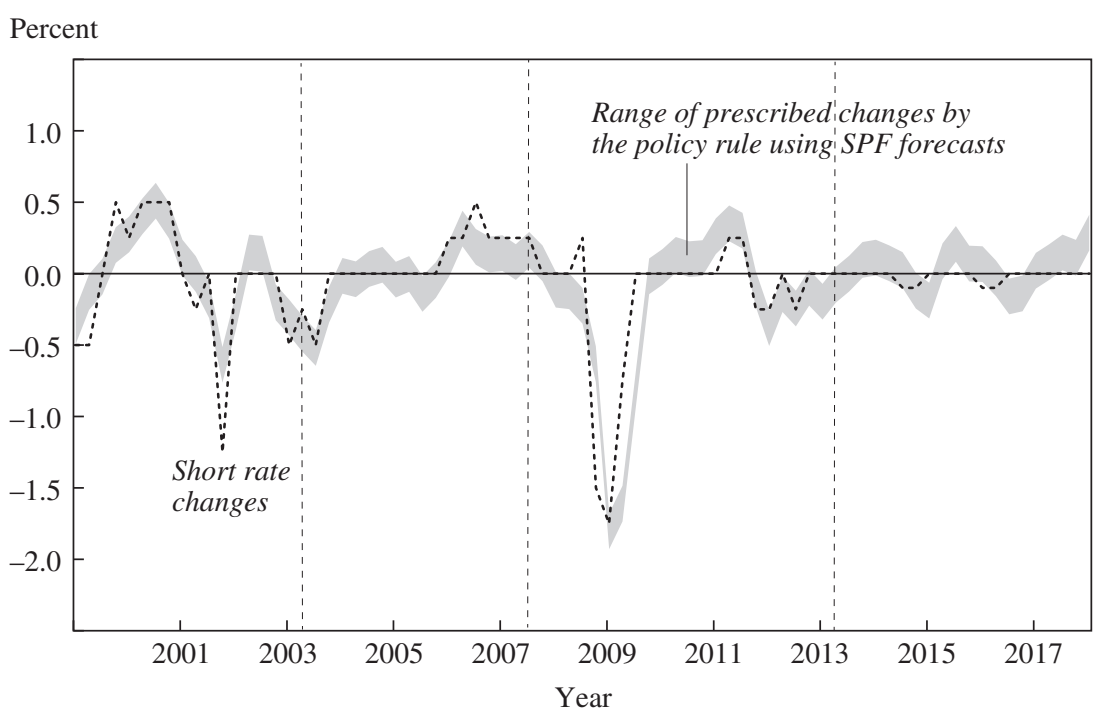

Sources: Authors' research; ECB data; ECB Survey of Professional Forecasters (SPF); European Commission.

a. This estimation uses the SPF findings, as given by Orphanides and Wieland (2013). The short rate changes combine the time series of the changes in the main refinancing operations rate up to 2008:Q3 with the changes in the deposit facility rate from 2008:Q4 onward. Changes are mid-quarter-on-quarter changes. The most recent observation is for 2018:Q1.

occasion of the announcement of the results of the ECB's monetary policy strategy review (ECB 2003b).

In the rest of this subsection, we go beyond the previous papers by using the ECB's own growth and inflation projections to derive the rule. Since their start in 1998, the ECB and the Eurosystem have produced quarterly macroeconomic projections, which typically are presented to the Governing Council in the first meeting in March, June, September, and December of each year as part of the economic analysis. ${ }^{61}$ Kontogeorgos

61. The June and December projections are called the Broad Macroeconomic Projection Exercise because it is a Eurosystem exercise involving the contributions of all the national central banks of the euro area, whereas the March and September Macroeconomic Projection Exercises are intermediate updates of the December and June Broad Macroeconomic Projection Exercises produced by ECB staff. Note that the ECB/Eurosystem's projections at first were based on a constant interest rate assumption; but since the June 2006 projection exercise, they have been based on market expectations of short- and long-term interest rates. Differences in technical assumptions for the oil prices or the exchange rate may explain part of the differences between SPF and ECB/Eurosystem projections. For a comprehensive description of the exercises, see ECB (2016a). 
and Lambrias (2018) recently investigated some of the properties of the $\mathrm{ECB} /$ Eurosystem staff projections for GDP growth and HICP inflation, and they find that they satisfy the properties of optimal forecasts. They are generally unbiased; errors are not correlated beyond what one theoretically could expect; and the uncertainty in the forecasted increases with the horizon. They outperform simple benchmarks - such as the Random Walk and an Autoregressive Model of Order 1 [AR(1)]—and, in the case of inflation, are rational. ${ }^{62}$ Unfortunately, a direct comparison with the SPF forecasts is difficult because the professional forecasters use different information sets and different technical assumptions. Paloviita and others (2017) focus on the properties of the ECB/Eurosystem staff forecasts over the projection horizon. They find that the ECB/Eurosystem staff projections exhibit stronger and faster mean reversion than are implied by persistence in the actual data. After about six quarters, the median inflation projections are already in the proximity of their levels at the end of the forecast horizon. They also find that inflation forecasts are too often close to the mean, and that three to four quarters out, the inflation and growth forecasts are not correlated with the actual outcomes. Some of these findings are illustrated in figure 23, which shows the mean, maximum/ minimum, and 25th/75th percentiles of the ECB/Eurosystem staff projections of year-on-year inflation and real GDP growth for different horizons. ${ }^{63}$

Figure 24 shows the outcome of applying the Orphanides rule to the $\mathrm{ECB} /$ Eurosystem staff projections. In order to align the interest rate decisions with the $\mathrm{ECB} /$ Eurosystem projections, we take the policy rate set when the projections are presented (that is, in the last month of the quarter). This explains the slightly different pattern of interest rate changes compared with figure 22 . The conclusions remain, however, roughly the same. The simple policy rule captures the ECB's policy decisions quite well. The increase in rates in 1999 and 2000 and the subsequent fall, the pause in 2004-5, the rise starting in 2006, the sharp fall in 2008 and 2009, and the slight increase in 2011, as well as the fall in 2012, are all captured fairly well by a simple response to deviations of the one-year-ahead inflation projection from the inflation aim and the deviations of the one-yearahead growth projection from estimated potential output growth. Not surprisingly, the correspondence is less striking as of July 2012, when the deposit rate is constrained by reaching zero (see subsection I.C), and

62. See also ECB (2013a); and Alessi and others (2014).

63. Paloviita and others (2017) show a similar figure. 
Figure 23. ECB/Eurosystem Staff Projections for Year-on-Year HICP Inflation and Real GDP Growth

HICP inflation

Percent

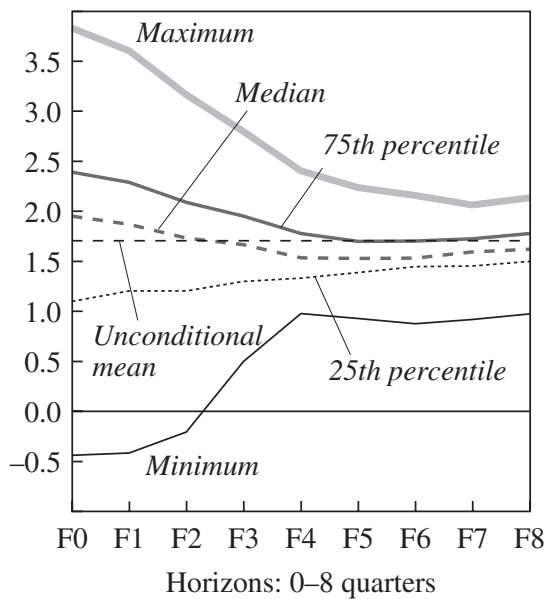

\section{Real GDP growth}

Percent

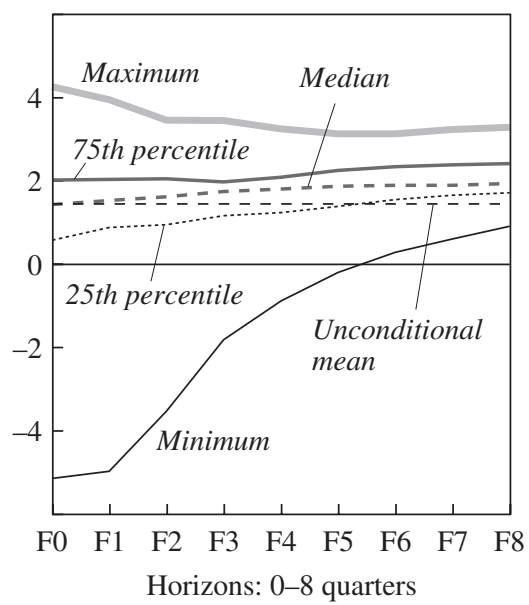

Sources: ECB data; ECB staff projections.

a. HICP $=$ Harmonised Index of Consumer Prices. F0-F8 refer to the 0-8 quarters-ahead forecast horizons, where the 0 quarter is the forecast for the current quarter. For each forecasted horizon, we show the minimum, maximum, 25th percentile, 75th percentile, median, and unconditional mean of forecasts over the sample period. The HICP inflation sample period is 1999:Q1-2018:Q1, and the real GDP growth sample period is 2000:Q1-2018:Q1.

only relatively small further changes into negative territory were feasible. Some of it can be reestablished with the help of "shadow interest rates" (the dashed line in figure 24), which we discuss in subsection II.C when we assess the ability of ECB nonstandard monetary policy measures to provide additional stimulus at the lower bound of interest rates.

Table 1 shows the results from estimating this rule. ${ }^{64}$ The estimated coefficients are somewhat smaller than, but not significantly different from, 0.5. The ECB's implicit inflation aim, which can be deduced from the estimated constant, is 1.81 percent. The $R^{2}$ is higher than 0.5 , which is

64. Other studies that have estimated policy reaction functions for the ECB include Gerdesmeier and Roffia (2003); Gorter, Jacbos, and de Haan (2008); Gerlach and Lewis (2014); and Paloviita and others (2017). Paloviita and others (2017) find support for monetary policy reaction functions with very-short-run (one quarter ahead) GDP growth projections; somewhat longer (one-year-ahead) inflation projections; and a proxy for the natural rate of interest. 
Figure 24. The Orphanides Rule for the Euro Area, with Forecasts Based on ECB/Eurosystem Staff Projections, 1999-2018

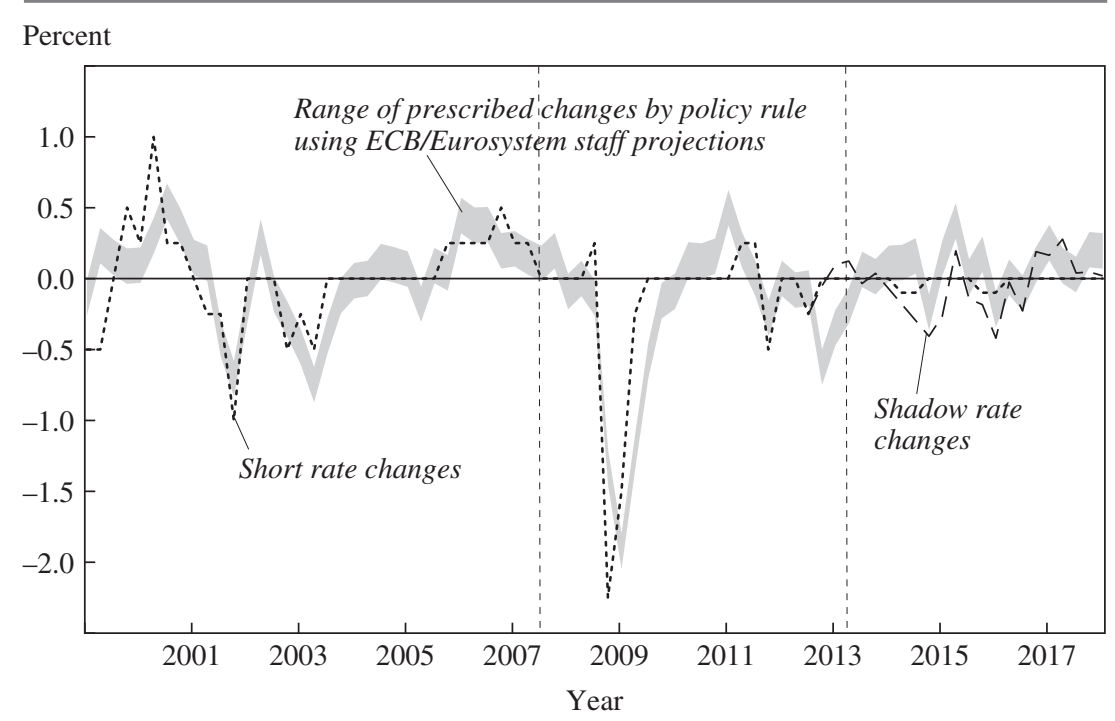

Sources: Authors' research; ECB data; ECB staff projections; European Commission. The shadow rates come from Krippner (2015), Kortela (2016), Lemke and Vladu (2017), and Wu and Xia (2017).

a. The short rate changes (the dotted line) combine the time series of the changes in the main refinancing operations rate up to 2008:Q3, with the time series of the changes in the deposit facility rate from 2008:Q4 onward. The shadow rate changes (the dashed line) are based on a shadow short-term interest rate, for which the zero lower bound is not binding and that therefore also captures the impact of unconventional monetary policy tools. It is calculated as the first principal component of the five shadow rates in figure 27 from 2012:Q3 (the time when the ECB's deposit facility rate reached zero) onward. Changes are end of quarter-on-quarter changes. The most recent observation is for 2018:Q1.

quite high, given that the variable we are trying to explain is expressed in first differences. Shortening the sample until the second quarter of 2012, when the ECB reached the zero lower bound on its deposit rate (see the second column of table 1), does not significantly change these results. In these regressions, we chose the horizon for year-on-year GDP growth to be $t+3$ quarters, reflecting the fact that at the time of the interest rate decisions in the last month of the quarter, the current quarter is not yet known, while the previous quarter is known, whereas for inflation we have $t+11$ months, reflecting the fact that inflation in the previous month is known. We tested for different forecasted horizons and found that for both GDP growth and inflation, the one-year-ahead projections are the most informative for policy decisions (the highest $R^{2}$ ).

Figure 25 shows the cumulated errors of both the calibrated and estimated rules. Using this set of benchmarks suggests that interest rate policy 


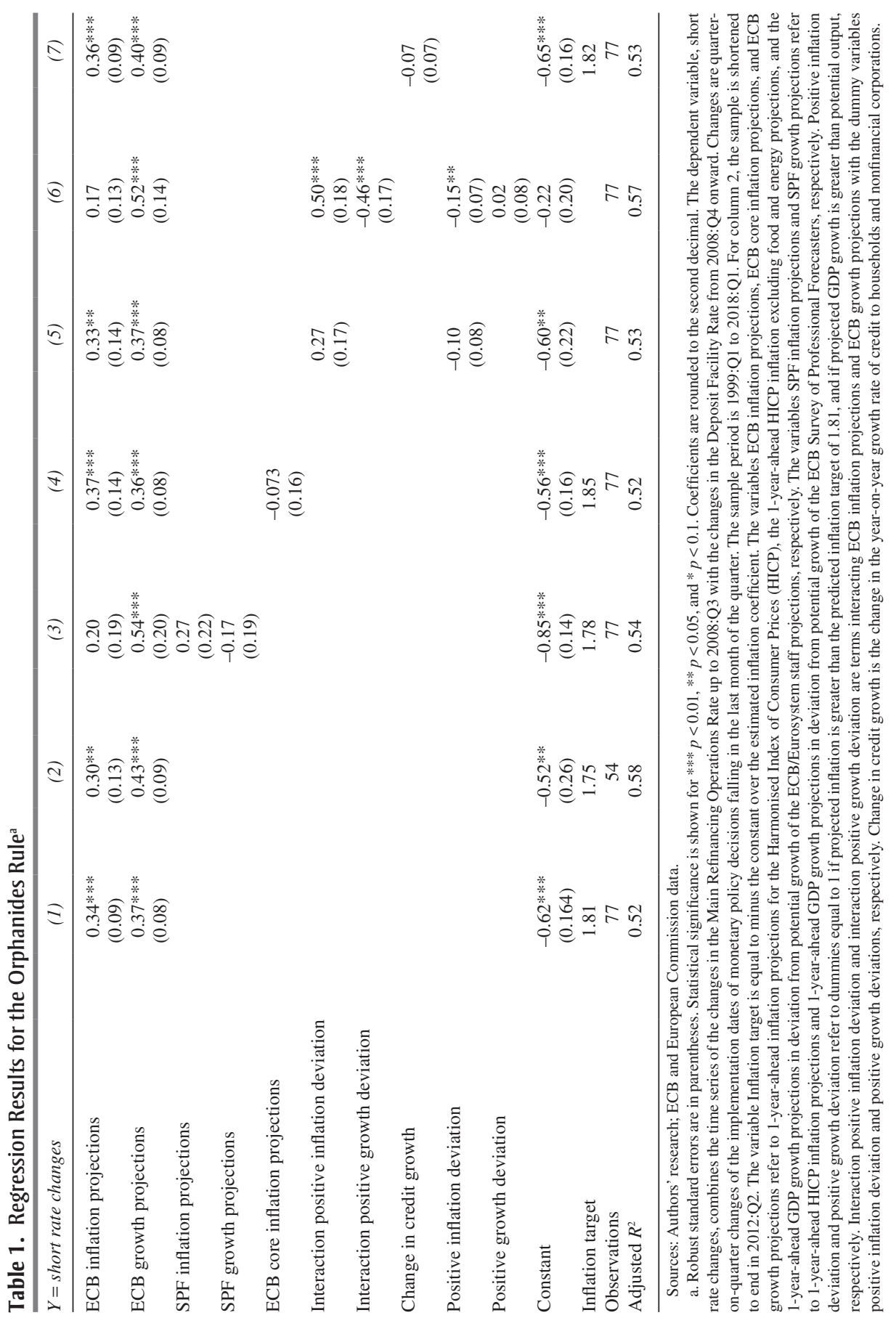


Figure 25. Cumulative Errors from the Orphanides Rule for the Euro Area, 1999-2018

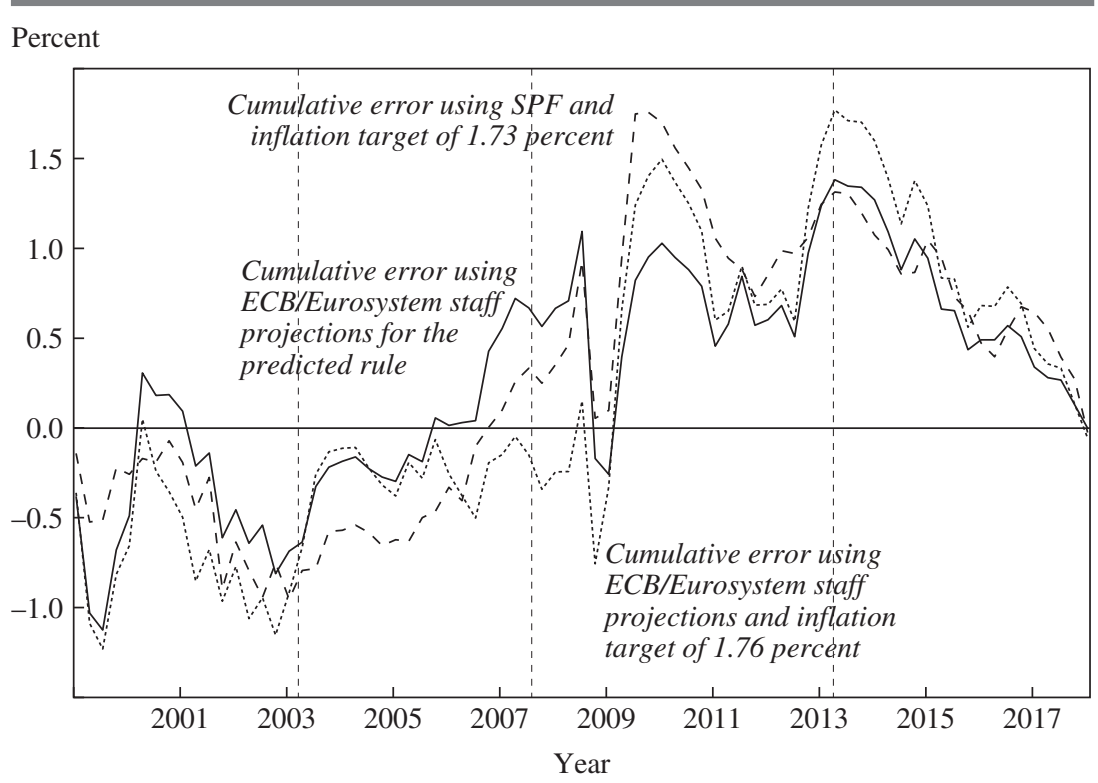

Sources: Authors' research; ECB data; ECB staff projections; ECB Survey of Professional Forecasters; European Commission data.

a. The cumulated error is calculated as the cumulated difference between the change in the short rate and the Orphanides rule, using the corresponding inflation targets-e.g., 1.73 percent, 1.76 percent, and 1.81 percent (for the predicted rule). The short rate combines the time series of the changes in the main refinancing operations rate up to 2008:Q3, with the time series of the changes in the deposit facility rate from 2008:Q4 onward. The most recent observation is for 2018:Q1.

may have been somewhat too loose in 2002 and too tight in 2009 and $2013 .{ }^{65}$ This finding is consistent with more elaborate thick-modeling exercises by ECB staff, which identify both 2009 and 2012-13 as periods in which the actual interest rate is above what a range of Taylor-type rules estimated before 2008 would have suggested. Of course, the latter periods are also when the ECB implemented a range of unconventional measures, as we discuss below. The interest rate increase in July 2008 does not appear to be justified by the ECB's own outlook for growth and inflation,

65. The finding of too-tight policy in 2009 is somewhat at odds with the findings of Giannone and others (2012) and Pill and Smets (2013), who show that by the end of 2009 and until 2012, the actual path of 3-month Euribor was below the counterfactual one based on the historical ECB monetary policy rule. Pill and Reichlin (2015) argue that the euro area experience contrasts with evidence from the United States, where the zero lower bound appears to have been a binding constraint on rate setting throughout the crisis period. 
but was quickly reversed. The interest rate increases in 2011 do not show up as a major policy mistake, but seem delayed as the inflation and growth projections suggested an earlier tightening move. Of course, this does not exclude the possibility that the ECB underestimated the impact of the financial and sovereign debt crises on economic activity and inflation; but similar results using SPF forecasts suggest that the ECB was not the only institution to do so. Finally, these benchmarks do not suggest that monetary policy was too loose during the time before the crisis, as suggested by Taylor (2007) for the United States.

In table 1, we also test a number of alternative specifications. First, the third column shows that the ECB/Eurosystem staff projections outperform the SPF forecasts in explaining the ECB's interest rate decisions. This is not surprising, given that the SPF forecasts are collected one to two months earlier than the ECB/Eurosystem staff projections and therefore do not incorporate the latest data available at the time of the interest rate decisions. Second, we test whether the projections for HICP inflation excluding food and energy add value in explaining the interest rate decisions (the fourth column). The estimated coefficient on the projection for core inflation is negative, but insignificant. This is consistent with empirical findings for the euro area that headline inflation leads core inflation and not the other way around and with the descriptive analysis in section I, which points to the fact that on a number of occasions the ECB was worried about second-round effects of changes in headline inflation driven by rising oil prices on wages and underlying inflation. This was, for example, the case for the interest rate increases in 2008 and 2011.

Next, we test whether the ECB responded more aggressively to positive deviations of projected inflation from its inflation aim than to negative deviations. The fifth column of table 1 shows that the relevant coefficient is not significantly different from zero. However, when we interact both inflation and output terms with a dummy when positive, we get the interesting finding that the coefficient is large, positive, and significant when inflation is above target, but otherwise is insignificant. However, we get the opposite finding for growth: It is large and significant when growth is below potential and insignificant when growth is above potential. Thus, over the sample period, the ECB seems to ease policy mainly in response to expected growth slowdowns and tighten policy mainly in response to expected inflation above its inflation aim.

Finally, we also tested whether indicators coming from the ECB's monetary analysis have additional explanatory information value for its interest rate decisions. Fischer and others (2008) and Smets (2010) do not 
find additional explanatory power coming from monetary analysis. This is consistent with the idea of monetary analysis being a cross-check. It is also consistent with the argument by Orphanides (2006) that the simple policy rule can also be derived from the combination of the quantity theory of money and a money demand function, and therefore already embeds an implicit role for money. The last column of table 1 includes changes in annual credit growth as an additional explanatory variable in the interest rate rule. The related coefficient is not significant and, if anything, is negative. Similar results are obtained with M3 growth or other money and credit growth indicators. Of course, this does not exclude the usefulness of monetary analysis as a cross-checking device (Beck and Wieland 2008, 2010).

\section{II.C. Reviewing the ECB's Nonstandard Monetary Policy Measures}

Understanding the working of and assessing nonstandard monetary policy are the subjects of an evolving literature. In this subsection, we first offer a conceptual framework for how to think about nonstandard policies from an ECB perspective. Subsequently, we review the literature about the success with which the ECB has used these policies to repair the monetary transmission mechanism (the complement of standard interest rate policy) and about the effectiveness with which the ECB has provided additional monetary stimuli with these measures (substitute for standard rate policy).

CLASSIFYING THE ECB'S NONSTANDARD POLICY MEASURES Figure 26 gives an overview of the nonstandard monetary policy measures the ECB has taken since 2007, reflecting the different crisis phases in the columns. ${ }^{66}$ These measures can be divided into four categories, as shown in the four rows of the figure: (1) credit operations with the ECB's counterparties, that is, euro area monetary and financial institutions; (2) outright asset purchases of both private and public sector securities; (3) negative interest rates; and (4) forward guidance, that is, enhanced communication about future policy actions. ${ }^{67}$

66. Most of these measures were using or amending the Eurosystem's operational framework. For detailed and comprehensive descriptions of this framework and the ECB's monetary policy instruments since the start of the financial crisis, see Eser and others (2012); Alvarez and others (2017); Task Force on the Use of Monetary Policy Instruments (2018); and Bindseil and others (2017).

67. The extent to which these measures can be classified as nonstandard is of course debatable. For example, in the early period of the financial crisis, the ECB primarily adjusted the conditions and features of its credit operations, which are standard instruments of the ECB's monetary policy operational framework. Similarly, negative interest rates and forward guidance can be seen as variants of the standard setting of policy-controlled interest rates and their communication. 


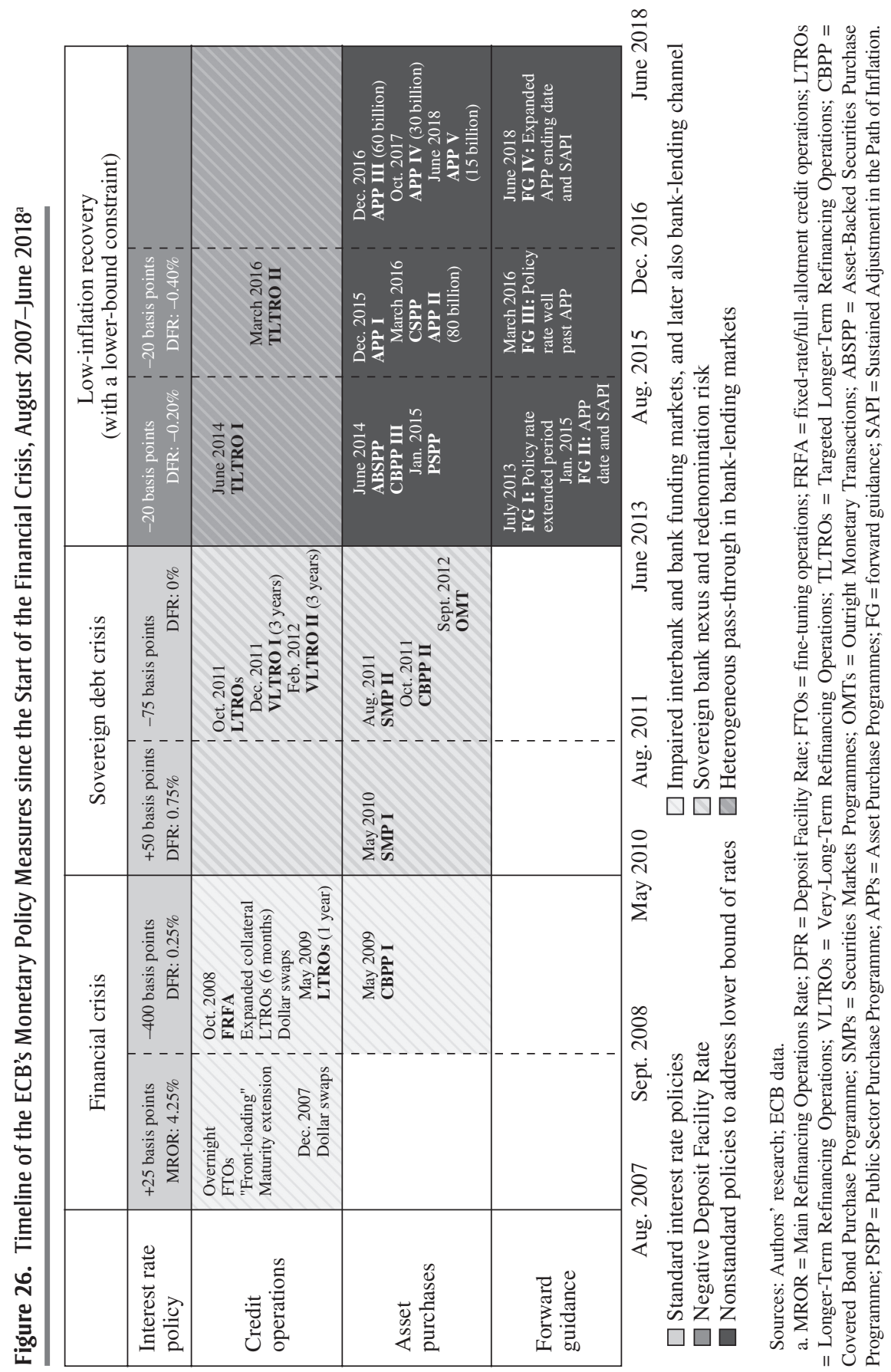


Broadly speaking, the use of the nonstandard measures served two purposes. First, some of the measures complemented standard reductions in policy-controlled interest rates in the presence of impairments in monetary policy transmission. In a financial crisis, it may be optimal to address the rise in funding and financing costs arising from malfunctioning financial markets through direct market interventions such as asset purchases or through lending operations, rather than try to offset them through a reduction in policy-controlled interest rates. Second, other measures were substitutes for standard policy: They provided additional stimulus in the presence of limited room for further standard interest rate easing close to the zero lower bound.$^{68}$ The two purposes are marked with graphical patterns in the different cells of figure 26. Measures complementing standard policy are indicated with stripes, where the different shades of gray (and the thickness of stripes) indicate the different types of impairments in the monetary transmission mechanism addressed. Standard interest policy (the light gray cells) and its various substitutes for providing an additional stimulus (the negative policy rates in medium gray, and asset purchases and forward guidance in black) are indicated with gray/black shades without stripes.

A number of observations are worth making regarding these two purposes. First, in the early stages of the financial crisis, when short-term interest rates were not yet constrained by the zero lower bound, the ECB in its communication made a clear distinction-through the so-called separation principle—-between standard policy, which was geared at maintaining price stability, and nonstandard measures that were focused on addressing malfunctioning financial markets and impairments in policy transmission. In practice, the two policies of course interact and together determine the monetary policy stance; but arguably, highlighting this distinction allowed the ECB to more easily take different directions in its standard and nonstandard monetary policy. This was, for example, the case in 2008 and 2011, when the ECB tightened standard monetary policy while nonstandard measures were still in place. One signal of the separation principle during the sovereign debt crisis was the decision to sterilize the SMP and potential OMT interventions. ${ }^{69}$

Second, the nature of the nonstandard measures depends on which impairments are being addressed. As discussed in section I and shown in figure 26, three stages can be distinguished. In the early stages of

68. For a discussion of the motivations, effectiveness, and risks of the ECB's nonstandard measures, also see Neri and Siviero (2019).

69. The ECB conducted regular one-week FTOs between May 2010 and June 2014 to absorb the liquidity effect of the SMP initiated on May 10, 2010. 
the financial crisis, the focus was primarily on banks' funding markets, in particular the money market and the covered bond market, but later also on bank lending (the striped cells in light gray). In the second stage, the financial crisis turned into a sovereign debt crisis with repercussions for bank funding markets (the so-called sovereign-bank nexus) and the emergence of self-fulfilling redenomination risk (the striped cells in medium gray). The last stage focused on the heterogeneous transmission in bank lending markets and involved funding for lending operations (TLTROs; the striped cells in dark gray). An evaluation of these differentnonstandard measures therefore involves an assessment of whether the specific impairments were addressed.

Third, the nonstandard measures geared at addressing impairments in the monetary transmission process are akin to classical lender-of-last-resort policies, whereby the central bank steps in to provide liquidity and avoid having market runs and self-fulfilling speculative attacks turn into solvency issues. One issue with these policies is that it is often not easy to distinguish between liquidity and solvency problems. In lending operations to multinational financial institutions, this is solved by requiring collateral, which are often government bonds. However, in a monetary union with national fiscal policies, sovereign risks may undermine the safety of such collateral and may make direct interventions in sovereign bond markets more problematic. This explains why nonstandard measures to address illiquidity and self-fulfilling redenomination risks in sovereign bond markets (SMP and OMT) required conditionality to ensure the soundness and sustainability of the underlying fiscal policies.

Finally, from figure 26, it is also clear that over time, as the euro area economy fell in a double-dip recession, more of the measures-in particular, the negative DFR, the large-scale APP, and enhanced forward guidance-served the second purpose of easing policy close to the zero lower bound. In line with this distinction, we next review the evidence on the effectiveness of nonstandard measures.

ADDRESSING IMPAIRMENTS IN THE MONETARY POLICY TRANSMISSION PROCESS During the early stages after the start of the financial crisis, nonstandard measures mostly focused on bank funding markets. Due to the fixed-rate/ full-allotment procedure, liquidity provision was primarily demanddetermined during that period. The Enhanced Credit Support (the right column with the striped cells in light gray in figure 26) program helped ease tensions in the money market, as indicated by the reduction in the Euribor-OIS spreads at various maturities (figure 13). Lucrezia Reichlin $(2014,388)$ and Huw Pill and Reichlin (2015) describe this period as the 
ECB taking a "market operation approach" to its role as lender of last resort (see also Garcia-de-Andoain and others 2016), and conclude that it contributed to the recovery of economic activity, which started in 2009:Q3. Michele Lenza, Pill, and Reichlin (2010); Domenico Giannone and others (2012); Gert Peersman (2011); and Seth Carpenter, Selva Demiralp, and Jens Eisenschmidt (2013) use a variety of counterfactual exercises to conclude that in this period, the effectiveness of the ECB's actions was not constrained by the zero lower bound and that these measures were supportive of economic activity, largely by preventing a more discontinuous and dramatic curtailment of credit provision to the real economy. See also Jef Boeckx, Maarten Dossche, and Peersman (2017). A model-based analysis is done by Christophe Cahn, Julien Matheron, and Jean-Guillaume Sahuc (2017). Using an estimated dynamic stochastic general equilibrium model with a frictional banking sector, they find that liquidity injections have played a key role in averting a major credit crunch. A counterfactual analysis suggests that during 2009, absent these nonstandard measures, output, consumption, investment, and the GDP deflator on average would, respectively, have been 2.5 percent, 0.5 percent, 9.7 percent, and 0.5 percent lower. For a similar analysis, also see the work of Dominic Quint and Oreste Tristani (2018).

Part of the Enhanced Credit Support policy was the first Covered Bond Purchases Programme (CBPP1). Purchases of $€ 60$ billion were made from July 2009 through June 2010, distributed across the euro area in both primary and secondary markets. John Beirne and others (2011) discuss the modalities and the impact of the CBPP1 and find that it has contributed to (1) a decline in money market term rates, (2) an easing of funding conditions for credit institutions and enterprises, (3) encouraging credit institutions to maintain and expand their lending to clients, and (4) improving market liquidity. Second and third installments of the CBPP were decided on, respectively, in October 2011, in the context of the intensification of the sovereign debt crisis, which again affected the bank's funding conditions; and in September 2014, as part of the comprehensive easing package to fight risks of deflation starting in June 2014.

The SMP was introduced to address malfunctioning sovereign bond markets after the start of the sovereign debt crisis, in particular in Greece, Portugal, and Ireland, which suffered from illiquidity and which were deemed to threaten monetary policy transmission. Interventions faded out in the relatively stable first half of 2011; but as the sovereign debt crisis negatively affected Italy and Spain in July 2011, a reactivation of the SMP was announced on August 7, 2011. The SMP ran until the end 
of December 2012 and reached an outstanding nominal amount of about $€ 218$ billion, although the volumes were not announced ex ante.

Various authors have assessed the impact of the SMP on sovereign bond yields. The SMP interventions succeeded in reducing yields and volatility of government bond segments of the countries under the program. Using a counterfactual exercise, Eric Ghysels and others (2017) find that purchases of Italian and Spanish bonds lowered two-year yields by 320 and 180 basis points, respectively, and 10-year yields by 230 basis points for both countries. Similarly, Fabian Eser and Bernd Schwaab (2016) find a significant impact of the SMP on the yields of those securities that were purchased. Their baseline model suggests that, on average, a daily SMP intervention of $€ 100$ million lowered yields by 0.1 to 2.0 basis points. This impact is stronger in markets that are smaller and less liquid, and where risk premiums are higher. (Also see Trebesch and Zettelmeyer 2018; and De Pooter, Martin, and Pruitt 2018.)

Nevertheless, the SMP was not able to stem the rising redenomination risk. Pill and Reichlin (2015) point to three reasons why the SMP did not succeed in stemming the rise in sovereign spreads. First, the SMP actions were characterized as limited and temporary, which undermined market confidence that the ECB was prepared to offer a full backstop. Second, the ECB had conditioned its provision to Italy and Spain on certain policy commitments that threatened the political feasibility of the support. Third, there were concerns about the subordination of private sector bond holders.

As discussed in subsection I.C, bolder ECB action became possible after European governments had started to strengthen fiscal governance, provided a backstop for governments in the form of the ESM, and decided to create a banking union with common supervision and resolution. After the famous "whatever it takes" speech of President Draghi in July 2012, the ECB announced its readiness to undertake ex-ante unlimited OMTs in euro area secondary sovereign bond markets, subject to countries complying with conditionality. ${ }^{70}$ Although, so far, OMTs have not been activated, the announcement was instrumental in addressing excessive risk premiums and improving financial market confidence, as shown in figure 13 above. The success of the OMT was dependent on a number of features: a strict and effective conditionality attached to an appropriate EFSF/ESM program, a focus on the shorter segment of the yield curve, no ex-ante quantitative limits on size, and pari-passu treatment. The conditionality was key 
for preserving the appropriate incentives for fiscal discipline and monetary dominance as well as to ensure proper risk management by the central bank. Using high-frequency data, Carlo Altavilla, Domenico Giannone, and Michele Lenza (2016) find that OMT announcements decreased the Italian and Spanish two-year government bond yields by about 2 percentage points, while leaving the bond yields in Germany and France unchanged. Using a multicountry vector autoregression model, they also find that the reduction in bond yields due to the OMT was associated with a significant increase in real activity, credit, and prices in Italy and Spain, with some positive spillovers in France and Germany. (For additional evidence on the financial market effects, see the papers by Krishnamurthy, Nagel, and Vissing-Jorgensen 2018; Szczerbowicz 2015; and De Santis 2016, 2018, forthcoming.) Philippe Aghion, Emmanuel Farhi, and Enisse Kharroubi (2017) find that growth effects worked particularly through highly indebted corporate sectors, notably via more easily adjustable short-term debt, but only if they were located in countries with relatively less regulated product markets. This bolsters the view that demand policies are more effective when accompanied by adequate supply policies. Using evidence from the ECB's Survey on the Access to Finance of Enterprises, Annalisa Ferrando, Alexander Popov, and Gregory Udell (2015) find that the ECB's OMT announcement was followed by an immediate decline in the share of credit-rationed firms and of firms discouraged from applying for loans. Firms with an improved outlook and credit history were particularly likely to benefit from easier credit access. Viral Acharya and others $(2017,2)$ also find positive effects of the revaluation of sovereign bond portfolios due to OMT on bank lending. They argue though that a significant fraction of this lending went to "zombie firms."

As part of the attempt to stop the doom loop, the ECB (2011c) also conducted two three-year VLTROs in December 2011 and February 2012. A combined gross amount of more than $€ 1$ trillion was allotted (see the vertically dashed area of figure 16), giving banks funding certainty, easing redemption of maturing bonds, and helping to sustain credit lines with households and firms. Matthieu Darracq-Paries and Roberto De Santis (2015) show that VLTROs increased real output and lending to NFCs over a two- to three-year horizon. ${ }^{71}$ Martina Jasova, Caterina Mendicino, and Dominik Supera (2018) use microeconomic bank-firm level data for Portugal to show that the lengthening of bank debt maturity with the ECB

71. For evidence on Spain, see Garcia-Posada and Marchetti (2016); and Szczerbowicz (2015). 
(reduction of rollover risk) had a positive and economically sizable impact on bank lending. Banks with a 1-standard-deviation-greater ability to draw on the VLTROs (for example, due to more available collateral) increased both existing and new lending by 5.3 percent. The effects are stronger on the supply of credit to smaller, younger, and riskier firms. However, they also show that unrestricted liquidity provision incentivized banks to purchase more government securities, partly offsetting the positive effects on lending. Matteo Crosignani, Miguel Faria-e-Castro, and Luis Fonseca (2018) find that VLTROs induced Portuguese banks to purchase short-term domestic government bonds and pledge them to obtain central bank liquidity. ${ }^{72}$

Turning to the funding for lending policies (see the striped cells in dark gray in figure 26), it is difficult to disentangle the effects of TLTROs from the other measures that were part of the comprehensive easing package that started in June 2014 and that also included negative rates and asset purchases. ${ }^{73}$ The ECB (2015b) shows that the rates on loans to NFCs declined markedly immediately after the announcement of the first series of TLTROs. The declines were sharper in countries where the composite lending rates to NFCs had been more elevated. Moreover, in vulnerable countries, banks that borrowed under TLTROs reduced their rates by more than banks that abstained from bidding. Altavilla, Fabio Canova, and Matteo Ciccarelli (2016) explicitly analyze developments over time in the pass-through of monetary policy measures on bank lending rates and find that, after 2014, nonstandard policy measures (including the TLTROs) significantly normalized the capacity of banks to grant loans and reduced the cross-sectional dispersion of interest rate pass-throughs.

PROVIDING ADDITIONAL STIMULUS AT THE EFFECTIVE LOWER BOUND As policycontrolled interest rates were increasingly constrained by the effective lower bound in 2013, the ECB took a number of additional nonstandard measures, such as the expanded APP and forward guidance, with the aim of further lowering medium- to long-term interest rates through portfolio rebalancing and signaling channels (see the black cells in figure 26). One way of capturing the impact of these unconventional measures is to calculate a shadow short-term interest rate, as proposed by Leo Krippner (2015). A shadow rate is the shortest maturity rate extracted from a term structure model that would generate the observed yield curve in the absence of a lower bound. It coincides with the policy rate in normal times, and is free to go into negative territory when the policy rate is stuck at the lower bound.

72. See also Acharya and Steffen (2015); and Van Bekkum, Gabarro, and Irani (2018).

73. The ECB (2017b) explains the features of the two TLTRO programs, as well as their impact on bank lending; also see ECB (2017c). 
Various researchers have shown that the shadow rate captures the stance of monetary policy during lower-bound periods in the same way the policy rate does in normal times (Claus, Claus, and Krippner 2016; Francis, Jackson, and Owyang 2017; Van Zandweghe 2015). They show (1) that the shadow rate captures the impact of both conventional and nonconventional policy measures, such as asset purchase programs, forward guidance on interest rates, and long-term refinancing operations; and (2) that the dynamic interactions between macroeconomic activity and the shortterm rate are preserved through the shadow rate. The latter is consistent with the results of David Debortoli, Jordi Galí, and Luca Gambetti (2018), who find that there has been no structural break in the macroeconomic relations since the use of nonstandard measures. These researchers conclude that nonconventional tools must have had a similar impact on the macroeconomy as conventional interest rate policy. Similarly, a number of vector autoregression exercises, where unconventional monetary policies are identified through the term structure changes during a narrow window around monetary policy decisions, have shown that quantitative easing has very similar effects on the economy. ${ }^{74}$ Finally, Jing Wu and Ji Zhang (2017) show that in a New Keynesian model for the United States, the negative shadow rates are a useful summary statistic to capture the impact of unconventional policies, especially quantitative easing and lending facilities.

At the same time, estimates of shadow rates are quite sensitive to differences in term structure models, and in particular to the assumptions made about where the effective lower bound on interest rates lies. This may particularly be an issue for the euro area, where the perceived effective lower bound has changed over time as interest rates have gone into negative territory. Figure 27 plots several shadow rate estimates for the euro area, together with the EONIA. It shows, generally speaking, that the shadow rates are close to the EONIA before 2012 and that nonstandard measures have had an easing impact on the yield curve since 2012. Although there is considerable co-movement, the levels of the shadow rates are however very diverse.

We therefore follow Mouabbi and Sahuc (2017) and use a common factor of five alternative shadow rate models for the euro area as a summary statistic for the stance of monetary policy in the euro area after the second quarter of 2012. The results of this exercise are also shown in figure 24, which compares changes in the shadow rate (the dashed line) with the outcome of the Orphanides rule (the dotted line) after the DFR reached

74. See Bundick and Smith (2016); Swanson (2017); and Inoue and Rossi (2018). 
Figure 27. Estimated Shadow Rates for the Euro Area and the ECB's Effective Policy Rate, 1999-2018

Percent

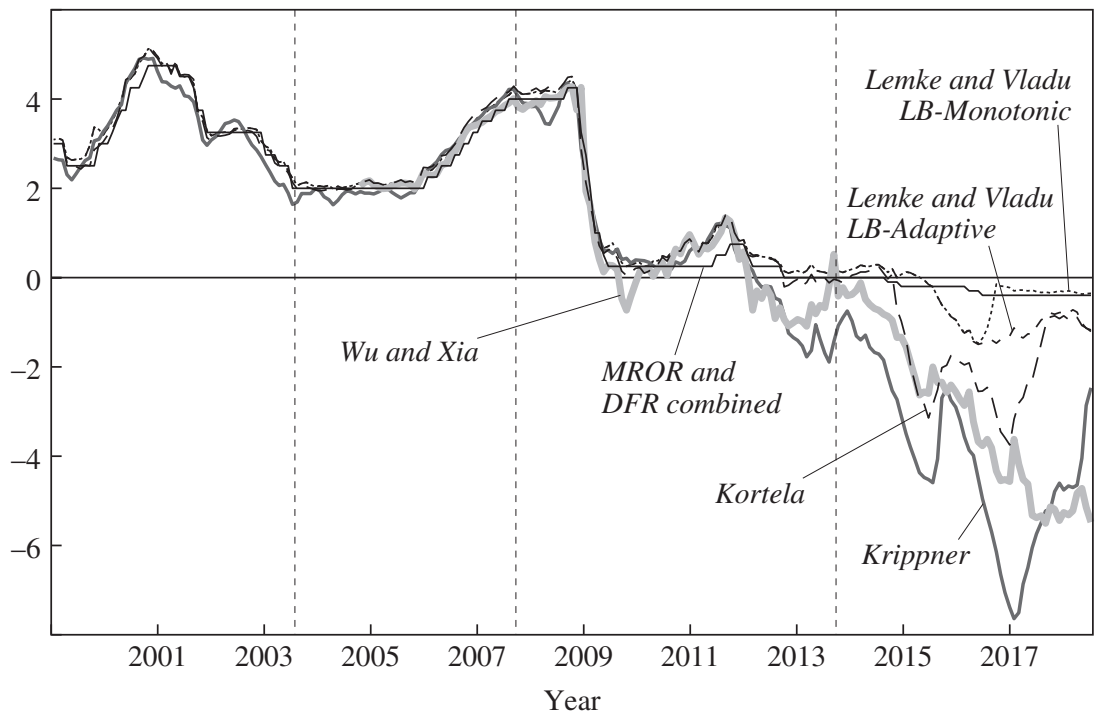

Sources: ECB data; Kortela (2016); Krippner (2015); Lemke and Vladu (2017); Wu and Xia (2017). a. MROR = Main Refinancing Operations Rate; DFR = Deposit Facility Rate. The shadow rate refers to a shadow short-term interest rate, for which the zero lower bound is not binding and that therefore also captures the impact of nonstandard monetary policy tools (see references in the sources). Lemke and Vladu LB-Adaptive and LB-Monotonic stand for two shadow rate versions based on different specifications of the lower bound. The version of LB-Adaptive sets the lower bound according to the minimum of forward rates observed at that point in time. LB-Monotonic also follows the same minimum rule, but the lower bound is never allowed to go up again. MROR and DFR combined refer to the effective policy rate, which is the main refinancing operations rate up to 2008:Q3 and the deposit facility rate from 2008:Q4 onward. The most recent observation is for March 2018.

0 percent in July 2012. As expected, the common component of estimated shadow rates tracks the range predicted by the policy rule for most times of this period better than the DFR. Broadly speaking, changes in the shadow rate capture the two periods that correspond to a slowdown in expected growth and inflation and the resulting intensification of nonstandard measures taken by the ECB, as discussed in subsection I.D and also reflected in figure 26 (three-pronged easing as of mid-2014 and its recalibration at the end of 2015 and in early 2016). In 2017, increases in the shadow rate reflect a relative tightening of monetary policy in line with the prescription of the rule (gray range). However, movements in the shadow rate in late 2012 and early 2013 do not capture the need for additional easing at that time. One issue here is that the powerful OMT announcement is not picked up well 
by the dashed line, as it happened quite close to the start of the calculation of the common component of the shadow rates. Further research seems to be needed in this area.

Mouabbi and Sahuc (2017) use the shadow rates to capture monetary policy after 2013 in an estimated dynamic stochastic general equilibrium model for the euro area, and they find that without the implemented nonstandard measures, year-on-year inflation and GDP growth would have been lower by 0.66 percent and 0.99 percent, respectively, over the period 2014:Q1-2017:Q2.

Overall, these estimates are in the same ballpark as estimates by the ECB that are based on a variety of methods (Draghi 2017; Praet 2017; Hutchinson and Smets 2017). ${ }^{75}$ ECB staff estimates indicate that the monetary policy contribution of the easing package since 2014 to euro area GDP has been about 1.8 percentage points, cumulatively over the period 2016-19 (see, for example, Hammermann and others 2019). About onethird of the 5-percentage-point increase in the employment rate observed in the euro area as a whole since mid-2014 is estimated to be due to the ECB's measures. This roughly corresponds to 2 to 3 million more jobs. Absent the ECB's policy package, inflation would on average be about 45 basis points lower than what is realized or currently projected for each year over the 2016-19 period.

The main transmission channel is through the easing of financial conditions and financing costs. Counterfactual simulations by ECB staff estimate that the 2014 policy package has had a considerable impact on euro area financing conditions. Figure 28 shows some of the results. For example, without the ECB's measures, the 10-year sovereign yield for a euro area GDP-weighted aggregate would be about 150 basis points higher and lending rates to euro area NFCs would be about 70 basis points higher. The ECB's measures have also had a sizable impact on the nominal euro effective exchange rate, which would have been about 13 percent higher without the measures (Altavilla, Carboni, and Motto 2015; Ambler and Rumler

75. The approaches can be categorized into two groups: a "direct" and an indirect, or "two-step," approach. In the direct approach, models tend to be fully specified structural models, such as dynamic stochastic general equilibrium models, which incorporate mechanisms to directly allow for asset purchases to affect economic activity and inflation. Typically, these models extend the workhorse New Keynesian model by including financial frictions so that central bank asset purchases have an impact on the economy. In the twostep approach, the first step involves estimating, off model, the impact of asset purchases on long-term yields and other financial prices. In the second step, this is fed into a macro model, which then estimates the impact on activity and inflation. 
Figure 28. Changes in Key Euro Area Financial Indicators since June 2014, and the Impact of the ECB's Policy Measures ${ }^{\mathrm{a}}$

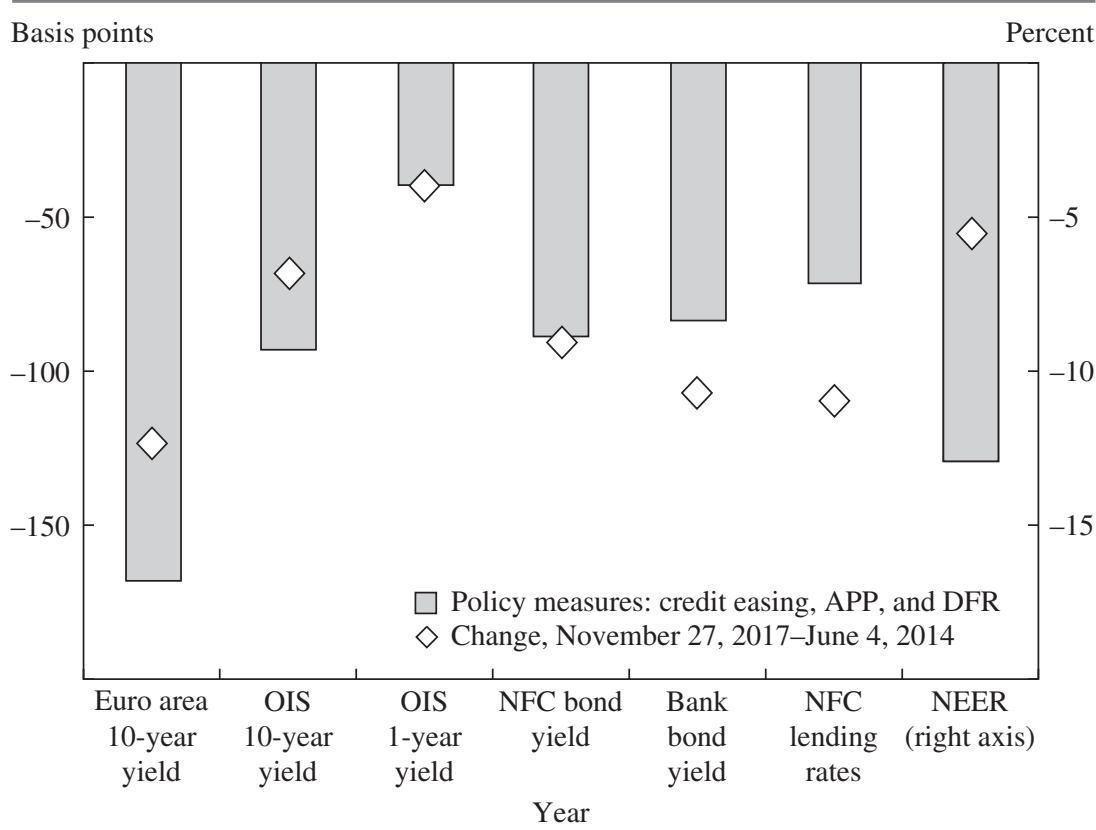

Sources: Bloomberg; ECB data; ECB staff calculations.

a. OIS = Euro Overnight Index Swap Rate; NFC = nonfinancial corporations; NEER = Nominal Effective Exchange Rate; APP = Asset Purchase Programme; DFR = Deposit Facility Rate. The impact of credit easing is estimated on the basis of an event-study methodology that focuses on the announcement effects of the June-September 2014 package; see ECB (2015b). The effects of the DFR cuts rest on the announcement effects of the September 2014 DFR cut. The APP encompasses the effects of measures taken in January 2015, December 2015, March 2016, December 2016, and October 2017. The January 2015 APP impact is estimated on the basis of two event-study exercises by considering a broad set of events that, starting in September 2014, have affected market expectations about the program; see Altavilla, Carboni, and Motto (2015) and De Santis (2016). The quantification of the impact of the December 2015 policy package on asset prices rests on a broad-based assessment comprising event studies and model-based counterfactual exercises. The impact of the March 2016 measures, the impact of the December 2016 measures, and the impact of the October 2017 measures are assessed via modelbased counterfactual exercises. Changes in lending rates are based on monthly data, the reference period for which is June 2014 to April 2017. The most recent observation is for November 27, 2017.

2017; De Santis 2016). There is also emerging evidence of the portfolio rebalancing effects of the APP (Paludkiewicz 2018).

To put all this in perspective, in figure 29 we compare estimates of GDP and inflation effects of central bank asset purchases from a selection of studies for the U.S. and U.K. with those for the euro area in a standardized format. Median ECB staff euro area estimates (the horizontal dashed lines) are based on a suite of models (encompassing both direct and two-step 
Figure 29. Comparison of the Effectiveness of Asset Purchases in the Euro Area, the United States, and the United Kingdoma
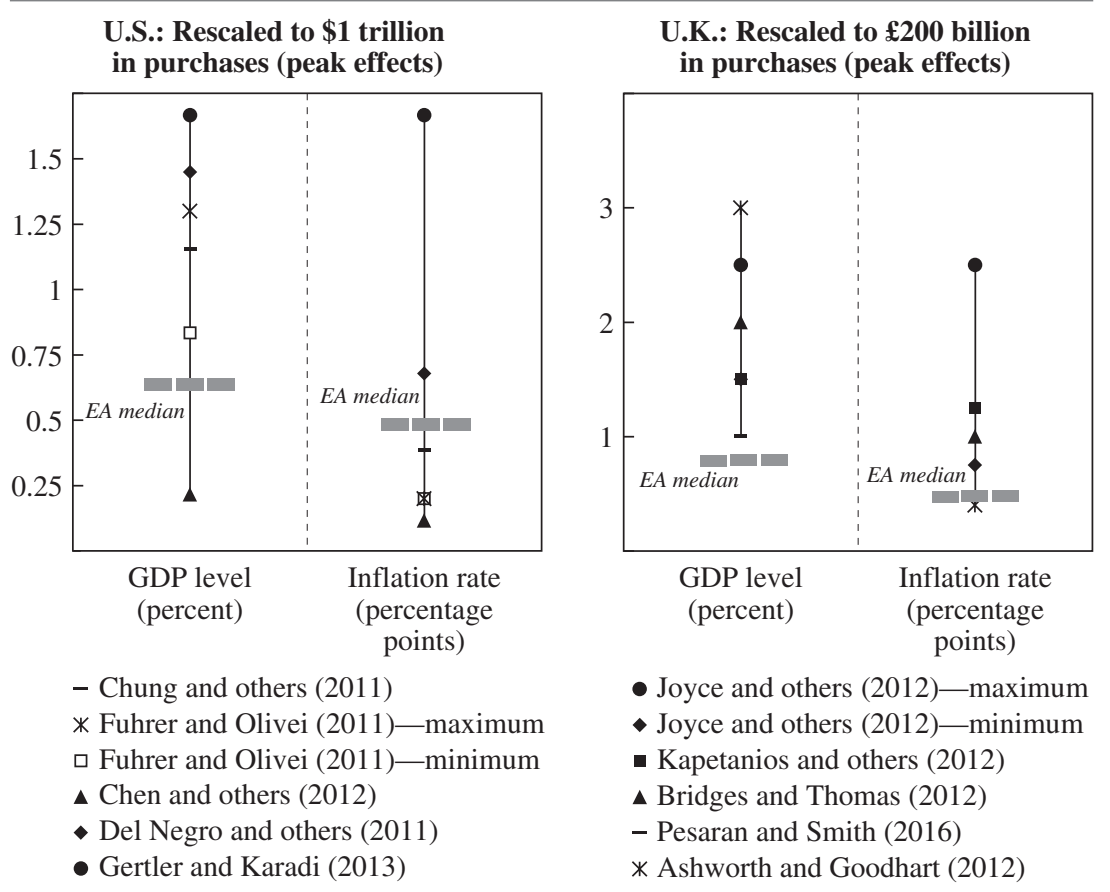

Sources: ECB calculations; Ashworth and Goodhart (2012); Bridges and Thomas (2012); Chen, Vasco-Cúrida, and Ferrero (2012); Chung and others (2011); Del Negro and others (2016); Fuhrer and Olivei (2011); Gertler and Karadi (2013); Joyce and others (2012); Kapetanios and others (2012); Pesaran and Smith (2016).

a. For the United States, the macroeconomic impact is scaled to $\$ 1$ trillion in asset purchases to allow for comparison across studies. Some of the studies provide the impact only for real GDP. The euro area median for GDP refers to the median of the cumulated impact over 2015, 2016, and 2017 of a range of models: vector autoregression; National Institute Global Econometric; Christiano, Motto, and Rostagno (2014); Darracq-Paries, Kok Sorensen, and Rodriguez-Palenzuela (2011); and dynamic stochastic general equilibrium. The euro area median for the inflation rate refers to the median of the peak impact of 2015-17 for the same models.

approaches). Though the euro area GDP estimates are in the lower midrange of the U.S. estimates, they are below the estimates for U.K. GDP and are in the lower part of the range for inflation. Also see the papers by Philippe Andrade and others (2016) and the ECB (2017b).

Finally, as part of the comprehensive easing program, the ECB also lowered the DFR into negative territory, a move that before the ECB only central banks of smaller jurisdictions had dared. Massimo Rostagno and others (2016) and Hartmann (2018) show that this shifted the yield curve down 
and twisted it (long rates coming down more), as one would expect from term-structure models allowing for negative rates (Lemke and Vladu 2017). In other words, the interest rate channel of monetary policy was extended. Moreover, contrary to the concerns of some skeptics, in the euro area case, it did not seem to hinder the bank-lending channel-quite the contrary. Florian Heider, Farzad Saidi, and Glenn Schepens (2018) find enhanced lending of banks with small retail depositor bases relative to banks with large retail deposits (which would suffer more from not being able to pass negative rates on liabilities on to households). Demiralp, Eisenschmidt, and Thomas Vlassopoulos (2019) find evidence that this also amounted to an aggregate lending effect. Eisenschmidt and Smets (2018) review the euro area's monetary policy experience with negative rates and the related literature further. They document the pass-through of negative policy rates on bank deposit and lending rates as well as on loan volumes in the euro area. They confirm that the zero-lower-bound constraint is binding for interest rates on household deposits held at banks. Nevertheless, the passthrough on loan rates is broadly unchanged in their analysis, even for banks with a high reliance on household deposit funding. The negative effect on the interest rate margin and profitability is generally offset by the positive impact of lower market rates on asset values and loan loss provisions (Altavilla and others 2019). Or, in other words, the "reversal rate" below which bank lending could be hurt does not seem to have been reached so far (Brunnermeier and Kobe 2018). At the same time, it needs to be acknowledged that the effects of negative policy rates cannot be perfectly disentangled from other nonstandard monetary policy measures active at the time. For example, in April 2014 and March 2016, TLTROs helped to reduce funding rates into negative territory for banks that exceeded certain lending targets (Rostagno and others 2016).

Overall, the research evidence on the effectiveness of the ECB's nonstandard measures in easing financial conditions, stimulating the economy, and bringing inflation back to the ECB's inflation aim is quite encouraging for the time period covered in this paper. It suggests that concerns that central banks may be powerless when interest rates hit the zero lower bound may be excessive (Swanson 2017).

\section{Conclusion}

In this paper, we have reviewed the ECB's monetary policy during its first 20 years of existence. Overall, the ECB has delivered on its price stability mandate, despite the very challenging crisis times of the last decade. 
Average inflation over this period has been 1.7 percent, which is in line with the ECB's aim of maintaining inflation below, but close to, 2 percent over the medium term. However, this average number masks quite stable inflation of about 2 percent before the start of the financial and sovereign debt crises and a much more volatile and, on average, lower inflation rate of about 1.5 percent thereafter. Throughout the whole 20 years, average five-year-ahead inflation expectations, as captured by the Survey of Professional Forecasters, have remained stable within a narrow range between 1.8 and 2.0 percent, underlining the ECB's credibility. But after the sovereign debt crisis, when headline inflation and various core inflation measures declined significantly below 1 percent, a series of indicators pointed to the emergence of tangible risks of deanchoring inflation expectations and even deflation risks. They only disappeared after the ECB initiated a comprehensive easing package starting in June 2014-including quantitative easing, targeted credit operations, and negative policy rates—and thereby dispelled doubts about whether it had an effective tool kit to address those risks in an environment of close-to-zero interest rates. Headline inflation is currently about 2 percent (August 2018); and underlying inflation, though still subdued, is slowly increasing toward values close to 2 percent.

One issue that has been debated regarding this price stability track record is whether the ECB could have been more proactive in responding to the fallout from the sovereign debt crisis from mid-2010 to mid-2012. A fair assessment requires a real-time and not an ex-post perspective. The simple real-time policy reaction function used in this paper arguably suggests that both the policy rate tightening in 2011 and the subsequent easing were broadly in line with the ECB's own and other professional forecasters' growth and inflation projections at the time. Moreover, this period was increasingly characterized by solvency issues in both banking and government finances, which lingered for too long and reinforced each other in the absence of sufficient institutions and tools for solving the related collective action problems in a highly integrated monetary union of sovereign states with primarily national fiscal and supervisory policies. The unresolved public and private balance sheet problems and the resulting financial fragmentation in the euro area imposed tremendous obstacles on the effectiveness of the ECB's monetary policy.

At the same time, monetary policy cannot directly address such solvency issues. In fact, the prohibition of monetary financing (Article 123 of the Treaty on the Functioning of the European Union) forbids the ECB from directly financing governments or government tasks such as the recapitalization of banks. Against this background, the ECB's actions had to 
balance the need to address impairments in the transmission of monetary policy due to malfunctioning financial markets and self-fulfilling market dynamics with the prohibition of monetary financing. This may explain, in part, what some observers regard as initially timid interventions in the government bond market through the SMP in 2010 and 2011. Leading up to the key June 2012 European Summit, necessary institutions and reforms to improve on the main weaknesses of EMU in the prudential and fiscal fields were put on a credible path. In this new context, the ECB stepped up its nonstandard tool kit to the next level, starting with President Draghi's "whatever it takes" speech and the powerful OMT program in the summer of 2012, as well as the comprehensive easing package (mentioned above) later on, in June 2014.

Overall, the main building blocks of the ECB's original monetary policy strategy and framework - its quantitative definition of price stability, the two pillars of economic and monetary analysis, the communication and accountability framework, and the broad-based and flexible operational framework-have served the ECB well during the past 20 years. However, as described in this paper, it was important that they evolved in response to challenges over time.

For example, as initial doubts by some observers about the ECB's antiinflation credibility during the early years turned into concerns about its ability to address downward risks to price stability in a low-interest-rate environment, the quantitative inflation aim was clarified as being close to 2 percent, providing a buffer against the zero lower bound. Our analysis of the ECB's interest rate reaction function in subsection II.B suggests that the ECB pursued this inflation aim symmetrically. Moreover, this analysis indicates that the ECB's economic analysis and its quarterly macroeconomic projections formed the main basis for its monthly monetary policy decisions. At the same time, its monetary analysis provided a crosscheck. It evolved from a narrower focus-with an emphasis on a reference value for M3 growth based on the quantity theory of money, which was useful in the first years to borrow the Deutsche Bundesbank's credibilityto a broad-based assessment of monetary developments and the state of financial intermediation and bank lending in the euro area economy. Before the crisis, this broad-based analysis was useful for considering the buildup of financial imbalances, though our interest-rate analysis does not show evidence that the ECB pursued a leaning-against-the-wind monetary policy approach. At the time, the ECB had neither a microprudential nor a macroprudential policy mandate and the related tools to address the financial imbalances at the source. Only with the advent of Banking 
Union did the ECB acquire an important banking supervisory role as of November 2014, which implied comprehensive microprudential and some limited macroprudential responsibilities. Following the start of the financial crisis, the broadened monetary analysis was increasingly helpful in assessing fragilities in the banking sector and how they influence bank lending and the monetary policy transmission mechanism, as well as the effectiveness of some of the nonstandard measures.

Moreover, the ECB's communication and accountability framework was adjusted, as the need for additional communication in a complex (nonstandard) policy environment arose and forward guidance became an essential tool for easing policy in a low-interest-rate context. Finally, the ECB's operational framework was well suited to provide ample liquidity to its wide range of counterparties and quickly against a wide set of collateral when the money market froze. This helped address impairments in the early steps of the monetary transmission mechanism and also contributed to financial stability. Moreover, when the zero lower bound became more and more a constraint after the sovereign debt crisis, the operational framework proved broad and flexible enough to allow the ECB to expand its tool set with other nonstandard policy measures. A review of the available research on the effectiveness of the ECB's nonstandard measures for easing financial conditions, stimulating the economy, and bringing inflation back to its inflation aim-also in comparison with the evidence from other constituencies having used similar instruments, such as the U.S. and the U.K.-is quite encouraging and suggests that concerns that central banks may be powerless when interest rates hit the zero lower bound may be excessive.

All in all, the ECB has adjusted its monetary policy to changing and challenging circumstances over time, making effective use of its strategy and framework and maintaining a clear focus on its primary mandate of price stability in the medium term. As it has broadened its tools over time, it has become more similar to many of its peers as well. At the same time, some elements of its policy framework seem to have inspired changes in other central banks' frameworks-including the medium-term orientation of its price-stability objective, the transparency and accountability associated with the press conferences conducted by its president and vice president soon after its formal monetary policy meetings, and its broad and flexible operational framework.

A series of important reforms after the crises-in particular, the establishment of the European Stability Mechanism; the implementation of the first two legs of the Banking Union, the Single Supervisory and Resolution 
Mechanisms; the signing of the Fiscal Compact; and the introduction of the European Semester, with the Macroeconomic Imbalance Procedurehave addressed some aspects of EMU's incompleteness that complicated the ECB's mission to maintain price stability over the past decade. In future years, the ECB's monetary policy will benefit tremendously from the thorough implementation of these reforms, compliance with their objectives and rules, and further progress toward completing European Economic and Monetary Union along the lines of the 2015 Five Presidents' Report (European Commission 2015).

ACKNOWLEDGMENTS Any views expressed are only the authors' own and should not be interpreted as views of the European Central Bank or the Eurosystem. The previous working paper version of this paper was circulated with the title "The First Twenty Years of the European Central Bank: Monetary Policy." We are beholden to numerous current and former ECB colleagues for comments—notably, Vítor Constâncio, Vítor Gaspar, Otmar Issing, and JeanPierre Vidal—and for generous help in compiling the information used for writing this paper. We give special thanks to Rupert de Vincent-Humphreys, Philipp Hochmuth, Christophe Kamps, Francesco Mongelli, Eric Persson, Benjamin Sahel, and David Sondermann. Also very helpful for improving the paper was the feedback that we received from participants in the Brookings Panel on Economic Activity, from the Hong Kong Monetary AuthorityFederal Reserve Bank of New York conference on "Monetary Policy and Heterogeneity," from the Federal Reserve Bank of Cleveland conference on "Inflation: Drivers and Dynamics," and from the Eurosystem monetary policy committee-as well as from lectures at the ECB, at the SAFE Institute at the University of Frankfurt, and at the European School of Management and Technology in Berlin, and from a roundtable at the Banque de France and Paris School of Economics. Alexandre Mendonça, Adrian Monninger, Lea Steininger, Desislava Tartova, Hannes Twieling, and Alexia Ventula Veghazy provided excellent research assistance. The remaining errors or omissions are our own. 


\section{References}

Acharya, Viral V., Itamar Drechsler, and Phillip Schnabl. 2014. "A Pyrrhic Victory? Bank Bailouts and Sovereign Credit Risk." Journal of Finance 69, no. 6: 2689-2739.

Acharya, Viral V., Tim Eisert, Christian W. Eufinger, and Christian Hirsch. 2017. "Whatever It Takes: The Real Effects of Unconventional Monetary Policy." Working Paper 152. Frankfurt: Sustainable Architecture for Finance in Europe. http://hdl.handle.net/10419/158505.

Acharya, Viral V., and Sascha Steffen. 2015. "The 'Greatest' Carry Trade Ever? Understanding Eurozone Bank Risks." Journal of Financial Economics 115, no. 2: 215-36.

Aghion, Philippe, Emmanuel Farhi, and Enisse Kharroubi. 2017. "On the Interaction between Monetary Policy, Corporate Balance Sheets and Structural Reforms." In Proceedings of the ECB Forum on Central Banking: Investment and Growth in Advanced Economies. Frankfurt: European Central Bank.

Aguiar, Alvaro and Manuel M. F. Martins. 2008. "Testing for Asymmetries in the Preferences of the Euro Area Policy-Maker." Applied Economics 40, no. 13: 1651-67.

Alesina, Alberto, Olivier Blanchard, Jordi Galí, Francesco Giavazzi, and Harald Uhlig. 2001. Defining a Macroeconomic Framework for the Euro Area: Monitoring the European Central Bank 3. London: Centre for Economic Policy Research.

Alessi, Lucia, Eric Ghysels, Luca Onorante, Richard Peach, and Simon Potter. 2014. "Central Bank Macroeconomic Forecasting during the Global Financial Crisis: The European Central Bank and Federal Reserve Bank of New York Experiences." Journal of Business \& Economic Statistics 32, no. 4: 483-500.

Altavilla, Carlo, Desislava Andreeva, Miguel Boucinha, and Sarah Holton. 2019. "Monetary Policy, Credit Institutions and the Bank Lending Channel in the Euro Area." ECB Occasional Paper 222. Frankfurt: European Central Bank.

Altavilla, Carlo, Fabio Canova, and Matteo Ciccarelli. 2016. "Mending the Broken Link: Heterogeneous Bank Lending and Monetary Policy PassThrough." Working Paper 1987. Frankfurt: European Central Bank. https:// www.ecb.europa.eu/pub/pdf/scpwps/ecbwp1978.en.pdf.

Altavilla, Carlo, Giacomo Carboni, and Roberto Motto. 2015. "Asset Purchase Programmes and Financial Markets: Lessons from the Euro Area." Working Paper 1864. Frankfurt: European Central Bank. https://www.ecb.europa.eu/pub/ pdf/scpwps/ecbwp1864.en.pdf.

Altavilla, Carlo, Domenico Giannone, and Michele Lenza. 2016. "The Financial and Macroeconomic Effects of OMT Announcements." International Journal of Central Banking 12, no. 3: 29-57.

Alvarez, Inmaculada, Fabio Casavecchia, Marino De Luca, Alexander Duering, Fabian Eser, Caspar Helmus, Christophe Hemous, Niko Herrala, Julija Jakovicka, Michelina Lo Russo, Filippo Pasqualone, Marc Rubens, Rita Soares, and 
Fabrizio Zennaro. 2017. "The Use of the Eurosystem's Monetary Policy Instruments and Operational Framework since 2012.” Occasional Paper 188. Frankfurt: European Central Bank. https://www.ecb.europa.eu/pub/pdf/scpops/ ecb.op188.en.pdf.

Alves, Nuno, Carlos Robalo Marques, and João Sousa. 2007. "Is the Euro Area M3 Abandoning Us?" Working Paper 20-2007. Lisbon: Banco de Portugal. https:// www.bportugal.pt/sites/default/files/anexos/papers/wp200720.pdf.

Ambler, Steve, and Fabio Rumler. 2017. "The Effectiveness of Unconventional Monetary Policy Announcements in the Euro Area: An Event and Econometric Study." Working Paper 212. Vienna: Oesterreichische Nationalbank. https://www.oenb.at/dam/jcr:774a56cf-aff2-4064-b0c3-4b3a55bae7c4/WorkingPaper-212.pdf.

Andrade, Philippe, Johannes Breckenfelder, Fiorella De Fiore, Peter Karadi, and Oreste Tristani. 2016. "The ECB's Asset Purchase Programme: An Early Assessment." Working Paper 1956. Frankfurt: European Central Bank. https:// www.ecb.europa.eu/pub/pdf/scpwps/ecbwp1956.en.pdf.

Angelini, Paolo, Andrea Nobili, and Cristina Piscillo. 2011. "The Interbank Market after August 2007: What Has Changed, and Why?" Journal of Money, Credit and Banking 43, no. 5: 923-58.

Artus, Patrick, Alan S. Blinder, Willem Buiter, Otmar Issing, and Robert M. Solow. 2008. "Round Table Discussion: Monetary Policy in the New International Environment." In Central Banks as Economic Institutions, edited by Jean-Philippe Touffut. Cheltenham, U.K.: Edward Elgar.

Ascari, Guido, Anna Florio, and Alessandro Gobbi. 2017. "Transparency, Expectations Anchoring and Inflation Targeting." European Economic Review 91: 261-73.

Ashworth, Jonathan P., and Charles A. E. Goodhart. 2012. "QE: A Successful Start May Be Running into Diminishing Returns." Oxford Review of Economic Policy 28, no. 4: 640-70.

Autrup, Søren Lejsgaard, and Magdalena Grothe. 2014. "Economic Surprises and Inflation Expectations: Has Anchoring of Expectations Survived the Crisis?" Working Paper 1671. Frankfurt: European Central Bank. https://www.ecb. europa.eu/pub/pdf/scpwps/ecbwp1671.pdf.

Ayuso, Juan, and Rafael Repullo. 2001. "Why Did the Banks Overbid? An Empirical Model of the Fixed Rate Tenders of the European Central Bank." Journal of International Money and Finance 20, no. 6: 857-70.

Baldwin, R., and F. Giavazzi. 2015. The Euro Zone Crisis: A Consensus View of the Causes and a Few Possible Solutions. VoxEU e-book. London: Centre for Economic Policy Research. https://voxeu.org/sites/default/files/file/reboot_ upload_0.pdf.

2016. How to Fix the Euro Zone: Views from Leading Economists. VoxEU e-book. London: Centre for Economic Policy Research.

Ball, Laurence. 2014. "The Case for a Long-Run Inflation Target of Four Percent." Working Paper 14/92. Washington: International Monetary Fund. 
Batini, Nicoletta, and Edward Nelson. 2001. "Optimal Horizons for Inflation Targeting." Journal of Economic Dynamics and Control 25, nos. 6-7: 891-910.

Bean, Charles. 2003. "Inflation Targeting: The U.K. Experience." Speech given at Annual Congress of German Economic Association, Zurich, October 1.

Beck, Guenter W., and Volker Wieland. 2008. "Central Bank Misperceptions and the Role of Money in Interest Rate Rules." Journal of Monetary Economics 55 (supplement): S1-S17.

- 2010. "Money in Monetary Policy Design: Monetary Cross-Checking in the New Keynesian Model.” Working Paper 1191. Frankfurt: European Central Bank.

Beechey, Meredith J., Benjamin K. Johannsen, and Andrew T. Levin. 2011. “Are Long-Run Inflation Expectations Anchored More Firmly in the Euro Area Than in the United States?" American Economic Journal: Macroeconomics 3, no. 2: 104-29.

Begg, David, Paul De Grauwe, Francesco Giavazzi, Harold Uhlig, and Charles Wyplosz. 1998. The ECB: Safe at Any Speed? London: Centre for Economic Policy Research. https://cepr.org/sites/default/files/geneva_reports/ GenevaP116.pdf.

Research.

Beirne, John, Lars Dalitz, Jacob Ejsing, Magdalena Grothe, Simone Manganelli, Fernando Monar, Benjamin Sahel, Matjaž Sušec, Jens Tapking, and Tana Vong. 2011. "The Impact of the Eurosystem's Covered Bond Purchase Programme on the Primary and Secondary Markets." Occasional Paper 122. Frankfurt: European Central Bank.

Benhabib, Jess, Stephanie Schmitt-Grohé, and Martín Uribe. 2001. "Monetary Policy and Multiple Equilibria." American Economic Review 91, no. 1: 167-86.

Bernanke, Ben S. 2002. "Deflation: Making Sure 'It' Doesn't Happen Here." Speech given at National Economists Club, Washington, November 21.

_. 2017. "Monetary Policy in a New Era." In Proceedings of the Rethinking Macroeconomic Policy Conference. Washington: Peterson Institute for International Economics.

Bernanke, Ben S., Thomas Laubach, F. Mishkin, and A. Posen. 1999. "Inflation Targeting for the United States and the European Monetary Union." In Inflation Targeting: Lessons from the International Experience. Princeton University Press.

Bernoth, Kerstin, and Jürgen von Hagen. 2004. "The Euribor Futures Market: Efficiency and the Impact of ECB Policy Announcements." International Finance 7, no. 1: 1-24.

Beyer, Andreas, and Lucrezia Reichlin, eds. 2006. Proceedings of the Fourth ECB Central Banking Conference: The Role of Money-Money and Monetary Policy in the Twenty-First Century. Frankfurt: European Central Bank. 
https://www.ecb.europa.eu/pub/pdf/other/roleofmoneyen2008en.pdf?646922 df8deac54767d75918036d8dfd.

Bindseil, Ulrich. 2005. "Over- and Underbidding in Central Bank Open Market Operations Conducted as Fixed-Rate Tender." German Economic Review 6, no. 1: 95-130.

Bindseil, Ulrich, Marco Corsi, Benjamin Sahel, and Ad Visser. 2017. "The Eurosystem Collateral Framework Explained." Occasional Paper 189. Frankfurt: European Central Bank. https://www.ecb.europa.eu/pub/pdf/scpops/ecb.op189. en.pdf.

Blanchard, Olivier, and Francesco Giavazzi. 2002. "Current Account Deficits in the Euro Area: The End of the Feldstein-Horioka Puzzle?" Brookings Papers on Economic Activity 2: 147-210. https://www.brookings.edu/wp-content/ uploads/2002/06/2002b_bpea_blanchard.pdf.

Blanchard, Olivier, Giovanni Dell' Ariccia, and Paolo Mauro. 2010. "Rethinking Macro Policy." VoxEU.org, February 16. https://voxeu.org/article/rethinkingmacro-policy.

Blattner, Tobias, Marco Catenaro, Michael Ehrmann, Rolf Strauch, and Jarkko Turunen. 2008. "The Predictability of Monetary Policy." Occasional Paper 83. Frankfurt: European Central Bank. https://www.ecb.europa.eu/pub/pdf/scpops/ ecbocp83.pdf.

Blei, M. David, Andrew Y. Ng, and Michael I. Jordan. 2003. "Latent Dirichlet Allocation.” Journal of Machine Learning Research 3: 993-1022.

Bletzinger Tilman, and Volker Wieland. 2016. "Forward Guidance and 'Lower for Longer': The Case of the ECB." Working Paper 102. Frankfurt: Institute for Monetary and Financial Stability. http://publikationen.ub.uni-frankfurt.de/ frontdoor/index/index/year/2016/docId/39578.

Boeckx, Jef, Maarten Dossche, and Gert Peersman. 2017. "Effectiveness and Transmission of the ECB's Balance Sheet Policies." International Journal of Central Banking 13, no. 1: 297-333.

Borio, Claudio, and Philip Lowe. 2002. "Asset Prices, Financial and Monetary Stability: Exploring the Nexus." BIS Working Paper 114. Basel: Bank for International Settlements.

Bridges, Jonathan, and Ryland Thomas. 2012. "The Impact of QE on the UK Economy: Some Supportive Monetarist Arithmetic." Working Paper 442. London: Bank of England. https://www.bankofengland.co.uk/working-paper/2012/ the-impact-of-qe-on-the-uk-economy-some-supportive-monetarist-arithmetic.

Bruggeman, Annick, Paola Donati, and Anders Warne. 2003. "Is the Demand for Euro Area M3 Stable?" Working Paper 255. Frankfurt: European Central Bank. https://www.ecb.europa.eu/pub/pdf/scpwps/ecbwp006.pdf?14e04cc5febe81364 8551a4836f7ead1.

Brunnermeier, Markus, and Yann Koby. 2018. "The Reversal Interest Rate." Working paper. https://scholar.princeton.edu/sites/default/files/markus/files/ 20p_reversalrate.pdf. 
Buiter, Willem. 1999. "Alice in Euroland.” Journal of Common Market Studies 37, no. 2: 181-210.

Bundick, Brent, and A. Lee Smith. 2016. "The Dynamic Effects of Forward Guidance Shocks." Research Working Paper 16-02. Kansas City: Federal Reserve Bank of Kansas City. https://www.kansascityfed.org/ /media/files/publicat/ reswkpap/pdf/rwp16-02.pdf?la=en.

Buti, M., S. Deroose, V. Gaspar, and J. Nogueira Martins, eds. 2010. The Euro: The First Decade. Cambridge University Press.

Cahn, Christophe, Julien Matheron, and Jean-Guillaume Sahuc. 2017. "Assessing the Macroeconomic Effects of LTROs during the Great Recession." Journal of Money, Credit and Banking 49, no. 7: 1443-82.

Camba-Méndez, Gonzalo, and Francesco Mongelli. 2017. "Policy Responses in Europe since the Onset of the Crisis (2007-Mid 2017)." Paper, ECB, October 26. https://www.researchgate.net/publication/321637875_Policy_Responses_in_ Europe_Since_the_Onset_of_the_Crisis_2007-Mid_2017.

Camba-Méndez, Gonzalo, and Thomas Werner. 2017. "The Inflation Risk Premium in the Post-Lehman Period." Working Paper 2033. Frankfurt: European Central Bank. https://www.ecb.europa.eu/pub/pdf/scpwps/ ecbwp2033.en.pdf.

Cao, Juan, Tian Xia, Jintao Li, Yongdong Zhang, and Sheng Tang. 2009. "A Density-Based Method for Adaptive LDA Model Selection." Neurocomputing 72, nos. 7-9: 1775-81.

Carpenter, Seth, Selva Demiralp, and Jens Eisenschmidt. 2013. “The Effectiveness of the Non-Standard Policy Measures during the Financial Crises: The Experiences of the Federal Reserve and the European Central Bank." Working Paper 1562. Frankfurt: European Central Bank. https://www.ecb.europa.eu/pub/pdf/ scpwps/ecbwp1562.pdf.

Cassola, Nuno, Mathias Drehmann, Philipp Hartmann, Marco Lo Duca, and Martin Scheicher. 2008. "A Research Perspective on the Propagation of the Credit Market Turmoil." Research Bulletin 7. Frankfurt: European Central Bank. https://www.ecb.europa.eu/pub/pdf/other/researchbulletin07en.pdf.

Cassola, Nuno, Alain Durré, and Cornelia Holthausen. 2011. "Implementing Monetary Policy in Crisis Times: The Case of the ECB." In Proceedings of the Sixth ECB Central Banking Conference: Approaches to Monetary Policy RevisitedLessons from the Crisis, edited by M. Jarocinski, F. Smets, and C. Thimann. Frankfurt: European Central Bank.

CEBS (Committee of European Banking Supervisors). 2009. "CEBS's Press Release on the Results of the EU-wide Stress Testing Exercise." London, October 1. https://eba.europa.eu/documents/10180/15977/CEBS-2009-180Annex-2-\%28Press-release-from-CEBS\%29.pdf.

. 2010. "Aggregate Outcome of the 2010 EU-wide Stress Test Exercise Coordinated by CEBS in Cooperation with the ECB." London, July 23. https:// eba.europa.eu/documents/10180/15938/Summaryreport.pdf/95030af2-7b524530-afe1-f067a895d163. 
Chen, Han, Vasco Cúrida, and Andrea Ferrero. 2012. "The Macroeconomic Effects of Large-Scale Asset Purchase Programmes." Economic Journal 122: F289-F315.

Christiano, Lawrence J., Roberto Motto, and Massimo Rostagno. 2014. "Risk Shocks." American Economic Review 104, no. 1: 27-65.

Chung, Hess, Jean-Phillippe Laforte, David Reifschneider, and John C. Williams. 2011. "Estimating the Macroeconomic Effects of the Fed's Asset Purchases." Economic Letter 2011-03. San Francisco: Federal Reserve Bank of San Francisco. https://www.frbsf.org/economic-research/files/el2011-03.pdf.

Ciccarelli, Matteo, and Chiara Osbat, eds. 2017. "Low Inflation in the Euro Area: Causes and Consequences." Occasional Paper 181. Frankfurt: European Central Bank. https://www.ecb.europa.eu/pub/pdf/scpops/ecbop181.en.pdf.

Claus, Edda, Iris Claus, and Leo Krippner. 2016. "Asset Markets and Monetary Policy Shocks at the Zero Lower Bound." Discussion Paper 2014/03a. Wellington: Reserve Bank of New Zealand.

Coenen, Günter, Michael Ehrmann, Gaetano Gaballo, Peter Hoffmann, Anton Nakov, Stefano Nardelli, Eric Persson, and Georg Strasser. 2017. "Communication of Monetary Policy in Unconventional Times." Working Paper 2080. Frankfurt: European Central Bank. https://www.ecb.europa.eu/pub/pdf/scpwps/ ecb.wp2080.en.pdf.

Coenen, Günter, Roland Straub, and Mathias Trabandt. 2012. "Fiscal Policy and the Great Recession in the Euro Area." American Economic Review: Papers \& Proceedings 102, no. 3: 71-76.

Coeuré, B. 2015. "Embarking on Public Sector Asset Purchases." Speech given at Second International Conference on Sovereign Bond Markets, March 10.

Coibion, Olivier, Yuriy Gorodnichenko, and Johannes Wieland. 2012. "The Optimal Inflation Rate in New Keynesian Models: Should Central Banks Raise Their Inflation Targets in Light of the Zero Lower Bound?" Review of Economic Studies 79: 1371-1406.

Constâncio, Vítor. 2013. "The European Crisis and the Role of the Financial System." Speech given at Bank of Greece Conference on the Crisis in the Euro Area, Athens, May, 23.

. 2018. "Past and Future of the ECB's Monetary Policy." Speech at Conference on Central Banks in Historical Perspective: What Changed after the Financial Crisis, Central Bank of Malta, Valletta, May 4.

Corsetti, Giancarlo. 2015. "Roots of the EZ Crisis: Incomplete Development and Imperfect Credibility of Institutions." VoxEU article, Centre for European Policy Research, September 7. https://voxeu.org/article/roots-ez-crisis.

Corsetti, Giancarlo, and Luca Dedola. 2016. "The Mystery of the Printing Press: Monetary Policy and Self-Fulfilling Debt Crises." Journal of the European Economic Association 14, no. 6: 1329-71.

Corsetti, Giancarlo, and Paolo Pesenti. 1999. "Stability, Asymmetry, and Discontinuity: The Launch of European Monetary Union." Brookings Papers on Economic Activity, no. 2: 295-372. 
Court of Justice. 2015. "Judgment of the Court of Justice of the European Union (Grand Chamber) of June 16, 2015, Peter Gauweiler and Others v. Deutscher Bundestag." https://eur-lex.europa.eu/legal-content/EN/TXT/?uri=CELEX:62014CJ0062.

Crosignani, Matteo, Miguel Faria-e-Castro, and Luís Fonseca. 2018, "The (Unintended) Consequence of the Largest Liquidity Injection Ever." Working Paper 2017-039C. Saint Louis: Federal Reserve Bank of Saint Louis. https:// research.stlouisfed.org/wp/more/2017-039.

Darracq-Paries, Matthieu, Christoffer Kok Sorensen, and Diego RodriguezPalenzuela. 2011. "Macroeconomic Propagation Across Different Regulatory Regimes: Evidence from an Estimated DSGE Model for the Euro Area." International Journal of Central Banking 7, no. 4: 49-113.

Darracq-Paries, Matthieu, and Roberto A. De Santis. 2015. "A Non-Standard Monetary Policy Shock: The ECB's 3-Year LTROs and the Shift in Credit Supply." Journal of International Money and Finance 54: 1-34.

De Bandt, Olivier, Philipp Hartmann, and José Luis Peydró-Alcalde. 2015. "Systemic Risk in Banking after the Great Financial Crisis." In The Oxford Handbook of Banking, edited by Allen N. Berger, Philip Molyneux, and John O. S. Wilson. Oxford University Press.

Debortoli, Davide, Jordi Galí, and Luca Gambetti. 2018. "On the Empirical (Ir)relevance of the Zero Lower Bound Constraint." Working Paper 1594. Barcelona: Universitat Pompeu Fabra. https://econ-papers.upf.edu/papers/ 1594.pdf.

Del Negro, Marco, Gauti Eggertsson, Andrea Ferrero, and Nobuhiro Kiyotaki. 2016. "The Great Escape? A Quantitative Evaluation of the Fed's Liquidity Facilities." Staff Report 520. New York: Federal Reserve Bank of New York. https://www.newyorkfed.org/medialibrary/media/research/staff_reports/ sr520.pdf.

Demertzis, Maria, Massimiliano Marcellino, and Nicola Viegi. 2009. "Anchors for Inflation Expectations.” Working Paper 229.Amsterdam: De Nederlandsche Bank.https://www.dnb.nl/en/binaries/229\%20Anchors\%20for\%20Inflation\%20 Expectations_tcm47-225545.pdf.

Demiralp, Selva, Jens Eisenschmidt, and Thomas Vlassopoulos. 2019. "Negative Interest Rates, Excess Liquidity and Retail Deposits: Banks' Reaction to Unconventional Monetary Policy in the Euro Area." ECB Working Paper 2283. Frankfurt: European Central Bank.

De Pooter, Michiel, Robert F. Martin, and Seth Pruitt. 2018. "The Liquidity Effects of Official Bond Market Intervention." Journal of Financial and Quantitative Analysis 53, no. 1: 243-68.

De Santis, Roberto A. 2016. "Impact of the Asset Purchase Programme on Euro Area Government Bond Yields Using Market News.” Working Paper 1939. Frankfurt: European Central Bank.

. 2018. "Unobservable Country Bond Premia and Fragmentation." Journal of International Money and Finance 82: 1-25.

—. Forthcoming. "Redenomination Risk." Journal of Money, Credit and Banking. https://onlinelibrary.wiley.com/doi/10.1111/jmcb.12582. 
Detken, Carsten, Dieter Gerdesmeier, and Barbara Roffina. 2010. "Interlinkages between Money, Credit and Asset Prices and Their Implications for Consumer Price Inflation: Recent Empirical Work." In Enhancing Monetary Analysis, edited by Lucas Papademos and Jürgen Stark. https://www.ecb.europa.eu/ pub/pdf/other/enhancingmonetaryanalysis2010en.pdf?13ffbb3e72c01de3783 $0173 \mathrm{~b} 8 \mathrm{a} 5 \mathrm{~b} 8217$.

Detken, Carsten, and Frank Smets. 2004. "Asset Price Booms and Monetary Policy." In Macroeconomic Policies in the World Economy, edited by Horst Siebert. Berlin: Springer-Verlag.

Deutsche Bundesbank. 2018. "Lower Bound, Inflation Target and the Anchoring of Inflation Expectations." Monthly Report, June, 31-50. https://www. bundesbank.de/resource/blob/749842/98826deabb00741b7796b903867f5c40/ mL/2018-06-zinsuntergrenze-data.pdf.

Domingues Semeano, João, and Marien Ferdinandusse. 2018. "The Fiscal Impact of Financial Sector Support Measures: Where Do We Stand a Decade on from the Financial Crisis?" ECB Economic Bulletin, June. https://www.ecb.europa. eu/pub/economic-bulletin/focus/2018/html/ecb.ebbox201806_04.en.html.

Dovern, Jonas, and Geoff Kenny. 2017. "The Long-Term Distribution of Expected Inflation in the Euro Area: What Has Changed since the Great Recession?" Working Paper 1999. Frankfurt: European Central Bank. https://www.ecb. europa.eu/pub/pdf/scpwps/ecbwp1999.en.pdf.

Draghi, Mario. 2012. "Verbatim of the remarks made by Mario Draghi, Speech at the Global Investment Conference, London, 26 July." https://www.ecb.europa. eu/press/key/date/2012/html/sp120726.en.html.

_. 2014a. "Monetary Policy Communication in Turbulent Times." Speech at conference "De Nederlandsche Bank 200 Years: Central Banking in the Next Two Decades," Amsterdam, April 24. https://www.ecb.europa.eu/press/key/ date/2014/html/sp140424.en.html.

. 2014b. "Unemployment in the Euro Area." Speech given at annual central bank symposium in Jackson Hole, Wyo., August 22.

2016. "Delivering a Symmetric Mandate with Asymmetric Tools: Monetary Policy in a Context of Low Interest Rates." Speech given at ceremony to mark 200th anniversary of Oesterreichische Nationalbank, Vienna, June 2.

2017. "Monetary Policy and the Economic Recovery in the Euro Area." Speech given at ECB and its Watchers XVIII Conference, Frankfurt, April 6.

Driffill, John, and Zeno Rotondi. 2004. "Monetary Policy and Lexicographic Preference Ordering." CEPR Discussion Paper 4247. https://cepr.org/active/ publications/discussion_papers/dp.php?dpno=4247.

Duisenberg, Willem F. 1998. "Introductory Statement and Transcript of Questions and Answers." ECB press conference, Frankfurt, October 13. https://www.ecb. europa.eu/press/pressconf/1998/html/is981013.en.html.

1999. “The Eurosystem's Monetary Policy Strategy: The First Year's Experience." Speech given at joint congress of the federations EUROFINAS and LEASEUROPE, Paris, October 11. https://www.ecb.europa.eu/press/key/ date/1999/html/sp991011.en.html. 
ECB (European Central Bank). 1999. “The Stability-Oriented Monetary Policy Strategy of the Eurosystem." ECB Monthly Bulletin, January, 39-50. https:// www.ecb.europa.eu/pub/pdf/mobu/mb199901en.pdf.

. 2000a. "Guideline of the European Central Bank of 31 August 2000 on Monetary Policy Instruments and Procedures of the Eurosystem." Official Journal of the European Communities, L 310/1, December 11. https://www.ecb. europa.eu/ecb/legal/pdf/01_a_en_ecb_2000_7.pdf.

_. 2000b. "Statement on the Euro by Dr. Willem F. Duisenberg, President of the European Central Bank.” Press release, Frankfurt, May 5. https://www. ecb.europa.eu/press/pr/date/2000/html/pr000505.en.html.

—. 2000c. "The ECB Announces Joint Intervention in the Exchange Markets." Press release, September 22. https://www.ecb.europa.eu/press/pr/date/2000/ html/pr000922.en.html.

. 2003a. "The Outcome of the ECB's Evaluation of Its Monetary Strategy." ECB Monthly Bulletin, June, 79-92. https://www.ecb.europa.eu/pub/pdf/other/ pp79_92_mb200306en.pdf?e366490ebb678c0d82b6d62a85e10d44.

_ 2003b. "Press Seminar on the Evaluation of the ECB's Monetary Policy Strategy.” Press release, May 8. https://www.ecb.europa.eu/press/pressconf/ 2003/html/is030508_1.en.html.

—. 2003c. "Introductory Statement by Jean Claude Trichet." December 4. https://www.ecb.europa.eu/press/pressconf/2003/html/is031204.en.html.

. 2005. "Asset Price Bubbles and Monetary Policy." Monthly Bulletin, April, 47-60.

. 2007a. "The ECB's Additional Open Market Operations in the Period from 8 August to 5 September 2007." Monthly Bulletin, September, 30-34. https://www.ecb.europa.eu/pub/pdf/mobu/mb200709en.pdf.

—. 2007b. "Measures Designed to Address Elevated Pressures in Short-Term Funding Markets." Press release, December 12. https://www.ecb.europa.eu/ press/pr/date/2007/html/pr071212.en.html.

—. 2008a. "The 10th Anniversary of the European Central Bank." Monthly Bulletin, June. https://www.ecb.europa.eu/pub/pdf/other/10thanniversaryofthee cbmb200806en.pdf.

- 2008b. "Measures to Further Expand the Collateral Framework and Enhance the Provision of Liquidity." Press release, October 15. https://www. ecb.europa.eu/press/pr/date/2008/html/pr081015.en.html.

- 2009a. "The Concept of Systemic Risk." Financial Stability Review, December, 134-42. https://www.ecb.europa.eu/pub/pdf/fsr/financialstability review200912en.pdf?10adf78b3dc425f72013840711c53aa7.

—. 2009b. "Wage Dynamics in Europe: Final Report of the Wage Dynamics Network (WDN)." December 4. https://www.ecb.europa.eu/home/pdf/wdn_ finalreport_dec2009.pdf.

. 2009c. "Longer-Term Refinancing Operations." Press Release, May 7. https://www.ecb.europa.eu/press/pr/date/2009/html/pr090507_2.en.html. 
2011a. "The Implementation of Monetary Policy in the Euro Area." General documentation on Eurosystem monetary policy instruments and procedures.

. 2011b. "Statement by the President of the ECB." Press release, August 7. https://www.ecb.europa.eu/press/pr/date/2011/html/pr110807.en.html.

. 2011c. "ECB Announces Measures to Support Bank Lending and Money Market Activity.” Press release, December 8. https://www.ecb.europa.eu/press/ pr/date/2011/html/pr111208_1.en.html.

2012a. "Financial Integration in Europe." https://www.ecb.europa.eu/ pub/pdf/fie/financialintegrationineurope201204en.pdf?555d50a5346bd5a322 c47e8df4f9e223.

- 2012b. "Technical Features of Outright Monetary Transactions." Press release, September 6. https://www.ecb.europa.eu/press/pr/date/2012/html/ pr120906_1.en.html.

. 2013a. "An Assessment of Eurosystem Staff Macroeconomic Projections." Monthly Bulletin, May. https://www.ecb.europa.eu/pub/pdf/mobu/ mb201305en.pdf.

. 2013b. "Financial Integration in Europe." https://www.ecb.europa.eu/pub/ pdf/other/financialintegrationineurope201304en.pdf.

— 2013c. "Introductory Statement to the Press Conference (with Q\&A)." Press release, July 4. https://www.ecb.europa.eu/press/pressconf/2013/html/ is130704.en.html.

2014. "Experience with Foreign Currency Liquidity-Providing Central Bank Swaps." Monthly Bulletin, May.

2015a. "Decision of the ECB of 4 March 2015 on a Secondary Markets Public Sector Asset Purchase Programme (ECB/2015/10).” https://www.ecb. europa.eu/ecb/legal/pdf/en_dec_ecb_2015_10_f_.sign.pdf.

2015b. "The Transmission of the ECB's Recent Non-Standard Monetary Policy Measures." Economic Bulletin 7, 32-51. https://www.ecb.europa.eu/pub/ pdf/ecbu/eb201507.en.pdf?3adaa9be8decd4be9a0ed7176ad6030f.

2015c. "Introductory Statement to the Press Conference (with Q\&A)." Press release, January 22. https://www.ecb.europa.eu/press/pressconf/2015/ $\mathrm{html} /$ is 150122.en.html.

. 2015d. "Introductory Statement to the Press Conference (with Q\&A)." Press release, December 3. https://www.ecb.europa.eu/press/pressconf/2015/ $\mathrm{html} /$ is 151203.en.html.

_. 2015e. "ECB Announces Expanded Asset Purchase Programme." Press release, January 22. https://www.ecb.europa.eu/press/pr/date/2015/html/ pr150122_1.en.html.

- 2016a. "A Guide to the Eurosystem/ECB Staff Macroeconomic Projection Exercises." https://www.ecb.europa.eu/pub/pdf/other/staffprojections guide201607.en.pdf.

2016b. "Monetary Policy Decisions." Press release, March 10. https:// www.ecb.europa.eu/press/pr/date/2016/html/pr160310.en.html. 
2016c. "Introductory Statement to the Press Conference (with Q\&A)." Press release, March 10. https://www.ecb.europa.eu/press/pressconf/2016/html/ is 160310.en.html.

2017a. "How Do Professional Forecasters Assess the Risks to Inflation?" Economic Bulletin 5. https://www.ecb.europa.eu/pub/economic-bulletin/html/ eb201705.en.html\#IDofBox4.

2017b. "Impact of the ECB's Non-Standard Measures on Financing Conditions: Taking Stock of Recent Evidence.” Economic Bulletin 2. https:// www.ecb.europa.eu/pub/pdf/ecbu/eb201702.en.pdf?5f73fe43bfa3863210291 ae55ed6f 265 .

. 2017c. "The Targeted Longer-Term Refinancing Operations: An Overview of the Take-Up and Their Impact on Bank Intermediation." Economic Bulletin 3. https://www.ecb.europa.eu/pub/pdf/ecbu/eb201703.en.pdf?fbcb755 119af8c03bf99092d87d2f7fd.

. 2017d. "Introductory Statement.” Press release, June 8. https://www.ecb. europa.eu/press/pressconf/2017/html/ecb.is170608.en.html.

. 2018a. "Euro Area Bank Lending Survey, 2018:Q4." https://www.ecb. europa.eu/stats/ecb_surveys/bank_lending_survey/html/index.en.html.

. 2018b. "Structure of the Euro Area Economy." https://www.ecb.europa.eu/ mopo/eaec/html/index.en.html.

_. 2018c. "Monetary Policy Decisions." Press release, June 14. https://www. ecb.europa.eu/press/pr/date/2018/html/ecb.mp180614.en.html.

Ehrhart, Karl-Martin. 2001. "European Central Bank Operations: Experimental Investigation of the Fixed Rate Tender." Journal of International Money and Finance 20, no. 6: 871-93.

Ehrmann, M., M. Fratzscher, R. Gürkaynak, and E. Swanson. 2011. “Convergence and Anchoring of Yield Curves in the Euro Area." Review of Economics and Statistics 93, no. 1: 350-64.

Eisenschmidt, Jens, and Frank Smets. 2018. "Negative Interest Rates: Lessons from the Euro Area." https:/www.bcentral.cl/documents/145129/900210/ Eisenschmidt+Smets+\%25282017\%2529+v2.pdf/da22c99f-b34a-fecf-ce6d690f6ad3b202.

Eisenschmidt, Jens, and Jens Tapking. 2009. "Liquidity Risk Premia in Unsecured Interbank Money Market Rates." ECB Working Paper 1025. https://www.ecb. europa.eu/pub/pdf/scpwps/ecbwp1025.pdf?68bbf7e8d380ec23151dc9a1f602 a1d9.

Eser, Fabian, Marta Carmona Amaro, Stefano Iacobelli, and Marc Rubens. 2012. "The Use of the Eurosystem's Monetary Policy Instruments and Operational Framework since 2009.” ECB Occasional Paper 135. https://www. ecb.europa.eu/pub/pdf/scpops/ecbocp135.pdf?c18a6c50e4fcefead8aff7a5d8 $2 \mathrm{db} 5 \mathrm{f} 4$.

Eser, Fabian, and Bernd Schwaab. 2016. "Evaluating the Impact of Unconventional Monetary Policy Measures: Empirical Evidence from the ECB's Securities Markets Programme.” Journal of Financial Economics 119, no. 1: 147-67. 
European Banking Authority. 2011. "Results of the 2011 EU-wide Stress Test under the Adverse Scenario, London, 15 July." https://eba.europa.eu/ risk-analysis-and-data/eu-wide-stress-testing/2011/results.

European Commission. 2008. "A European Economic Recovery Plan." Communication from Commission to European Council, Brussels, November 26. http://ec.europa.eu/economy_finance/publications/pages/publication13504_ en.pdf.

2015. Completing Europe's Economic and Monetary Union. Report by Jean-Claude Juncker in close collaboration with Donald Tusk, Jeroen Dijsselbloem, Mario Draghi, and Martin Schulz. Brussels: European Commission. https://ec.europa.eu/commission/sites/beta-political/files/5-presidentsreport_en.pdf.

.2017. "Coping with the International Financial Crisis at the National Level in a European Context: Impact and Financial Sector Policy Responses in 2008-2015." European Commission Staff Document SWD (2017) 373. European Commission, Brussels. https://ec.europa.eu/info/system/files/eucountriesresponses-to-financial-crisis.pdf.

. 2018. "Spring 2018 Economic Forecast: Expansion to Continue, Amid New Risks." https://ec.europa.eu/info/business-economy-euro/economicperformance-and-forecasts/economic-forecasts/spring-2018-economic-forecastexpansion-continue-amid-new-risks_en.

European Council. 2012a. "Euro Area Summit Statement, Brussels, 29 June." https://www.consilium.europa.eu/media/21400/20120629-euro-area-summitstatement-en.pdf.

. 2012b. "Towards a Genuine Economic and Monetary Union: Prepared by Herman Van Rompuy, President of the European Council, in Close Collaboration with José Manuel Barroso, President of the European Commission, Jean-Claude Juncker, President of the Eurogroup, and Mario Draghi, President of the European Central Bank, 5 December." https://www.consilium.europa.eu/ media/23818/134069.pdf.

. 2012c. "Towards a Genuine Economic and Monetary Union: Report by the President of the European Council Herman Van Rompuy, Brussels, 26 June." https://www.consilium.europa.eu/media/33785/131201.pdf.

European Union. 2012a. "Consolidated Version of the Treaty on European Union." Official Journal of the European Union, C326/13, October 26. https://eur-lex. europa.eu/resource.html?uri=cellar:c382f65d-618a-4c72-9135-1e68087499fa. 0006.02/DOC_2\&format=PDF.

.2012b. "Consolidated Version of the Treaty on the Functioning of the European Union." Official Journal of the European Union, C326/47, October 26. https://eur-lex.europa.eu/resource.html?uri=cellar:c382f65d-618a-4c72-91351e68087499fa.0006.02/DOC_3\&format=PDF.

_ - 2012c. "Protocol No. 4 on the Statute of the European System of Central Banks and the European Central Bank." Official Journal of the European Union, C326/230, October 26. https://eur-lex.europa.eu/resource. 
html?uri=cellar:c382f65d-618a-4c72-9135-1e68087499fa.0006.02/DOC_4\& format $=$ PDF.

2013. "Council Regulation (EU) No. 1024/2013 of 15 October 2013 Conferring Specific Tasks on the European Central Bank Concerning Policies Relating to the Prudential Supervision of Credit Institutions." Official Journal of the European Union, L287/63, October 29.

Evanoff, Douglas D., Philipp Hartmann, and George G. Kaufman, eds. 2009. The First Credit Market Turmoil of the 21st Century. Hackensack, N.J.: World Scientific Publishing.

Fahr, Stephan, Roberto Motto, Massimo Rostagno, Frank Smets, and Oreste Tristani. 2013. "A Monetary Policy Strategy in Good and Bad Times: Lessons from the Recent Past." Economic Policy 28, no. 74: 243-88.

Feld, Lars, Christoph Schmidt, Isabel Schnabel, and Volker Wieland. 2016. "Causes of the Eurozone Crisis: A Nuanced View." VoxEU article, March 22. https://voxeu.org/article/causes-eurozone-crisis-nuanced-view.

Ferrando, Annalisa, Alexander Popov, and Gregory F. Udell. 2015. "Sovereign Stress, Unconventional Monetary Policy, and SME Access to Finance." Working Paper 1820. Frankfurt: European Central Bank. https:/www.ecb.europa.eu/ pub/pdf/scpwps/ecbwp1820.en.pdf?1a09169e5aa2d3a6002675b624554421.

Fischer, Björn, Michele Lenza, Huw Pill, and Lucrezia Reichlin. 2008. "Money and Monetary Policy: The ECB Experience 1999-2006." In Proceedings of the Fourth ECB Central Banking Conference: The Role of Money-Money and Monetary Policy in the Twenty-First Century, edited by Andreas Beyer and Lucrezia Reichlin. Frankfurt: European Central Bank.

Fraccaroli, Nicolo, Alessandro Giovannini, and Jean-François Jamet. 2018. "Accounting for Accountability at the ECB." Vox-EU article. https://voxeu.org/ article/accounting-accountability-evolution-ecb-s-accountability-practicesduring-crisis.

Francis, Neville R., Laura E. Jackson, and Michael T. Owyang. 2017. "How Has Empirical Monetary Policy Analysis Changed after the Financial Crisis?" Working Paper 2014-19C, Federal Reserve Bank of Saint Louis. https:// s3.amazonaws.com/real.stlouisfed.org/wp/2014/2014-019.pdf.

Fuhrer, Jeffrey C., and Giovanni P. Olivei. 2011. "The Estimated Macroeconomic Effects of the Federal Reserve's Large-Scale Treasury Purchase Program.” Public Policy Brief 11-2, Federal Reserve Bank of Boston. https://www.bostonfed.org/ publications/public-policy-brief/2011/the-estimated-macroeconomic-effects-ofthe-federal-reserves-largescale-treasury-purchase-program.aspx.

Galati, Gabriele, Steven Poelhekke, and Chen Zhou. 2011. "Did the Crisis Affect Inflation Expectations?" International Journal of Central Banking 7, no. 1: 167-207.

Galí, J. 2003. "Monetary Policy in the Early Years of EMU." In EMU and Economic Policy in Europe: Challenges of the Early Years, edited by M. Buti and A. Sapir. Cheltenham, U.K.: Edward Elgar.

Garcia-de-Andoain, C., F. Heider, M. Hoerova, and S. Manganelli. 2016. "Lending-of-Last-Resort Is as Lending-of-Last-Resort Does: Central Bank 
Liquidity Provision and Interbank Market Functioning in the Euro Area." Journal of Financial Intermediation 28: 32-47.

Garcia-Posada, Miguel, and Marcos Marchetti. 2016. "The Bank Lending Channel of Unconventional Monetary Policy: The Impact of the VLTROs on Credit Supply in Spain.” Economic Modelling 58: 427-41.

Gaspar, Vitor, Frank Smets, and David Vestin. 2010. "Is Time Ripe for Price Level Path Stability?" In Challenges in Central Banking, edited by Pierre L. Siklos, Martin T. Bohl, and Mark E. Wohar. Cambridge University Press.

Geraats, Petra. 2002. "Central Bank Transparency." Economic Journal 112: F532-F565.

Geraats, Petra, Francesco Giavazzi, and Charles Wyplosz. 2008. "Transparency and Governance in the Eurozone." Vox-EU article, Centre for European Policy Research. https://voxeu.org/article/transparency-and-governance-eurozone.

Gerdesmeier, Dieter, and Barbara Roffia. 2003. "Empirical Estimates of Reaction Functions for the Euro Area.” Working Paper 206. Frankfurt: European Central Bank. https://www.ecb.europa.eu/pub/pdf/scpwps/ecbwp206.pdf?7b1765155c6 9a259582cc3bb5332d66c.

Gerlach, Stefan, and John Lewis. 2014. "ECB Reaction Functions and the Crisis of 2008." International Journal of Central Banking 10, no. 1: 137-57.

Gertler, Mark, and Peter Karadi. 2013. "QE 1 vs. 2 vs. 3. . . : A Framework for Analyzing Large-Scale Asset Purchases as a Monetary Policy Tool.” International Journal of Central Banking 9, no. S1: 5-53.

Ghysels, Eric, Julien Idier, Simone Manganelli, and Olivier Vergote. 2017. "A High-Frequency Assessment of the ECB Securities Markets Programme." Journal of the European Economic Association 15, no. 1: 218-43.

Giannone, Domenico, Michele Lenza, Huw Pill, and Lucrezia Reichlin. 2012. "The ECB and the Interbank Market." Economic Journal 122: F467-F486.

Gorter, Janka, Jan Jacobs, and Jakob de Haan. 2008. "Taylor Rules for the ECB Using Expectations Data." Scandinavian Journal of Economics 110, no. 3: 473-88.

Gorton, Gary, and Andrew Metrick. 2012. "Securitized Banking and the Run on Repo." Journal of Financial Economics 104, no. 3: 425-51.

Grishchenko, Olesya, Sarah Mouabbi, and Jean-Paul Renne. 2017. "Measuring Inflation Anchoring and Uncertainty: A U.S. and Euro Area Comparison." Finance and Economics Discussion Series 2017-102. Washington: Board of Governors of the Federal Reserve System. https://www.federalreserve.gov/ econres/feds/files/2017102pap.pdf.

Gürkaynak, Refet S., Andrew Levin, and Eric Swanson. 2010. "Does Inflation Targeting Anchor Long-Run Inflation Expectations? Evidence from the U.S., U.K., and Sweden." Journal of the European Economic Association 8, no. 6: $1208-42$.

Hamilton, James. 2018. "The Effectiveness of Large-Scale Asset Purchases.” VoxEU article, October 12, Centre for Economic Policy Research. https://voxeu. org/article/effectiveness-large-scale-asset-purchases. 
Hammermann, Felix, Kieran Leonard, Stefano Nardelli, and Julian von Landesberger. 2019. "Taking Stock of the Eurosystem's Asset Purchase Programme after the End of Net Asset Purchases." Economic Bulletin, March 18. https://www.ecb.europa.eu/pub/economic-bulletin/articles/2019/ html/ecb.ebart201902_01 3049319b8d.en.html.

Hartmann, Philipp. 2010. "How Europe Handled the Financial Crisis," executive address at Sixth Annual FX Week Asia Congress, Singapore, October 12.

2015. "Real-Estate Markets and Macroprudential Policy in Europe." Journal of Money, Credit and Banking 47, no. S1: 69-80.

. 2018. "Policy Considerations on the Prolonged Period of Low Interest Rates: A Euro Area Perspective," panel remarks at 62nd Federal Reserve Bank of Boston Annual Economics Conference, Boston, September 7. https:// www.bostonfed.org/-/media/Images/research-conference-2018/presentations/ hartmann-presentation.pdf.

Hartmann, P., H. Huang, and D. Schoenmaker, eds. 2018. The Changing Fortunes of Central Banking. Cambridge University Press.

Hartmann, Philipp, Angela Maddaloni, and Simone Manganelli. 2003. "The EuroArea Financial System: Structure, Integration and Policy Initiatives." Oxford Review of Economic Policy 19, no. 1: 180-213.

Hartmann, Philipp, Michele Manna, and Andrés Manzanares. 2001. "The Microstructure of the Euro Money Market." Journal of International Money and Finance 20, no. 6: 895-48.

Hartmann, Philipp, and Frank Smets. 2018. "The First Twenty Years of the European Central Bank: Financial Stability.” ECB, in progress.

Heider, F., M. Hoerova, and C. Holthausen. 2015. "Liquidity Hoarding and Interbank Market Rates: The Role of Counterparty Risk." Journal of Financial Economics 118, no. 2: 336-54.

Heider, Florian, Farzad Saidi, and Glenn Schepens. 2018. "Life Below Zero: Bank Lending under Negative Policy Rates.” ECB Working Paper 2173. Forthcoming in Review of Financial Studies. https://www.ecb.europa.eu/pub/pdf/scpwps/ ecb.wp2173.en.pdf.

High-Level Group on Financial Supervision in the EU. 2009. "De Larosière Report." Brussels, February 25. http://ec.europa.eu/economy_finance/publications/pages/ publication14527_en.pdf.

Hutchinson, John, and Frank Smets. 2017. "Monetary Policy in Uncertain Times: ECB Monetary Policy since June 2014.” Manchester School 85, no. S2: e1-e15.

Inoue, Atsushi, and Barbara Rossi. 2018. "The Effects of Conventional and Unconventional Monetary Policy on Exchange Rates.” Economics Working Paper 1638. Barcelona: Universitat Pompeu Fabra. https://econ-papers.upf.edu/ papers/1638.pdf.

International Monetary Fund. 2018. World Economic Outlook, April 2018: Cyclical Upswing, Structural Change. Washington: International Monetary Fund. https://www.imf.org/en/Publications/WEO/Issues/2018/03/20/world-economicoutlook-april-2018. 
Issing, Otmar. 1999. "The Eurosystem: Transparent and Accountable or 'Willem in Euroland."' Journal of Common Market Studies 37, no. 3: 503-19.

2003a. "Background Studies for the ECB's Evaluation of Its Monetary Policy Strategy.” European Central Bank, Frankfurt. https://www.ecb.europa. eu/pub/pdf/other/monetarypolicystrategyreview_backgrounden.pdf.

_. 2003b. "Monetary and Financial Stability: Is There a Trade-Off?" Speech given at conference on monetary stability, financial stability, and the business cycle, Bank for International Settlements, Basel, March 28-29.

. 2005. "The Role of Money in the Monetary Policy Strategy of the ECB." Speech given at ECB workshop on what central banks can learn from money and credit aggregates, Eltville, October 28. https://www.ecb.europa.eu/press/ key/date/2005/html/sp051028.en.html.

. 2008. The Birth of the Euro. Cambridge University Press.

Issing, Otmar, Vítor Gaspar, Ignazio Angeloni, and Oreste Tristani. 2001. Monetary Policy in the Euro Area: Strategy and Decision-Making at the European Central Bank. Cambridge University Press.

Issing, Otmar, Vítor Gaspar, Oreste Tristani, and David Vestin. 2005. Imperfect Knowledge and Monetary Policy; The Stone Lectures in Economics. Cambridge University Press.

Jackson, Harriet. 2015. "The International Experience with Negative Policy Rates." Staff Discussion Paper 2015-13. Ottawa: Bank of Canada.

Jasova, Martina, Caterina Mendicino, and Dominik Supera. 2018. "Rollover Risk and Bank Lending Behaviour: Evidence from Unconventional Central Bank Liquidity." Working paper. https://cepr.org/sites/default/files/40021_Supera_ roll_over_risk_and_bank_lending_behavior.pdf.

Joslin, Scott, Kenneth J. Singleton, and Haoxiang Zhu. 2011. "A New Perspective on Gaussian Dynamic Term Structure Models." Review of Financial Studies 24, no. 3: 926-70.

Joyce, Michael, David Miles, Andrew Scott, and Dimitri Vayano. 2012. "Quantitative Easing and Unconventional Monetary Policy: An Introduction." Economic Journal 122: F271-F288.

Kapetanios, George, Haroon Mumatz, Ibrahim Stevens, and Konstantinos Theodoridis. 2012. "Assessing the Economy-wide Effects of Quantitative Easing.” Economic Journal 122, no. 564: F316-F347.

Kiley, Michael T., and John M. Roberts. 2017. "Monetary Policy in a Low Interest Rate World.” Brookings Papers on Economic Activity, Spring: 317-72.

Kontogeorgos, Georgios, and Kyriacos Lambrias. 2018. "An Analysis of the ECB/ Eurosystem Projections.” Unpublished paper, European Central Bank.

Kortela, Tomi. 2016. "A Shadow Rate Model with Time-Varying Lower Bound of Interest Rates." Research Discussion Paper 19/2016. Helsinki: Bank of Finland. https://helda.helsinki.fi/bof/bitstream/handle/123456789/14300/BoF_DP_ 1619.pdf? sequence $=1$.

Krippner, Leo. 2015. Zero Lower Bound Term Structure Modeling: A Practitioner's Guide. New York: Palgrave Macmillan. 
Krishnamurthy, Arvind, Stefan Nagel, and Annette Vissing-Jorgensen. 2018. "ECB Policies Involving Government Bond Purchases: Impact and Channels.” Review of Finance 22, no. 1: 1-44.

Krugman, Paul R. 2014. "Inflation Targets Reconsidered." In Proceedings of the ECB Forum on Central Banking Monetary Policy in a Changing Financial Landscape. Frankfurt: European Central Bank. https://www.ecb.europa.eu/ pub/pdf/sintra/ecb.forumcentbank201410.en.pdf.

Lane, Philip. 2015. "International Financial Flows and the Eurozone Crisis." Vox-EU article, September 7. https://voxeu.org/article/international-financialflows-and-eurozone-crisis.

Lemke, Wolfgang, and Andreea Liliana Vladu. 2017. "Below the Zero Lower Bound: A Shadow-Rate Term Structure Model for the Euro Area." Working Paper 1991. Frankfurt: European Central Bank. https://www.ecb.europa.eu/ pub/pdf/scpwps/ecbwp1991.en.pdf?29fac2eb9ccb9e00ef5fe6a910c8dc93.

Lenza, Michele, Huw Pill, and Lucrezia Reichlin. 2010. "Monetary Policy in Exceptional Times." Economic Policy 25, no. 62: 295-339.

Lyziak, Thomasz, and Maritta Paloviita. 2017. "Anchoring of Inflation Expectations in the Euro Area: Recent Evidence Based on Survey Data." European Journal of Political Economy 46: 52-73.

Mackowiak, B., F. Mongelli, G. Noblet, and F. Smets, eds. 2008. "The Euro at Ten: Lessons and Challenges." Paper presented at Fifth ECB Central Banking Conference, Frankfurt, November 13-14.

Martin, Philippe, and Thomas Philippon. 2017. "Inspecting the Mechanism: Leverage and the Great Recession in the Eurozone." American Economic Review 107, no. 7: 1904-37.

Martínez Pagés, Jorge, and Antonio Millaruelo. 2016. “The Recent Application of Negative Policy Interest Rates in the Euro Area and in Other Economies: Rationale and Preliminary Evidence on Their Effects." Economic Bulletin (Bank of Spain), July-August, 3-13.

Mouabbi, Sarah, and Jean-Guillaume Sahuc. 2017. "Evaluating the Macroeconomic Effects of the ECB's Unconventional Monetary Policies." Working paper, Centre for Economic Policy Research. https://cepr.org/sites/default/files/40006_ MOUABBI\%20-\%20Evaluating\%20the\%20Macroeconomic\%20Effetcs\%20of $\% 20$ the \%20ECBs\%20Unconventional\%20Monetary\%20Policies.pdf.

Natoli, Filippo, and Laura Sigalotti. 2018. "Tail Co-movement in Inflation Expectations as an Indicator of Anchoring." International Journal of Central Banking 14, no. 1: $35-71$.

Nautz, Dieter, and Jörg Oechssler. 2006. "Overbidding in Fixed-Rate Tenders: An Empirical Assessment of Alternative Explanations." European Economic Review 50, no. 3: 631-46.

Neri, S., and S. Siviero. 2019. "The Non-Standard Monetary Policy Measures of the ECB: Motivations, Effectiveness and Risks." Occasional Paper 486. Rome: Banca d'Italia. http://www.bancaditalia.it/pubblicazioni/qef/2019-0486/index. html?com.dotmarketing.htmlpage language $=1$.

Nessén, Marianne, and David Vestin. 2005. “Average Inflation Targeting.” Journal of Money, Credit and Banking 37, no. 5: 837-63. 
Neumann, Manfred J. M. 2010. "Some Observations on the ECB's Monetary Policy." In The Euro: The First Decade, edited by Marco Buti, Servaas Deroose, Vítor Gaspar, and João Nogueira Martins. Cambridge University Press.

Nickell, Stephen. 2006. "Discussion on 'European Monetary Union: The Dark Sides of a Major Success' by Charles Wyplosz." Economic Policy 21, no. 46. https://academic.oup.com/economicpolicy/article/21/46/208/2918717.

Organization for Economic Cooperation and Development. 2018. Economic Outlook, May. https:/www.oecd.org/eco/outlook/General-assessment-of-the-macroeconomic-situation-november-2018-OECD-economic-outlook-chapter.pdf.

Orphanides, Athanasios. 2003. "Historical Monetary Policy Analysis and the Taylor Rule.” Journal of Monetary Economics 50, no. 5: 983-1022.

2006. "The Road to Price Stability." American Economic Review 96, no. 2: $178-81$.

Orphanides, Athanasios, and Volker Wieland. 2013. "Complexity and Monetary Policy.” International Journal of Central Banking 9, issue S1: 167-203.

Orphanides, Athanasios, and John C. Williams. 2005. "Imperfect Knowledge, Inflation Expectations and Monetary Policy." In The Inflation Targeting Debate, edited by B. Bernanke and M. Woodford. University of Chicago Press.

. 2008. "Learning, Expectations Formation, and the Pitfalls of Optimal Control Monetary Policy.” Journal of Monetary Economics 55, issue S: S80-S96.

Paloviita, Maritta, Markus Haavio, Pirkka Jalasjoki, and Juha Kilponen. 2017. "What Does 'Below, but Close to, Two Percent' Mean? Assessing the ECB's Reaction Function with Real Time Data." Research Discussion Paper 29. Helsinki: Bank of Finland. https://helda.helsinki.fi/bof/bitstream/handle/ 123456789/14932/BoF_DP_1729.pdf?sequence=1\&isAllowed=y.

Paludkiewicz, Karol. 2018. "Unconventional Monetary Policy, Bank Lending, and Security Holdings: The Yield-Induced Portfolio Rebalancing Channel." Discussion Paper 22/2018. Frankfurt: Deutsche Bundesbank. https://www.econstor.eu/ bitstream/10419/180675/1/1027071376.pdf.

Papademos, Lucas. 2006. "The Role of Money in the Conduct of Monetary Policy." In Proceedings of the Fourth ECB Central Banking Conference: The Role of Money-Money and Monetary Policy in the Twenty-First Century, edited by Andreas Beyer and Lucrezia Reichlin. Frankfurt: European Central Bank.

Papademos, Lucas D., and Jürgen Stark, eds. 2010. Enhancing Monetary Analysis. Frankfurt: European Central Bank. https://www.ecb.europa.eu/pub/pdf/other/ enhancingmonetaryanalysis2010en.pdf?13ffbb3e72c01de37830173b8a5b8217.

Peersman, Gert. 2011. "Macroeconomic Effects of Unconventional Monetary Policy in the Euro Area.” Working Paper 1397. Frankfurt: European Central Bank. https://www.ecb.europa.eu/pub/pdf/scpwps/ecbwp1397.pdf?99ef78cb1a a613f60d8716d0db59b585.

Pesaran, M. Hashem, and Ron P. Smith. 2016. "Counterfactual Analysis in Macroeconometrics: An Empirical Investigation into the Effects of Quantitative Easing." Research in Economics 70, no. 2: 262-80. 
Pill, Huw, and Lucrezia Reichlin. 2015. "Exceptional Policies for Exceptional Times: The ECB's Response to the Rolling Crises of the Euro Area." In Handbook of the Economics of European Integration, edited by Harald Badinger and Volker Nitsch. New York: Routledge.

Pill, Huw, and Frank Smets. 2013. "Monetary Policy Frameworks after the Great Financial Crisis." In The Great Recessions, edited by Jacob Braude, Zvi Eckstein, Stanley Fischer, and Karnit Flug. MIT Press.

Poole, William. 1970. "Optimal Choice of Monetary Policy Instruments in a Simple Stochastic Macro Model.” Quarterly Journal of Economics 84, no. 2: 197-216. Praet, Peter. 2013. "Forward Guidance and the ECB." VoxEU article, August 6. https://www.ecb.europa.eu/press/key/date/2013/html/sp130806.en.html.

_ 2017. "Maintaining Price Stability with Unconventional Monetary Policy Measures." Speech given at MMF Monetary and Financial Policy Conference, London, October 2.

2018. "Delivering on Our Mandate: 20 Years of ECB Monetary Policy." Speech given at an event organized by ECB's representative office in Brussels, July 5. https://www.ecb.europa.eu/press/key/date/2018/html/ecb.sp180705. en.html.

Quint, Dominic, and Oreste Tristani. 2018. "Liquidity Provision as a Monetary Policy Tool: The ECB's Non-Standard Measures after the Financial Crisis." Journal of International Money and Finance 80: 15-34.

Reichlin, Lucrezia. 2014. "Monetary Policy and Banks in the Euro Area: The Tale of Two Crises." Journal of Macroeconomics 39: 287-400.

Reifschneider, David, John C. Williams, Christopher A. Sims, and John B. Taylor. 2000. "Three Lessons for Monetary Policy in a Low-Inflation Era." Journal of Money, Credit and Banking 32, no. 4: 936-66.

Rostagno, Massimo, Ulrich Bindseil, Annette Kamps, Wolfgang Lemke, Tomohiro Sugo, and Thomas Vlassopoulos. 2016. "Breaking Through the Zero Line: The ECB's Negative Interest Rate Policy.” Presentation given at Brookings Institution, Washington, June 6.

Shambaugh, Jay C. 2012. "The Euro's Three Crises.” Brookings Papers on Economic Activity, Spring: 157-211.

Smets, Frank, 2003. "Maintaining Price Stability: How Long Is the Medium Term?" Journal of Monetary Economics 50, no. 6: 1293-1309.

_. 2010. "Comment on Chapters 6 and 7." In The Euro: The First Decade, edited by Marco Buti, Servaas Deroose, Vítor Gaspar, and João Nogueira Martins. Cambridge University Press.

2014. "Financial Stability and Monetary Policy: How Closely Interlinked?" International Journal of Central Banking 10, no. 2: 263-300.

Stolz, Stéphanie Marie, and Michael Wedow. 2010. "Extraordinary Measures in Extraordinary Times: Public Measures in Support of the Financial Sector in the EU and the United States." ECB Occasional Paper 117. Frankfurt: European Central Bank. https://www.ecb.europa.eu//pub/pdf/scpops/ecbocp117.pdf.

Surico, Paolo. 2007. "The Monetary Policy of the European Central Bank." Scandinavian Journal of Economics 109, no. 1: 115-35. 
Svensson, Lars E. O. 1999a. "Monetary Policy Issues for the Eurosystem." CarnegieRochester Conference Series on Public Policy 51: 79-136.

. 1999b. "Price-Level Targeting versus Inflation Targeting: A Free Lunch?" Journal of Money, Credit and Banking 31, no. 3: 277-95.

2003. "In the Right Direction, but Not Enough: The Modification of the Monetary Policy Strategy of the ECB." Briefing paper for Committee on Economic and Monetary Affairs of European Parliament. http://citeseerx.ist.psu.edu/ viewdoc/download; jsessionid=7525C6653D727EA72718192ECEFA233D? doi=10.1.1.15.3587\&rep=rep1\&type=pdf.

Swanson, Eric T. 2017. "Measuring the Effects of Federal Reserve Forward Guidance and Asset Purchases on Financial Markets." NBER Working Paper 23311. Cambridge, Mass.: National Bureau of Economic Research. https://www.nber.org/papers/w23311.pdf.

. 2018. "The Federal Reserve Is Not Very Constrained by the Lower Bound on Nominal Interest Rates.” NBER Working Paper 25123. Cambridge, Mass.: National Bureau of Economic Research. https://www.nber.org/papers/w25123. pdf. Also in this issue of Brookings Papers on Economic Activity.

Szczerbowicz, U. 2015. “The ECB's Unconventional Monetary Policies: Have They Lowered Market Borrowing Costs for Banks and Governments?" International Journal of Central Banking 11, no. 4: 91-127.

Szörfi, Béla, and Máté Tóth. 2018. "Measures of Slack in the Euro Area." Economic Bulletin 3. Frankfurt: European Central Bank. https://www.ecb.europa. eu/pub/pdf/ecbu/eb201803.en.pdf?a002c6f56b79f07df072d758fca1025b.

Task Force on the Use of Monetary Policy Instruments. 2018. "The Use of the Eurosystem's Monetary Policy Instruments and Its Monetary Policy Implementation Framework Q2 2016-Q4 2017.” Occasional Paper 209. Frankfurt: European Central Bank. https://www.ecb.europa.eu/pub/pdf/scpops/ ecb.op209.en.pdf.

Taylor, John B. 2007. "Housing and Monetary Policy." NBER Working Paper 13682. Cambridge, Mass.: National Bureau of Economic Research.

Trebesch, Christoph, and Jeromin Zettelmeyer. 2018. "ECB Interventions in Distressed Sovereign Debt Markets: The Case of Greek Bonds." IMF Economic Review 66, no. 2: 287-332.

Trichet, Jean-Claude. 2003a. "Asset Price Bubbles and Their Implications for Monetary Policy and Financial Stability.” In Asset Price Bubbles: The Implications for Monetary, Regulatory and International Policies, edited by William C. Hunter, George G. Kaufman, and Michael Pomerleano. MIT Press.

2003b. "The ECB's Monetary Policy Strategy After the Evaluation and Clarification of May 2003." Speech given at Center for Financial Studies, November 20. https://www.ecb.europa.eu/press/key/date/2003/html/sp031120. en.html.

2005. "Asset Price Bubbles and Monetary Policy." Mas Lecture in Singapore, June 8. https://www.bis.org/review/r050614d.pdf.

. 2006. "Structural Reforms in Europe." Speech given at forum of Organization for Economic Cooperation and Development, Paris, May 22. 
2008. "Some Lessons from the Financial Market Correction." Speech given at European Banker of the Year 2007 award ceremony, Frankfurt, September 30.

_. 2009. "The ECB's Enhanced Credit Support." Speech given at University of Munich, Munich, September 4.

Tucker, Paul. 2018. Unelected Power: The Quest for Legitimacy in Central Banking and the Regulatory State. Princeton University Press.

Van Bekkum, Sjoerd, Marc Gabarro, and Rustom M. Irani. 2018. "Does a Larger Menu Increase Appetite? Collateral Eligibility and Credit Supply." Review of Financial Studies 31, no. 3: 943-79.

Van Zandweghe, Willem. 2015. "Monetary Policy Shocks and Aggregate Supply." Economic Review Q3: 31-56.

Weidmann, Jens. 2015. "Responsibility and Liability in a Monetary Union." Speech given at conference sponsored by Consiglio Regionale del Veneto, Venice, February 5. https://www.bis.org/review/r150205f.htm.

Wilhelmsen, Bjørn-Roger, and Andrea Zaghini. 2011. "Monetary Policy Predictability in the Euro Area: An International Comparison." Applied Economics 43, no. 20: 2533-44.

Woodford, Michael. 2006. 'Does a 'Two-Pillar Phillips Curve' Justify a Two-Pillar Monetary Policy Strategy?” In Proceedings of the Fourth ECB Central Banking Conference: The Role of Money-Money and Monetary Policy in the TwentyFirst Century, edited by Andreas Beyer and Lucrezia Reichlin. Frankfurt: European Central Bank.

Wu, Jing Cynthia, and Fan Dora Xia. 2017. "Time-Varying Lower Bound of Interests in Europe." Research Paper 17-06. Chicago: Chicago Booth. https:// papers.ssrn.com/sol3/papers.cfm?abstract_id=2946239.

Wu, Jing Cynthia, and Ji Zhang. 2017. “A Shadow Rate New Keynesian Model." NBER Working Paper 22856. Cambridge, Mass.: National Bureau of Economic Research. https://www.nber.org/papers/w22856.pdf.

Wyplosz, Charles. 2001. "Do We Know How Low Should Inflation Be?" In Proceedings of the First ECB Central Banking Conference: "Why Price Stability?" edited by Alica García Herrero, Vítor Gaspar, Lex Hoogduin, Julian Morgan, and Bernhard Winkler. Frankfurt: European Central Bank.

Yellen, Janet. 2012. "Revolution and Evolution in Central Bank Communications." Speech given at Haas School of Business, University of California, Berkeley, November 13.

Zettelmeyer, J., C. Trebesch, and M. Gulati. 2013. “The Greek Debt Restructuring: An Autopsy." Economic Policy 28, no. 75: 513-63. 


\section{Comments and Discussion}

\section{COMMENT BY}

LORENZO BINI SMAGHI My discussion of the very interesting paper by Philipp Hartmann and Frank Smets on the first 20 years of the European Central Bank (ECB) is inevitably influenced by my professional and academic background. First, I was a member of the Executive Board and of the Governing Council of the ECB between June 1, 2005, and December 31, 2011. During that period, I voted in favor of all the decisions that were made by the ECB. Second, I studied monetary theory and policy at the University of Chicago in the early 1980s, and thus have been influenced by Milton Friedman's writings, in particular his 1967 AEA presidential address on the role of monetary policy, in particular when he states that

the first and most important lesson that history teaches about what monetary policy can do ... is that monetary policy can prevent money itself from being a major source of economic disturbance. This sounds like a negative proposition: avoid major mistakes." (Friedman 1968, 12)

Avoiding making big mistakes is what haunted me during my ECB term. And that is the approach that I would like to take in discussing the paper by Hartmann and Smets.

The biggest mistake that any central bank wants to avoid is to miss its main objective, which is price stability. As Hartmann and Smets confirm in their paper, over the last 20 years, the average rate of inflation in the euro area has been about 1.7 percent, which seems to be within the range of what could be an arithmetic definition of price stability.

I broadly share Hartmann and Smets's conclusions that, overall, the ECB has fulfilled its mandate. It has acquired a high level of credibility as a central bank, in particularly difficult times. Inflation expectations have been firmly anchored. However, precisely because of the high credibility 
gained on the ground, the ECB should be slightly more open to assess its performance in response to the various criticisms that have been raised by academics, markets participants, and the public opinion over the last few years. Here, I make a few suggestions concerning the issues that should stimulate further research.

THE DEFINITION OF PRICE STABILITY The ECB has never given a precise numerical definition of price stability. Hartmann and Smets quote Otmar Issing at a 2003 press conference, stating that "a narrow range between roughly $1.7 \%$ and $1.9 \%$ " should be considered as being consistent with price stability (ECB 2003b). This reminds me of the same sort of calculation that Jean-Claude Trichet was continuously making during his term. As he left the ECB, at the end of October 2011, he was proud to mentionwith a certain humor, however-that since the start of the euro, inflation had been on average 1.99 percent, and thus - at least in his view-fully in line with the objective of price stability (Trichet 2011). How bewildered would he now be to learn that - with the benefit of hindsight- 1.99 percent was in fact too high, being outside the range of 1.7 to 1.9 percent mentioned by Hartmann and Smets and, in fact, "too close" to 2 percent!

Let us face it, the word "below"-inserted just before 2 percent in the definition of price stability — was added, in my opinion, with a view to emulate the Bundesbank, given that some members of the Governing Council thought at the time that a symmetric target would lead markets to think that the ECB would be excessively tolerant with an inflation rate above 2 percent. And perhaps it was also to reassure the German public that the ECB Governing Council would be as tough as the Bundesbank. In fact, the evidence over the last 20 years shows that the ECB's performance has been much closer to target than the Bundesbank was in the previous decades, albeit in a different inflationary environment.

The words "close to" were added in 2003, at the time of a review of the monetary policy strategy to avoid the impression that the ECB would tolerate deflation. Not doing like all other central banks- that is, providing a symmetric target of about 2 percent—might have been "prudent" 20 years ago. It is doubtful that it remains appropriate after 20 years of experience. All in all, having a qualitative-rather than a quantitative-definition of price stability has not helped the ECB, and has not even shielded it from criticisms, including those by Otmar Issing himself, who recently stated that an inflation rate of 1 percent was perfectly consistent with the "close to 2 percent" (ECB 2003a, 79), suggesting that he himself had forgotten about his 2003 range. In fact, Hartmann and Smets confirm that the ECB's reaction function over the last 20 years has been consistent 
with a symmetric inflation target. To conclude, a first lesson that could be drawn from the evidence is that the time may be ripe to move to an explicit 2 percent target, which would be not only more credible but also more transparent.

THE LEADS AND LAGS OF MONETARY POLICY Hartmann and Smets's judgment that the ECB did not made big mistakes, having achieved an inflation rate of close to 2 percent, is based on the average performance over 20 years of monetary union. Central banks cannot be held accountable for keeping inflation at target month after month, but over a certain period of time, given that monetary policy operates with long and variable lags. It is not by chance that the words "over the medium term" are an integral part of the ECB's definition of price stability (ECB 2003b, 79). What is thus the appropriate time period for assessing whether inflation has been on target? One year may be too short, but for sure 20 years is too long. The lags with which monetary policy instruments hit their objective range between 18 to 36 months. This is why central banks make forecasts over such a horizon. If this is an appropriate criterion, we may want to test the hypothesis whether the ECB failed to meet its objective between 2013 and 2018. During these six years, as can be seen from the figures in Hartmann and Smets's paper, inflation — both headline and core-is, for the most part, below the range of 1.7 to 1.9 percent. It is thus legitimate to investigate the reasons for such an underperformance, which incidentally is not unique to the ECB. The key question is whether, during this period, monetary policy has been behind the curve-in other words, has been reacting too little too late.

THE FINANCIAL CRISIS AND MONETARY POLICY The financial crisis hit the monetary union after less than 10 years of its young life. The ECB reacted forcefully, but in an environment where it did not always have all the relevant information to fully appreciate the situation or the tools to calibrate its response. Here I point to a few examples, which may deserve greater analysis and a better understanding.

After August 2007. In August 2007, as the money market stopped functioning properly, the ECB intervened by injecting more than $€ 90$ billion in one day, accommodating all the demand for liquidity from its counterparties (ECB 2007). In the following months, the money market continued to malfunction, especially at 3-month maturity, which is a key reference rate. The ECB nevertheless kept its tender procedures unchanged, in spite of the growing divergence between market and policy rates. It decided to move to fixed-rates/full-allotment procedures only in October 2008, long after Lehmann Brothers' crash. 
This - in my view - might have been a mistake, which derived from a less than complete understanding of the health of the banking system. In that period, the ECB was able to gather information on the euro zone banking industry only indirectly, through the national bank supervisors. This was a large source of inefficiency, because local supervisors had the incentive to underreport the problems of their financial sector.

The July 2008 rate hike. In June 2008, the ECB decided to call for vigilance, which was the catchword for announcing an interest rate rise at its meeting the next month. With the benefit of hindsight, that decision may look like a mistake, and has been widely criticized by observers. The crisis erupted two months later, and the ECB had to rescind its decision, cutting rates in October 2008. Figure 22 in Hartmann and Smets' paper shows that such a decision was not warranted, based on a Taylor rule.

Although no single interest rate decision can constitute a major policy mistake, it is useful to clarify the reasoning underlying this decision. First, the euro zone's headline inflation had been above 3 percent for several months, and inflation expectations were at risk of dis-anchoring. Credit growth was still strong. Conversely, core inflation was still hovering around 2 percent, and the economy was showing signs of slowing down, after a buoyant first quarter. The ECB clearly did not read the signals coming from the real economy, which was decelerating rapidly from the middle of the second quarter. Part of the reason for such a misreading derived from the fact that at the time, the ECB had to rely mainly on national central banks to assess short-term cyclical developments.

The 2008 decision-seen in retrospect-also shows the excessive emphasis that the ECB put on the monetary pillar of its strategy. I will not elaborate further on the two-pillar strategy, an issue extensively discussed by Hartmann and Smets. However, the time may have come to reassess it. The emphasis on monetary indicators, in spite of the lack of stability in the demand for money in the euro zone, may have been a price to be paid at the start of the monetary union, but has become less justified.

The 2011 interest rate hikes. In 2011, the ECB decided to raise rates twice, as announced in March and June. These hikes were reversed after a few months, as the financial crisis deepened. There is a large debate in the literature as to whether these decisions are not to be put in the "big mistake" category, because they may have made the crisis even worse.

My personal judgment is that while the decision announced in March was not a big mistake, the second one might instead have been one. Looking at the data available in the spring of 2011, the euro zone was recovering quite strongly and inflation was moving again, toward 3 percent. Under 
these circumstances, a hike of 25 basis points could have been justified. Figure 24 in Hartmann and Smets's paper suggests that a rate hike could have been appropriate even earlier. Other central banks had also raised rates.

At the time of the second hike, the situation had changed substantially, not so much with respect to the real economy but to the risks to financial stability in the euro zone. The restructuring of Greek debt became a clear option at the end of April. Long-term rates started rising gradually but steadily in most peripheral countries. The ECB was opposed to debt restructuring, because of the potential contagion to other countries. It nevertheless made the decision to hike its policy rates, in the expectation that it would not have an impact on the financial situation. It is difficult to assess the extent to which the decision exacerbated the worsening financial conditions. To say the least, it did not help.

SMP versus "whatever it takes." An issue for discussion is why did the ECB wait for more than two years to state that it would do whatever it takes to ensure the stability of the euro and to avoid having a country driven out of the euro against its will. The answer is complex. In 2010, when the ECB started the Securities Market Programme (SMP), the crisis appeared to be circumscribed to three countries; but in 2012, it became systemic. Second, in 2010 the European Stability Mechanism had not yet been established, and the procedure for setting the conditionality for the countries requesting financial support was not yet defined. Third, the institutional framework underlying fiscal discipline had been weakened, especially after the disclosure of Greek budgetary overshooting, thus putting at risk the boundaries between fiscal and monetary policy. The Fiscal Compact, which was adopted in 2012, created the conditions for protecting the ECB from the risk of fiscal dominance.

Overall, the conditions for adopting the Outright Monetary Transactions (OMT) program were not yet mature in 2010. However, the temporary and limited nature of the SMP, which was periodically conveyed to the markets, over time became factors in reducing its effectiveness. One of the OMT's key features is precisely its unlimited nature, which is a fundamental characteristic of a fiat money system, whereby the central bank can create unlimited amounts of central bank money to accommodate demand, and thus stop any panic. This is why the OMT is still untested. If it appeared at any time that there were limits to the OMT, markets would immediately test it. The fact that the SMP was declared to be limited and temporary reduced its effectiveness. Markets interpreted this limit as a sign of the ECB's unwillingness to fully implement the program, and they periodically tested the ECB's resolution. 
Negative rates versus quantitative easing. In the spring of 2014, the ECB decided to lower its deposit rates into negative territory. About one year later, it decided to also start quantitative easing (QE). It is fair to ask whether this sequence was right. The decision to cut rates was probably made in the expectation that it would be a sufficiently bold move to allow the ECB to avoid starting QE, which was politically controversial. With the benefit of hindsight, it is legitimate to ask whether and to what extent the ECB underestimated the impact of the financial crisis on the real economy, starting with the recession in 2012-13 and then with the slow pace of the recovery. It also appears that the ECB may have underestimated the extent to which the banking part of the transmission channel of monetary policy was clogged, partly due to the fact that banking union really started only at the end of 2014, when the SSM took full responsibiliy. It looks like a coincidence that QE started in May 2015, only six months after the start of the banking union.

The argument against QE in Europe was largely based on the assumption that though in the U.S. monetary policy operated mainly through markets, in the euro zone monetary policy operated through the banking system. However, at the zero lower bound, or in negative territory, a fixed-rate/full-allotment tender procedure makes the supply of money entirely demand determined. As Paul Samuelson (1948, 353-54) would remind us, "You can lead a horse to water, but you can't make him drink."

The reasons why banks did not drink may not have been fully perceived and understood. To be sure, the Target 2 data were providing confusing evidence. Balances increased during the crisis, until July 2012, and then decreased sharply after the "whatever it takes" statement (Draghi 2012). At the time, this was considered as a signal that financial tensions were easing, but it also revealed that the supply of central bank money was remaining stable, as the economy was getting out of the slump, signaling that monetary policy was too restrictive. In fact, the size of the ECB's balance sheet started rising only when QE was implemented.

These issues should be thoroughly discussed to understand whether indeed, as some may suggest, monetary policy might have reacted too slowly during the crisis and may have maintained an excessively restrictive stance during the recovery. To be sure, these policy decisions were not uncontroversial. However, with the benefit of hindsight, those who thought that monetary policy was being too expansionary and was putting price stability at risk were proved consistently wrong.

OVERSTEPPING THE MANDATE Throughout the global financial crisis, central banks were criticized for having come very close, or even overstepped, 
their mandate. The ECB was not immune from this criticism, which came from several sides and different perspectives. The most publicized is the compatibility with the Lisbon Treaty (EU 2007) of the SMP, the OMT and QE-all of which imply the purchase of government bonds. The compatibility of these policies with the ECB's independence and with the prohibition of monetary financing has always been relatively clear, at least from an economic point of view-in particular, because these instruments have been adopted by other independent central banks - and subsequently from a legal point of view.

Other controversial issues have received less attention, but are at least as important for the conduct of monetary policy and the integrity of the monetary union. I only mention three.

The collateral framework. In 2006, the ECB revised its collateral framework to set a minimum standard rating for the assets posted as collateral for monetary policy operations. At that time, the issue was not considered so relevant, because all countries had a rating much above the threshold. The threshold was set in such a way as to make sure that all government bonds could be used as collateral. The decision was not without controversy within the Governing Council. Some raised the issue of arbitrariness and the risk of creating a kink effect that could destabilize financial markets. The ECB is, to my knowledge, the only central bank that may refuse government bonds as collateral and resorts to external rating to set haircuts. This policy produces procyclical effects and may add to financial instability.

Such a policy seems to be based on a priority given to the quality of the balance sheet, and the need to avoid losses to the central bank, at the expense of other priorities that do not concern the ECB directly. However, central banks do not have the maximization of profits as an objective, nor the minimization of losses. The Lisbon Treaty states that, without prejudice to the primary objective, the ECB should support the general economic policies of the Community - as laid down in Article 2 of the treaty, which states that the task of the Community is to "promot[e] throughout the Community a harmonious, balanced and sustainable development of economic activities, a high level of employment and of social protection, equality between men and women, sustainable and non-inflationary growth, a high degree of competitiveness and convergence of economic performance, a high level of protection and improvement in the quality of the environment, the raising of the standard of living and quality of life, and economic and social cohesion and solidarity among Member States" (EC 2006). To sum up, it may be time to revise the ECB's collateral framework, to avoid it being part of the problem rather than the solution. 
Emergency Liquidity Assistance. At the start of the monetary union, the Emergency Liquidity Assistance (ELA) policy has been designed for banks that, though solvent, do not have adequate collateral to apply for the ECB's regular monetary policy operations. The ELA policy foresees that the liquidity is provided by the national central bank, with collateral, and thus the risk, posted with that central bank, which are not shared within the Eurosystem. The ECB can only revoke the decision on the basis of a special procedure (ECB 2017). The reason is that the responsibility for assessing whether the bank is solvent was in the hands of the national supervisors. However, with the creation of the Single Supervisory Mechanism at the ECB, the responsibility for declaring a bank solvent has been centralized. It thus appears logical that the risk, and the decision to grant ELA, become centralized.

One specific instance in which the ECB has been strongly criticized is in dealing with the Greek crisis, in particular on the eve of the June 2015 referendum. The ECB limited Greek banks' access to ELA, in a way that might have fueled a run on the banks and caused a loss of confidence. It was obviously difficult for the ECB to consider Greek banks on the same level as other banks a few days before a referendum that was calling Greece's membership in the euro zone into question. Conversely, the ECB's decision had a direct effect on Greece's financial situation, which may not have been fully in line with the mandate of the ECB itself.

Participation in the Troika. Since its inception, the ECB has been part of the Troika-together with the European Commission and the International Monetary Fund-which is in charge of the technical discussions underlying the definition and monitoring of the adjustment program. This role was particularly important with respect to the need to have adequate information about the banking system and making sure that the adjustment program foresaw an adequate capitalization. However, such a role is quite peculiar for a central bank, given that it gets into policies that are not of its competence. There is a risk of getting involved in political discussions, and thus losing degrees of freedom. Now that the banking union has transferred supervisory functions at the ECB, there is much less need for it to participate in the Troika.

CONCLUSION To assess the ECB's performance over the last 20 years on the basis of its primary objective, which is price stability, is necessary but probably not sufficient. The ECB is one of the European Union's institutions, and cannot be immune from the economic, social, and political developments that affect the Union. Although the ECB has demonstrated in a few years that it is an effective and efficient central bank, it should 
not fear that its credibility can be undermined by an open discussion of its key decisions over the years. Like other EU institutions, the ECB has been affected by a negative confidence trend, as reflected by the Eurobarometer polls. Although the last Eurobarometer shows that favorable opinions about the euro have gone back above precrisis levels and reached a peak (74 percent), and those against the euro have fallen to a minimum (20 percent), the share of respondents who "trust the ECB" has fallen below those that do not trust it (42 percent against 45 percent; it was 46 percent against 27 percent before the global financial crisis) (EC 2018). Changing these opinions is certainly a challenge for the years to come. Hartmann and Smets's paper is a good start in this endeavor, but only a start.

With respect to the issues that may need be reassessed, 20 years later and in light of experience, I suggest these: (1) the definition of price stability, symmetric at 2 percent; (2) the further downgrading or elimination of the monetary pillar; (3) centralization of the ELA policy; (4) a review of collateral policy; and (5) an exit from the Troika.

\section{REFERENCES FOR THE BINI SMAGHI COMMENT}

Draghi, Mario. 2012. "Verbatim of the Remarks Made by Mario Draghi." Speech at Global Investment Conference, London, July 26. https://www.ecb.europa.eu/ press/key/date/2012/html/sp120726.en.html.

EC (European Parliament and Council of the European Union). 2006. "Directive 2006/123/EC of the European Parliament and of the Council." https://eur-lex. europa.eu/LexUriServ/LexUriServ.do?uri=CELEX:32006L0123:en:HTML\# d1e39-36-1.

. 2018. "Eurobarometer: Support for the Euro Steady at All-Time High Levels November." https://ec.europa.eu/info/news/eurobarometer-2018-nov-20_en.

ECB (European Central Bank). 2003a. "The Outcome of the ECB's Evaluation of Its Monetary Strategy." ECB Monthly Bulletin, June, 79-92. https://www.ecb. europa.eu/pub/pdf/other/pp79_92_mb200306en.pdf?e366490ebb678c0d82b6d $62 \mathrm{a} 85 \mathrm{e} 10 \mathrm{~d} 44$.

2003b. "Press Seminar on the Evaluation of the ECB's Monetary Policy Strategy." Press release, May 8. https://www.ecb.europa.eu/press/pressconf/ 2003/html/is030508_1.en.html.

2007. Monthly Economic Bulletin, September.

2017. "Agreement on Emergency Liquidity Assistance." https://www. ecb.europa.eu/pub/pdf/other/Agreement_on_emergency_liquidity_assistance_ 20170517.en.pdf.

EU (European Union). 2007. "Treaty of Lisbon Amending the Treaty on European Union and the Treaty Establishing the European Community, Signed at Lisbon, 13 December 2007." https://eur-lex.europa.eu/eli/treaty/lis/sign?eliuri=eli:treaty: lis:sign. 
Friedman, Milton. 1968. "The Role of Monetary Policy." Presidential Address delivered at 80th Annual Meeting of American Economic Association, December 29. Published in the American Economic Review 58, no. 1: 1-17.

Samuelson, Paul. 1948. Economics. New York: McGraw-Hill.

Trichet, Jean Claude. 2011. "Remarks at the Farewell Event, Frankfurt, October 19. https://www.ecb.europa.eu/press/key/date/2011/html/sp111019.en.html.

\section{COMMENT BY}

LUCREZIA REICHLIN The paper by Philipp Hartmann and Frank Smets provides a useful narrative of the first 20 years of the European Central Bank (ECB) and an assessment of its performance. Overall, the authors' assessment of the ECB's record is very positive. There are four main conclusions:

1. The ECB has been successful in respecting its price stability mandate throughout its 20 years of history.

2. Its two-pillar strategy and definition of price stability target have served it well.

3. The tools associated with its strategy have evolved over time in a pragmatic way and responded successfully to the challenges of the global financial crisis.

4. Its operational framework revealed itself to be robust to the test of the worst crisis since World War II.

There is a lot to agree with in this assessment, and especially on the broad conclusion that, notwithstanding the global financial crisis and contrary to the expectation of many, the euro has emerged as one of the world's main currencies and the ECB - at least so far - has been a credible custodian of its value.

My own assessment is nevertheless more nuanced. In my view, the main question that should be answered, after 20 years of the life of the euro and 10 years after the global financial crisis, is whether the economic framework on which the European Economic and Monetary Union is based, and the ECB's central role in it as a central bank without a state, is adequate to face periods of particular financial and economic stress. The answer here is not straightforward, and the analysis of the crisis should give elements for reflection on necessary reform.

My remarks are organized in two sections. First, I discuss the ECB's nonstandard policies during the crisis. And second, I comment on interest rate policy during the same period. I base my remarks on my published work on the subject (in particular, Lenza, Pill, and Reichlin 2010; Pill and Reichlin 2014, 2016a, 2016b; and Reichlin 2014, 2018). 
NONSTANDARD POLICIES, 2007-14 I analyze four distinct episodes of ECB action. Unlike Hartmann and Smets, I do not follow a chronological order but rather use four case studies to make my points.

The periods 2007-10 and 2011-12: two examples of nonstandard liquidity policies. The first symptoms of the liquidity crisis in the banking sector emerged in the euro zone in August 2007, with tensions in the money markets. The first phase of the crisis can be defined as one of a generalized counterparty risk that generated a significant increase in the demand for liquidity from the central bank by the banks, both fragile and healthy. With the collapse of Lehman Brothers in the United States in 2008, the nature of the crisis changed. A number of banks failed, and the global economy entered its worst recession since the 1930s. The interbank market effectively collapsed.

As I have argued elsewhere (Lenza, Pill, and Reichlin 2010; Pill and Reichlin 2014, 2016a), the response to this liquidity crisis can be considered a success. Hartmann and Smets agree with this view. The ECB acted aggressively and swiftly, thanks to an operating model that was fit to deal with this kind of crisis. As Tommaso Padoa-Schioppa (2004) had predicted in writing years before the crisis, the ECB's operating model was well prepared to act as a "lender of last resort" in cases of a widespread liquidity crisis, because it had both an open market transaction system that was well equipped to deal with systemic crises, and an instrument for providing emergency liquidity assistance to individual institutions. The ECB also had a head start over the leading central banks, including the Federal Reserve in the United States. It had a larger budget (in part because it remunerates bank reserves, a policy only adopted by the Fed after the crisis), and therefore had a greater capacity to absorb liquidity shocks. In addition, it started from a broader definition of eligible collateral in its operations with banks and accepted a broader category of institutions as counterparties in its operations (Pill and Reichlin 2016a). This enabled the ECB to adopt a systemic approach to the crisis right from the start, rather than have recourse to specific rescues. The bank's action at this stage respected the classic Bagehot's rule, according to which the central bank must act as a lender of last resort when counterparty risk blocks the entire system and therefore has an effect on both fragile and robust banks.

As a consequence of the refinancing operations in cooperation with banks with fixed-rate/full-allotment credit operations (in order to meet demand), the ECB's balance sheet increased in size, although the mechanism (and its motivation) was not the same as that implemented at the same time by 
other central banks, such as the Fed and the Bank of England. As Huw Pill and I have observed (2016a), the action of the ECB at this stage should be interpreted as aimed at keeping the financial system and its infrastructure working by acting as an intermediary for transactions for which the market had stopped functioning as an intermediary, thus acting as a central counterparty of last resort. These policies need to be seen as complementary to the traditional policies of setting the Main Refinancing Operations interest rate. The motivation was different than that of using balance sheet policies as a substitute for interest rate policy when the latter reaches the zero lower bound. However, as with quantitative easing and credit easing, both the size of the balance sheet and the composition of its assets increased as a result. Quantitative works by Lenza, Pill, and Reichlin (2010) and by Giannone and others (2012) have shown the effectiveness of these policies in supporting lending and economic activity.

However, as the generalized liquidity crisis became a banking crisis and the insolvency of some institutions threatened the stability of the system, this clear distinction between liquidity policy and solvency was blurred. Here is where the limits of the euro area's governance became obvious.

It is interesting to analyze the difference between what happened in the period 2007-9 and in 2011. In late 2011, when Mario Draghi took over from Jean-Claude Trichet as president of the ECB, there was the risk of a new banking crisis. The issue facing the ECB was no longer one of a generalized liquidity drying out, but one of solvency. In this context, without the tools for a comprehensive approach to recapitalization, the ECB found itself as the only institution in the euro zone able to act across the monetary union with the power, if not to resolve the situation, at least to avoid the worst, and thus enable the euro-zone's governments and the European institutions to take the time to devise other solutions.

Against this background, Draghi announced a series of long-term refinancing operations (LTROs) in December 2011 and February 2012 (fixed-rate/full-allotment, 3-year refinancing operations). As for the LTROs adopted by Trichet in 2009, by means of these operations, the ECB became a centralized counterparty in the interbank market, but now for the longer term and therefore with more relevance for financing the banks and not just for managing liquidity. LTROs were also crucial in supporting the public sector at a time of great tensions in the sovereign debt market. In fact, with these measures, the banks were able to borrow funds from the ECB at a much lower rate and reinvest them in government bonds of peripheral countries that yielded much higher rates. In this way the banks not only 
made profits but also supported the very market from which foreign investors had fled.

In this situation, the ECB acted as an intermediary for cross-border capital flows in an intra-euro zone market that, given the correlation between bank risk and country risk, was once again segmented by country. This phenomenon, known as the diabolic loop (see Brunnermeier and others 2016), consists of the fact that a country that has difficulties refinancing its debt puts pressure on its banks to purchase national government bonds, while a bank in crisis puts potential pressure on the public finances of its country if it is at risk of failure. The purchasing of their own country's sovereign bonds by banks was made possible by targeted LTROs- that is, loans to banks made over a time frame of up to four years at favorable terms, on the condition that the beneficiary institutions use the funds to provide credit to the real economy-which were introduced in June 2014 and again in March 2016. These targeted LTROs reinforced this correlation between bank risk and sovereign risk, which in turn created heterogeneity between the bank rates to customers, reducing the efficacy of Frankfurt's monetary policy. The ECB provided cheap financing to the banks, and the banks used it to buy sovereign debt (indirectly financing the sovereign) to use as collateral to obtain ECB financing. As a consequence, we saw a substitution in banks' balance sheets-from loans to the private sector to holdings of sovereign bonds.

This episode is an illustration of how the ECB's operations, as they were conceived under its original mandate, can nevertheless lead to it being the conduit for cross-border risk sharing via the portfolio of collateral it comes to hold—with sizable geographical distribution effects.

Bank defaults were avoided or postponed, but the euro zone's economy entered a credit crunch. In this period, there was a far larger fall in the growth of new loans to businesses and households than during the 2008-9 global financial crisis, even after conditioning for the dynamics of industrial production (Reichlin 2014).

There are two lessons from this narrative. The first is about the tension between liquidity policies and the ECB's narrow mandate. Central banks' ability to create liquidity at will means that they are uniquely well placed to resolve liquidity problems in the financial sector. This is the basis for both Bagehot's rule ("Lend freely against good collateral") and Friedman's rule ("Provide central bank liquidity at its marginal social cost—which is zero").

And because liquidity stresses may have solvency concerns at their root, the central bank is bound to monitor the strength of the banking system 
overall, as well as the strength of individual institutions. Add to this the fact that central banks have an informational advantage, from their oversight of the payments system, and we can see that it is inevitable that central banks will play a central role in the maintenance of financial stability, whether this is explicitly recognized in their mandates or not.

Bagehot's rule is apparently clear, logical, and consistent with the ECB's narrow mandate, and it was what the ECB applied in the first phase of the crisis. However, in practice the rule is useless because the distinction between illiquidity and insolvency is often impossible to make in real time. In the end, central banks will always act to defend the monetary system, whether it is in their mandate or not, and defending the monetary system will have both monetary and fiscal consequences. The fiscal consequences were clear in the second phase of the crisis.

The second lesson, which is a consequence of the first, is that the governance structure should recognize and anticipate this fact. As Charles Goodhart has argued (1999), the question is not whether or not to act as a lender of last resort, but how best to organize this function so that it preserves the central bank's independence on one hand and ensures its fiscal backing on the other hand. This is a question of institutional design.

The sovereign debt crisis: The Security Market Programme (SMP) and Outright Monetary Transactions (OMTs). I have been describing the ECB's actions in response to a crisis in the banking system. But the ECB was also faced with a crisis in relation to the sovereign states of the euro area.

To understand the effectiveness of the ECB at this juncture, it is useful to compare two programs: the SMP and the OMT. On May 14, 2010, the ECB established the SMP, a program consisting in national central banks buying the government bonds of stressed countries. This program was initially a response to the Greek debt crisis, which gradually developed starting in the autumn of 2009, when the new Greek government first acknowledged the country's poor fiscal situation, to a real funding strike in the early spring of 2010 .

This placed the ECB in a bind. On one hand, the ECB was understandably concerned that permitting a default on the sovereign debt of a euro area country threatened that country with financial collapse, given that the banking system held a significant amount of sovereign debt, much of which was used as collateral for ECB operations by this point. Such a financial collapse might then trigger exits from the euro if national authorities were forced to revert to their national currency to sustain payments and provide liquidity. 
Moreover, the fear of contagion to other countries was considerable: If Greece were to default and/or exit, then this possibility would be entertained for other peripheral euro area economies, such as Ireland and Portugal. And banks in core countries had significant exposures to Greek sovereign debt.

On the other hand, the ECB was not well equipped on its own to address the solvency problem that threatened Greece. It was subject to institutional constraints that were expressly designed to protect it from pressure to deliver quasi-fiscal support to address solvency problems.

The ECB looked to the euro zone's national governments to provide the necessary fiscal support, but this was challenged on the grounds of the Maastricht Treaty's "no bail out" clause. But by late April 2010, a set of bilateral loans from other euro area countries had been agreed to- $\mathrm{a}$ framework that eventually took a stronger institutional form in the European Financial Stability Facility, and ultimately the European Stability Mechanism (ESM), within the context of an adjustment program under the auspices of, and also cofinanced by, the International Monetary Fund.

Yet even this initiative failed to restore market confidence, in part because official loans were to be made senior to private sector holdings. In early May, market tensions in Greece reached fever pitch, cross-border contagion intensified, and the SMP was eventually launched.

Despite this program-on which a total of $€ 223$ billion was eventually spent - the effect on sovereign spreads was limited, and the contagion also affected Italy and Spain. Indeed, in August 2011, the SMP was extended to Italy and Spain, but again with not much of an effect on sovereign credit spreads.

The failure of the SMP to calm markets can be attributed to the lack of a solid mandate. We should recall that Axel Weber, the president of the Deutsche Bundesbank, resigned in April 2011 in opposition to the ECB's action. In fact, the ECB itself described it as a limited and temporary program rather than an actual backstop.

This brings me to the second example of the ECB's intervention in the sovereign bond markets: the OMT announcement in July 2012.

In response to the worsening of the sovereign debt crisis, ECB president Draghi declared on July 26, 2012, during a conference in London: "Within our mandate, the ECB is ready to do whatever it takes to preserve the euro. And believe me, it will be enough" (Draghi 2012). He focused his speech on financial fragmentation as the main short-term challenge for restoring the transmission of the ECB's monetary policy.

A few days later, on August 2, the ECB announced outright purchases of sovereign debt in secondary bond markets, and in September it announced 
the key parameters of the OMT program. Under the program, the ECB could purchase unlimited amounts of euro zone government bonds with maturities of one to three years, provided that the country whose bonds the ECB would buy met four key conditions. First, it had to receive financial support from the ESM. Second, it had to comply with the reform measures required by the respective ESM program. Third, the OMT program could only be activated if the country had regained complete access to private lending markets. Fourth and finally, the country's government bond yields had to be higher than what could be justified by the fundamental economic data.

As of today, the OMT program has never been used. Yet quantitative evidence in a substantial body of empirical literature, amply acknowledged by Hartmann and Smets, shows that the announcement had a large effect on sovereign yields, much larger than the effect of the actual purchases under the SMP. Equally, the OMT was much more successful in easing the funding conditions for banks in peripheral countries than the LTROs discussed above. This is explained by the fact that those conditions were partly affected by sovereign risks in banks that had had incentives to buy large quantities of domestic sovereign bonds.

So what made the difference? Why was the OMT announcement successful when the SMP was not?

Unlike the SMP, the OMT was conditional on countries entering a "program." This can be seen as a compromise: recognizing, on one hand, that a bad equilibrium resulting from a self-fulfilling crisis is possible; but also recognizing, on the other hand, the moral hazard issue due to the role of underlying solvency problems. In other words, it can be viewed as a mechanism to govern a trade-off between the risk of moral hazard (and therefore price instability) and financial instability via a solution that conditioned policy action to reform.

The fact that the scale of potential bond buying under the OMT was unlimited-and that, by intervening directly in the bond market, the ECB did not make itself a senior claimant-were also important factors contributing to the effectiveness of the OMT program in comparison with the SMP.

However, perhaps more significant than any of these specific aspects was the fact that the institutional context had changed. The ESM had been created, and the banking union had been agreed to. Crucially, the OMT was backed by a political agreement between the major countries; most notably, it was supported by German chancellor Angela Merkel, despite opposition from the Bundesbank. 
The conditionality provided greater control over the fiscal dynamics, but the ECB's purchase of sovereign bonds meant taking credit risk onto the balance sheet of the Eurosystem, which implied some degree of fiscal backing. In other words, the OMT's credibility was due to a new bargain with the sovereign fiscal authorities on shared responsibilities involving new institution building.

The role of the lender of last resort for the sovereign in the euro area has been the subject of policy and academic debate. The case for an active ECB role as lender of last resort has been made, for example, by Paul de Grauwe (2012), on the basis of the observation that within a currency union, member states issue bonds in a "foreign" currency-that is, one that they do not themselves control. Hence, these member states cannot give a guarantee equivalent to the one that can be given by a sovereign with its own central bank, and investors may rightly fear that the sovereign will not be able to redeem the bonds when they mature. This means that the market for sovereign bonds of states within a monetary union is prone to liquidity crises and contagion-in much the same way that banking systems were afflicted by such emergencies before central banks stepped in as lenders of last resort.

The extreme behavior of spreads on sovereign bonds-going from around zero up until 2010, then spiking in 2010-12, and then falling again after 2012-is taken as evidence to support this argument. The proponents of this view maintain that even if the probability of default is driven by fundamental solvency issues, the central bank should intervene anyway, because in real time solvency and liquidity problems cannot be distinguished. Giancarlo Corsetti and Luca Dedola (2016) have recently studied this problem using a model with multiple solutions for the interest rate that private investors demand on bonds issued by the fiscal authority. Given that the monetary authority can issue liabilities at a lower interest rate than can a government that is subject to default risk, it can also lower the overall cost of borrowing for the public sector-which makes full repayment via taxation a more likely outcome than default and partial repayment. These researchers thus show that a suboptimal equilibrium can be avoided if the central bank announces its willingness to intervene.

However-and this is the key issue with the simplified version of this argument propounded by De Grauwe (2012) —in some states of the world, default could occur irrespective of whether the central bank made bond purchases. If the state defaults, the monetary authority would then suffer a capital loss and, if its balance sheet is sufficiently impaired, excessive inflation could result. To avoid this inflation scenario, the central bank must 
recapitalize, which requires an agreement with the fiscal authorities. It is easy to imagine that if the ECB were to ask national central banks for recapitalization, political questions related to the redistributional effects of monetary policy could lead to paralysis, eventually impairing the ECB's credibility. This problem was originally analyzed by Christopher Sims (1999, 2012), who discusses fiscal backing in the Eurosystem. See also Corsetti and others (2016) for a recent discussion and relevant references.

The comparison between the SMP and the OMT provides a relevant case study showing that the central bank's credibility, and therefore effectiveness, depends on its backing by government. But if the power of the central bank ultimately comes from the backing of the sovereign, there is a problem of institutional design. The OMT in principle provides the fiscal backstop, but the fact that this instrument is in the hands of a central bank rather than democratically elected fiscal authorities could potentially constitute a challenge to the ECB's independence. To design an instrument for the euro area's common fiscal capacity would be more effective and would provide for more accountable governance of the monetary union.

MACRO STABILIZATION: INTEREST RATE POLICY AND THE ECB RULE The paper analyzes the ECB's interest rate policy through the lenses of a policy rule specified by Athanasios Orphanides (2003). According to Hartmann and Smets, this rule captures well the ECB's interest rate setting since 1999, including the crisis years. The implicit inflation target derived by the rule is 1.75 percent, which is very close to the price stability target definition of inflation of "below, but close to, 2 percent in the medium term"- an impressive outcome!

However, it is not clear that this rule was the right one to follow from a normative perspective. Other rules should also have been analyzedfor example, providing measures of the result in terms of inflation and unemployment.

Without such analyses, from a purely descriptive perspective, two episodes are particularly controversial. The first is the interest rate increase of July 2008. At the time, the interest rate increase was motivated by headline inflation (according to the Harmonised Index of Consumer Prices) being well above the target, having reached 3.75 percent. We now know, however, that the euro area had entered a recession in the first quarter of 2008, and of course the financial sector had already given signs of weaknesses on both sides of the Atlantic. The high level of inflation was explained by oil prices. The same was true in 2011, when the ECB 
increased interest rates twice. At the time, headline inflation was about 3 percent, while core inflation was well below 2 percent. (For a quantitative assessment of the direct and indirect effects of oil prices on headline inflation, see Reichlin 2018.)

It is interesting to quote the ECB's press statement on April 7, 2011 (ECB 2011):

The adjustment of the current very accommodative monetary policy stance is warranted in the light of upside risks to price stability that we have identified in our economic analysis....

With regard to price developments, euro area annual HICP inflation was $2.6 \%$ in March 2011, according to Eurostat's flash estimate, after 2.4\% in February. The increase in inflation rates in early 2011 largely reflects higher commodity prices. Pressure stemming from the sharp increases in energy and food prices is also discernible in the earlier stages of the production process. It is of paramount importance that the rise in HICP inflation does not lead to second-round effects in price and wage-setting behaviour and thereby give rise to broad-based inflationary pressures over the medium term. Inflation expectations must remain firmly anchored in line with the Governing Council's aim of maintaining inflation rates below, but close to, $2 \%$ over the medium term.

Risks to the medium-term outlook for price developments remain on the upside. They relate, in particular, to higher than assumed increases in energy prices, not least owing to ongoing political tensions in North Africa and the Middle East. More generally, strong economic growth in emerging markets, supported by ample liquidity at the global level, may further fuel commodity price rises. Moreover, increases in indirect taxes and administered prices may be greater than currently assumed, owing to the need for fiscal consolidation in the coming years. Finally, risks also relate to stronger than expected domestic price pressures in the context of the ongoing recovery in activity.

Interestingly, it is recognized that inflation dynamics are explained by commodity prices but, as in July 2008, potential second round effects are emphasized. The first observation is that the ECB has historically given too much weight to headline inflation rather than monitoring measures of underlying inflation, as in other central banks.

Another observation is that the stress on second-round effects was done in a context in which the debt crisis was in full displacement, affecting both banks and sovereigns. Hartmann and Smets comment on these episodes as a possible underestimation of the effect of the credit crunch (for the reasons discussed in the previous section) on the real economy and on underlying inflation.

The question is whether, in this underevaluation, we can identify a problem that again has to do with the narrow interpretation of the mandate, seeing the monetary policy objective and the price stability mandate not 
only as separate from the financial stability objective but also as independent. Although it can be argued that, in the spring of 2011, the second recession had not yet started in the euro area, there was ample evidence of a credit crunch, a segmentation of the financial market along national lines, and a substitution of countries' sovereign bonds for loans on the banks' assets that was affecting the real economy.

In the years 2012-14, the interest rate reached the zero bound. At the same time, the balance sheet of the Eurosystem, which had expanded as an endogenous consequence of liquidity operations, began to shrink.

During that period, it can be argued that the ECB was slow to act. Quantitative easing finally found the support of a vast majority of the Governing Council, when it became clear that the inflation target that the ECB is required to meet under the Maastricht Treaty was still not being met, and the European Union was risking entering a period of deflation, as Japan had done in the 1990s. It is of little comfort that the implied inflation target for the first 20 years of the ECB's history, as calculated by the Hartmann-Smets rule, was 1.76 percent.

CONCLUSION Maastricht is the child of the precrisis consensus, which led to the ECB's design - an extreme form of independence, and a constitutional mandate of price stability.

During the global financial crisis, the ECB was confronted with the problem of defending price stability but also defending the stability of the financial system. Because liquidity and solvency concerns cannot be separated in practice, a strict "separation principle" was not always useful for guidance. The ECB, by acting to defend the stability of the financial system, implemented policies with potential fiscal implications and geographical distributional consequences.

In this, it was no different than other central banks. The nature, visibility, and political sensitivity of distributional consequences related to nonstandard policies are similar in many countries. Because these policies are likely to also remain in the tool kits of central banks during normal times, new problems of institutional design are likely to emerge. In the euro area, where politics is still largely national and distributional consequences often arise between member states, it is not surprising that these problems are more controversial.

These exceptional policies were seen to be necessary - to stabilize the financial system, and even to save the euro. However, as we have seen, they were less successful when the backing of the fiscal authorities was uncertain. Ultimately, the power of central banks comes from the sovereign, and the ECB case powerfully illustrates this point. 
So, if we are to ask whether the ECB did the right thing-whether it did what was necessary in pursuit of its mandated objectives-we must also ask if it needed to overstep the remit given in the Maastricht Treaty. And if so, then what does this imply for the necessary institutional reform?

\section{REFERENCES FOR THE REICHLIN COMMENT}

Brunnermeier, Markus K., Sam Langfield, Marco Pagano, Ricardo Reis, Stijn Van Nieuwerburgh, and Dimitri Vayanos. 2016. "ESBies: Safety in the Tranches." Working Paper 21. Brussels: European Union, European Systemic Risk Board. https://www.esrb.europa.eu/pub/pdf/wp/esrbwp21.en.pdf.

Corsetti, Giancarlo, and Luca Dedola. 2016. "The Mystery of the Printing Press, Monetary Policy and Self-Fulfilling Debt Crises." Journal of the European Economic Association 14, no. 6: 1329-71.

Corsetti, Giancarlo, Luca Dedola, Marek Jarocinski, Bartosz Maćkowiak, and Sebastian Schmidt. 2016. "Macroeconomic Stabilization, Monetary-Fiscal Interactions, and Europe's Monetary Union.” ECB Working Paper 1988. Frankfurt: European Central Bank.

De Grauwe, Paul. 2012. "The Governance of a Fragile Eurozone.” Australian Economic Review 45, no. 3: 255-68.

Draghi, Mario. 2012. "Verbatim of the Remarks Made by Mario Draghi." Speech at Global Investment Conference, London, July 26. https://www.ecb.europa.eu/ press/key/date/2012/html/sp120726.en.html.

ECB (European Central Bank). 2011. "Introductory Statement to the Press Conference (with Q\&A)," by Jean-Claude Trichet and Vítor Constâncio, Frankfurt, April 7. https://www.ecb.europa.eu/press/pressconf/2011/html/ is110407.en.html.

Giannone, Domenico, Michele Lenza, Huw Pill, and Lucrezia Reichlin. 2012. “The ECB and the Interbank Market." Economic Journal 122, no. 564: 467-86.

Goodhart, Charles. 1999. "Myths about the Lender of Last Resort." Journal of Finance 2, no. 3: 339-60.

Lenza, Michele, Huw Pill, and Lucrezia Reichlin. 2012. "Monetary Policy in Exceptional Times. Economic Policy 25, no. 62: 295-339.

Orphanides, Athanasios. 2003. "Historical Monetary Policy Analysis and the Taylor Rule.” Journal of Monetary Economics 50, no. 3: 983-1022.

Padoa-Schioppa, Tommaso. 2004. Regulating Finance: Balancing Freedom and Risk. Oxford University Press.

Pill, Huw, and Lucrezia Reichlin. 2016a. "Exceptional Policies for Exceptional Times: The ECB's Response to the Rolling Crises of the Euro Area." In Routledge Handbook of the Economics of European Integration, edited by $\mathrm{H}$. Badinger and V. Nitsch. New York: Routledge.

. 2016b. "Non-standard Monetary Policy and Financial Stability: Developing an Appropriate Macrofinancial Policy Mix." In Preparing for the Next 
Financial Crisis: Policies, Tools, and Models, edited by Esa Jokivuolle and Radu Tunaru. Cambridge University Press.

Reichlin, Lucrezia. 2014. "Monetary Policy and Banks in the Euro Area: The Tale of Two Crises." Journal of Macroeconomics 39, part B: 387-400.

. 2018. "Comment on 'Slack and Cyclically Sensitive Inflation' by J. Stock and M. Watson.” Paper presented at European Central Bank's Annual Forum, "Price and Wage Setting in Advanced Economies, Sintra, June 18-20.

Sims, Christopher A. 1999. The Precarious Fiscal Foundations of EMU. Staff Report 34. Amsterdam: Dutch National Bank.

. 2012. "Gaps in the Institutional Structure of the Euro Area." Financial Stability Review (Banque de France) 16: 217-23.

GENERAL DISCUSSION Athanasios Orphanides began by saying that the European Central Bank (ECB) has made some major mistakes. It is important for this panel to discuss these mistakes and draw lessons from them, he said, so they are not repeated in the future.

During the past several years, the ECB's actions have compromised the safe asset status of sovereign debt in the euro area, he said. This greatly exacerbated the destabilization of the euro area, and he pointed to the increasing Italian spreads over the three months leading up to this conference as the latest example. He highlighted two issues that should be discussed better in the paper by Hartmann and Smets. First, when evaluating the solvency of sovereigns, the ECB has decided to rely exclusively on market interest rates-including unrealistic risk premia that may reflect adverse self-fulfilling equilibria, which has a destabilizing effect. Second, he noted that the ECB is the only central bank that questions whether the government debt of its own member countries is eligible collateral for monetary policy operations, regardless of fundamentals. This happens because of a discretionary decision made before the global financial crisis that delegated the determination of collateral eligibility to rating agencies. He called this an unfortunate decision because it creates destabilizing cliff effects and leads to adverse equilibria. Policymakers know that these policies worked terribly during the crisis, he said, and he wondered whether these mistakes would be corrected.

Jason Furman noted that the paper by Hartmann and Smets treats the neutral interest rate as fixed over the ECB's 20 years. He questioned why the authors made that choice, and if they were to choose differently, wondered if the analysis would show considerably more monetary policy tightening during the examined period relative to the authors' results. 
Jón Steinsson found it notable that there was little mention of unemployment rates. The main point he gathered from the paper was that the ECB hit its inflation target, and because the unemployment rate is not part of the ECB's mandate, the authors do not discuss it. However, he noted that there is a view that during the crisis, allowing for a somewhat higher level of inflation would have helped real wages and unemployment rates adjust in Southern Europe. One of the many reasons why this policy was not pursued, he conjectured, is because unemployment is not part of the ECB's mandate. He wondered if this is indicative of a problem with the ECB's mandate itself, and whether a dual mandate like that the U.S. Federal Reserve could work better.

Eric Rosengren asked the authors whether they expect the ECB to hit the zero lower bound frequently in the future, and if that consideration would alter the ECB's policy framework.

Frederic Mishkin said that he found the ECB's framework problematic, particularly regarding the inflation target. Because the language of the mandate indicates that the ECB wants inflation to be slightly lower than 2 percent, it is asymmetric in nature, he said. He thinks that the ECB chose this language because when it was formed, the ECB aimed to inherit the credibility of the Deutsche Bundesbank, and the Bundesbank had an asymmetric inflation target. The unfortunate policy consequence is that the ECB is more concerned about overshoots than undershoots, he said. He thought that this asymmetry was one of the key factors in the ECB's decision to raise interest rates in 2011. He then pointed to the U.S. Federal Reserve, noting how it emphasizes that its target is symmetric. There are even arguments for overshooting for temporary periods. He concluded by acknowledging that the ECB performed well during the initial phases of the global financial crisis, but that the inflation targeting aspect of European monetary policy should be changed.

Robert Gordon referred back to Steinsson's point about the Federal Reserve's dual mandate versus the ECB's inflation mandate. He claimed that the ECB gives a disproportionate amount of attention to inflation movements and inflation expectations, to the exclusion of factors such as unemployment, potential output, actual output, and output gaps-all factors that the Fed considers relevant context for monetary policy. As an evaluation of the ECB's performance over the past 20 years, the paper should have included comparisons on employment rates and actual and potential output growth between the euro area and the United States, he said; but any differences may not be entirely related to monetary policy. He suggested that someone should write a paper comparing actions by the ECB and 
the Fed, including the different interest rate sequences and the timing of quantitative easing programs. That paper should also distinguish between fiscal austerity in Southern versus Northern Europe, and document the lack of fiscal coordination in the euro area. He noted that the U.S. did not have to face this problem, despite its own fiscal austerity in 2013 and 2014.

Jay Shambaugh discussed the policy rule - which indicates the central bank's interest rate response according to economic conditions- that the authors examine in the paper. On one hand, he thought that it was fascinating to see how closely the ECB followed the rule. On the other hand, he wondered if it was desirable for the ECB to follow this particular rule so closely, especially since it closely follows headline inflation. Given that the rule suggests raising rates in 2008 and 2011, he questioned whether this is the right rule for ECB to follow. Further, he wondered if the forecasts incorporated in the rule were biased. For example, if the forecasts systematically underestimate deflation risk, even if the ECB followed the rule, it would systematically prescribe actions that are too tight. Finally, he echoed previous comments that questioned the merits of inflation target asymmetry and, more broadly, whether the ECB's mandate should be expanded.

Glenn Rudebusch said that the authors' policy rule choice also puzzled him. Because the rule relates the change in the interest rate to a change in the price level, it is essentially a price level-targeting rule. He also thought that the metric used to assess whether the ECB followed this rule was weak. He suggested that the authors examine the ECB's response with the Taylor rule, and suspected that it would probably fit just as well as the first-difference rule that the authors used. He noted that it is important to clarify if the rule incorporates an output gap in levels or an output gap in growth terms.

Richard Cooper began by stating that he agrees with the substance of many previous comments. He added that much of this discussion, however, essentially questioned the Maastrich Treaty—something that the ECB cannot change itself. Any revision would need the ratification of all member governments. Although the treaty mandates price stability, Cooper noted that it does not specify an inflation target, nor whether it should be asymmetric or not. Thus, he claimed that the ECB has adopted an asymmetric target around price stability by stating "below, but close to, 2 percent inflation." Thus, Cooper agreed with the criticisms on the asymmetry point. He noted that he was against the Maastricht Treaty from the beginning, because he believed that it was a poor instrument for achieving monetary union in Europe. 
Lorenzo Bini Smaghi addressed two issues: the asymmetry of the 2 percent inflation target, and whether the ECB should adopt a dual mandate. He agreed that the ECB should revisit and discuss the inflation target. Although the ECB was very set on its initial definition of price stability, the ECB should to go back and discuss what "close to 2 percent" actually means, he said. However, he does not agree with the comments suggesting that the ECB should adopt a dual mandate like that of the U.S. Federal Reserve. When observing economic variables (like GDP per capita), he said that the euro area and the U.S. have been on similar trends, with the exception of the second recession in the euro area in 2012 and 2013. Indeed, after the second recession, the euro area recovered and fell back in line with the United States. The real difference, he claimed, was the response to the global financial crisis. The crisis was not dealt with well in the euro area, whereas there was a smarter response in the U.S. The underlying issue was financial stability, he said, and the ECB's mandate did not fully incorporate that.

Further, it is unclear how fiscal policy contributed to financial stability in the euro area, Bini Smaghi noted. He thinks that the ECB is moving to make the euro area's financial system more resilient by having a fiscal backstop and having a single supervisor. But he urged the audience to remember that long-term economic performance in the euro area has not done worse, on average, than in the U.S. He noted that some European countries have even done better (such as Germany and Finland). It is important to look at the structural issues related to these economies, he concluded.

Philipp Hartmann started out by asking the rhetorical question of whether at the occasion of the European Central Bank's 20th anniversary, anybody in the room had something positive to say about the ECB or Economic and Monetary Union (EMU). Next, he expressed his impression that a number of the conference participants seem to imply that ECB policymakers should "first, break all the rules," as suggested by the title of the best-selling book by Marcus Buckingham and Curt Coffman. ${ }^{1}$ Even though the true recommendations of those authors for industry leaders had a somewhat different meaning, Hartmann would not find it wise for central bank policymakers to go against the mandates and laws given to them by the democratic political process.

More specifically, he grouped his answers into three main points. First, he addressed the claims that the ECB's price stability aim was asymmetric.

1. Marcus Buckingham and Curt Coffman, First, Break All The Rules: What the World's Greatest Managers Do Differently (New York: Simon \& Schuster, 1999). 
He recalled that the paper tested for the asymmetry of the policy rule and rejected that hypothesis. Further, he stressed that the ECB, in its communications, has repeated since the early days of the euro that its aim is symmetric. Given both the scientific analysis and the consistent communication, Hartmann said that the people who still believe that the ECB's inflation aim is asymmetric should provide evidence supporting their perception. Maybe the wording of an inflation rate "below, but close, to 2 percent" in the medium term, which is different from formulations of inflation targets in the academic literature or of other central banks, troubled some observers. If this was the case, Hartmann thought that one could perhaps revisit this wording in the future. All in all, however, the available evidence does not support asymmetry, implying that the issue was not of first order for actual policy, contrary to what some conference participants seem to think.

Second, Hartmann proposed a different narrative for the performance of the euro area's macroeconomy than did those observers who were eager to find ECB "mistakes." Taking the global financial crisis period as an example, he asked what was the main difference between the euro area and the U.S. The main difference was that, due to the European sovereign debt crisis, the euro area had a second deep recession starting in 2011. This recession was mainly caused by the malicious interaction between banking and fiscal instability in (and across) a number of countries, the sovereign-bank nexus. For example, many euro area countries had not addressed their banking problems as swiftly as had the U.S. Moreover, some euro area countries had entered the crisis with high public debt levels-way above the limits prescribed by the fiscal framework for EMU—and some were fiscally weakened by high bank bailout costs. The resulting combined fiscal and banking crisis induced huge obstacles to the ECB for maintaining price stability and forced it to deploy untested and unprecedented unconventional policies in subsequent years. At the time, the ECB was not a banking supervisor and, in general, it is forbidden from financing public debts or government tasks (the prohibition of monetary financing in Article 123 of the Treaty on the Functioning of the European Union), including bank recapitalizations. The underlying sources of the sovereign debt crisis were outside its mandate. At the same time, the paper by Hartmann and Smets provides a scientific analysis of the ECB's interest rate decisions and, through the lens of policy rules, transparently gives a few indications when its monetary policy might have been a bit too loose or too tight during the last 20 years. But overall, this broader perspective 
suggests that the first-order reason for the double-dip recession and its depth was not monetary policy but the imperfect handling of banking and fiscal problems. These imperfections included the initial absence of effective euro area institutions and tools for solving the collective action problems of sovereign countries in a monetary union with primarily national prudential and fiscal policies. Such institutions and tools-for example, the European Stability Mechanism or the Banking Union (with Single Supervisory and Resolution Mechanisms) — were only established or put on a credible path with the political agreements that were reached during 2012. Before this time, it is hard to see how the ECB could have run a much more expansionary monetary policy and stayed clear of monetary financing.

Third, Hartmann took up the differences in central bank mandates, laws, and approaches between the euro area and the U.S. He started with the observation that the Federal Reserve is the only Group of Seven central bank with a dual mandate that includes maximum employment as a primary statutory objective. Much like the other central banks, the ECB can pursue employment only without prejudice to the primary price stability objective; the former is clearly subordinated to the latter. Next, he shared his impression that many participants in the conference seem to interpret the role of lender of last resort very broadly. In fact, in the academic literature there is a school of thought that represents the view that the central bank should not only act as lender of last resort for bank liquidity problems but also for fiscal authorities, at least in specific situations. And many of those academics seem to assume that the Federal Reserve would do so when needed. In the EMU, this is not allowed, as reflected in the prohibition of monetary financing. And there are some good reasons for this, one being that it can create a circularity problem between the central bank and the fiscal authority that can contribute to multiple equilibria. Still, Hartmann expressed sympathy with Lorenzo Bini Smaghi's point that the current national approach to providing emergency liquidity assistance to banks could be centralized at the ECB in the future, as ECB president Draghi had also recently hinted in one of the hearings at the European Parliament. In order not to inject money into insolvent banks, however, and therefore not to take over fiscal or bank resolution tasks, this should be accompanied by arrangements ensuring the temporary nature of such operations and adequate fiscal guarantees where solvency cannot be ascertained immediately. Hartmann also agreed with Lucrezia Reichlin that the ECB had a "textbook" lender-of-last-resort reaction to the liquidity problems in the early stages of the crisis. 
In response to Jason Furman's and Eric Rosengren's comments, it was clarified that the estimated policy rule does not assume a constant equilibrium real rate (in contrast to the Taylor rule). The paper briefly acknowledges that estimates of the natural rate of interest have been sliding down over time, and that this makes the effective lower bound to policy rates a serious issue. 